
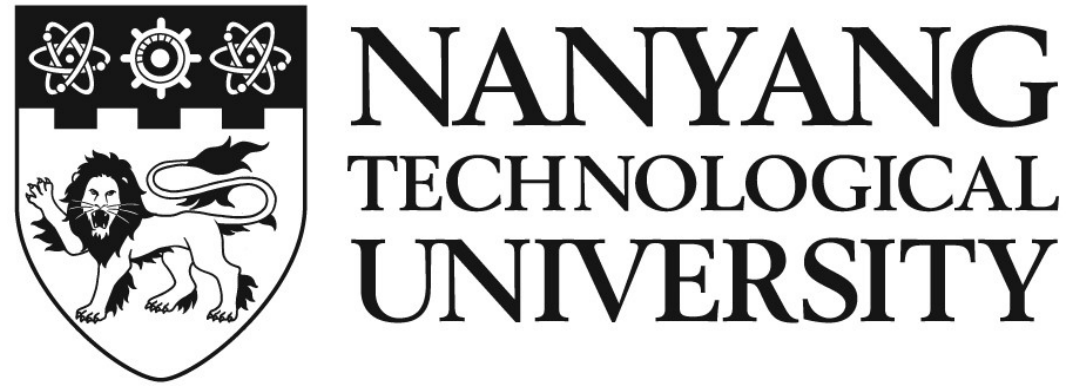

\title{
DEVELOPMENT OF STRAIN HARDENING ULTRA-HIGH PERFORMANCE CONCRETE INCORPORATING CARBON NANOFIBER COATED POLYETHYLENE FIBERS
}

\section{HE SHAN}

School of Civil and Environmental Engineering 2017 


\title{
DEVELOPMENT OF STRAIN HARDENING ULTRA-HIGH PERFORMANCE CONCRETE INCORPORATING CARBON NANOFIBER COATED POLYETHYLENE FIBERS
}

\section{HE SHAN}

School of Civil and Environmental Engineering

\author{
A thesis submitted to \\ the Nanyang Technological University \\ in partial fulfilment of the requirements for the degree of \\ Master of Engineering
}




\section{ACKNOWLEDGEMENTS}

First, I would like to express my gratitude to my supervisor, Assistant Professor Yang En-Hua, for giving me the opportunity to learn how to conduct research. In the past two years, he has always shown me the right path and has always calm me down when I was anxious. From his words and deeds, I have learned not only the scientific knowledge but also the essentials of being a reliable researcher.

I am grateful to all the group members and technicians in PE/CT lab for their help. They guided me along. It is them, who filled the time and overtime I spend in the lab full of memories. I would like to particularly thank Dr. Chen Zhitao and Dr. Qiu Jishen for sharing with me their invaluable hands-on experience. Without the help from them, I could never have attempted anything within this two years.

I must acknowledge ceEntek Pte Ltd for the financial and technical supports, and especially the supply of carbon nanofiber suspension. A lot of in-depth discussions have also been generated during the meetings.

Since the day my parents waved me off to university, it has been almost six years. Every day, without any exception, I would receive a call from them. Things changed over the years, as I think my hair has become thinner; but the frequency of the calls has never changed. It is really those calls that constantly comfort me and support me over the years, although I sometimes found it annoying. I never say thank you to my

parents, but I know that it is their understanding and trust that allows me to live and study a thousand miles away from home, free from worries. 


\section{TABLE OF CONTENTS}

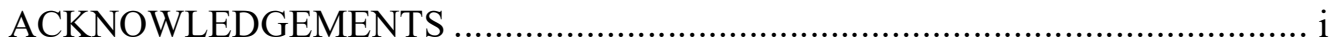

TABLE OF CONTENTS ......................................................................... ii

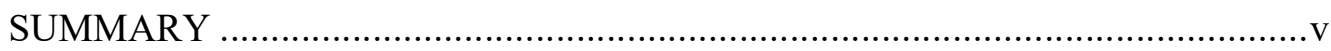

LIST OF TABLES ...................................................................................

LIST OF FIGURES …............................................................................... vii

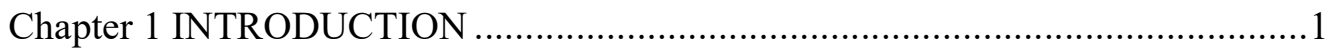

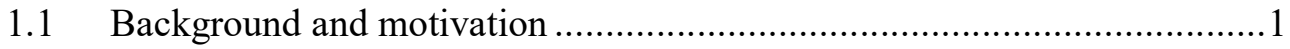

$1.2 \quad$ Research objectives and methodology.............................................

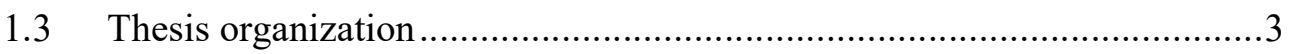

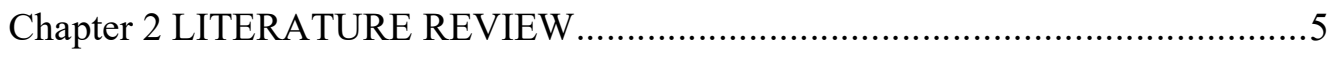

2.1 Strain hardening ultra-high performance concrete.................................... 5

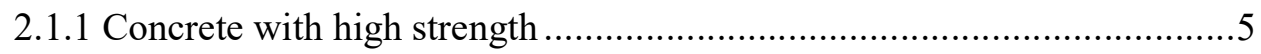

2.1.2 Concrete with high ductility ................................................... 8

2.1.3 Concrete with high strength and high ductility ................................. 10

2.2 Carbon nanofiber reinforced cementitious composite ............................. 12

2.2.1 Carbon nanofiber and carbon nanotube ........................................ 12

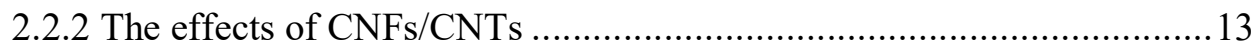

Chapter 3 MATRIX DESIGN OF STRAIN HARDENING ULTRA-HIGH

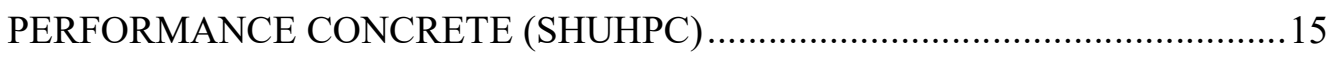

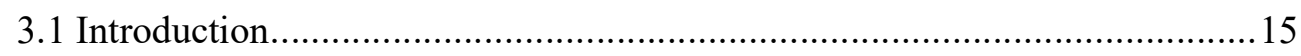

3.2 Material and experimental program ................................................. 15

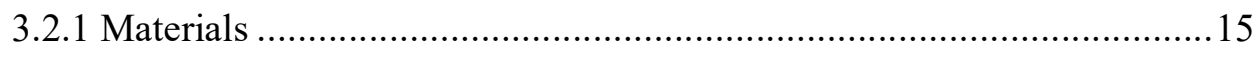

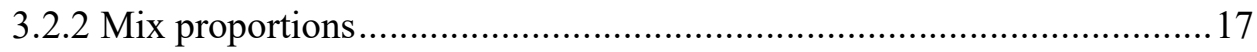

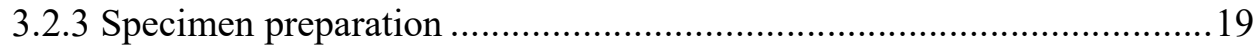

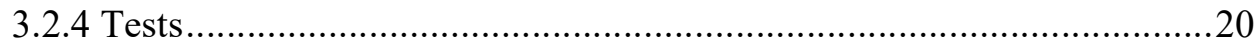




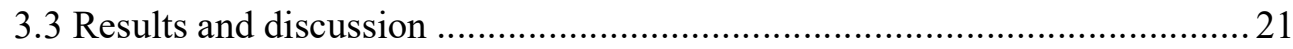

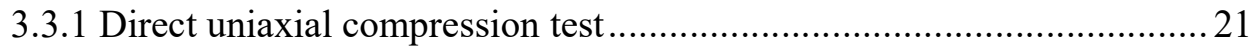

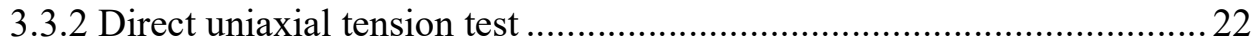

3.3.3 Micromechanics-based modeling of strain hardening potential........... 23

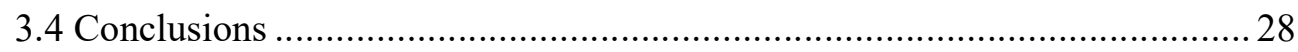

Chapter 4 SHUHPC INCORPORATION CNF-COATED PE FIBERS (CNF-

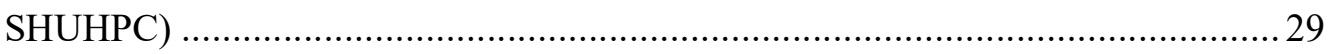

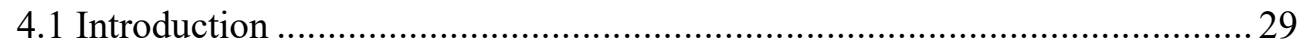

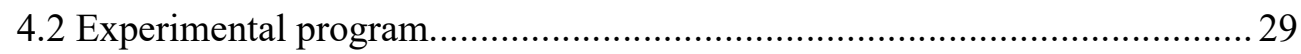

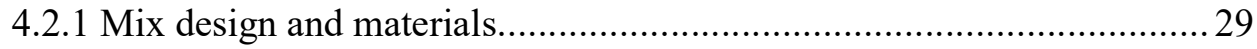

4.2.2 Specimen preparation .............................................................. 31

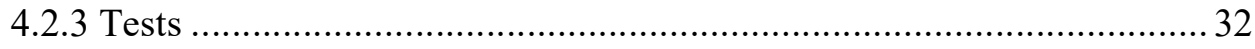

4.2.4 Micromechanics-based modeling of strain hardening potential.............33

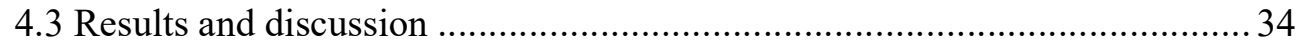

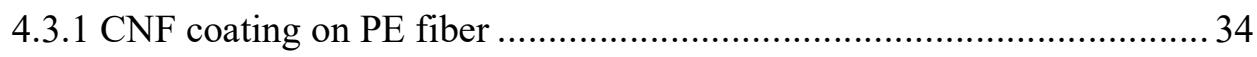

4.3.2 Mechanical properties of CNF-SHUHPC ........................................ 37

4.3.3 Fiber/matrix interface properties of CNF-SHUHPC ........................ 42

4.4 Micromechanics-based modeling of strain hardening potential................... 45

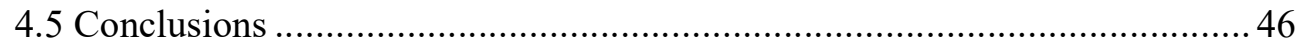

Chapter 5 MICROSTRUCTURAL INVESTIGATIONS ON REINFORCING

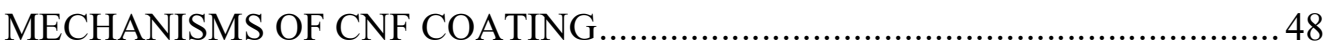

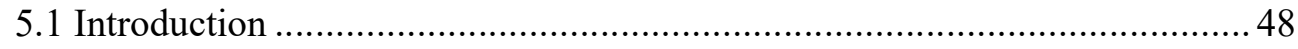

5.2 Effect of CNF on the nanoscale mechanical properties of the interface transition zone (ITZ) between polyethylene (PE) fiber and cement paste ......................... 49

5.2.1 Specimen preparation ............................................................ 49

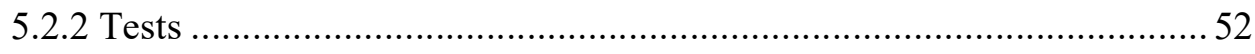

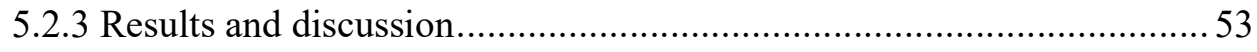


5.3 Effect of CNF on the heat of hydration of cement paste .............................57

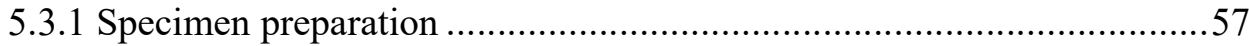

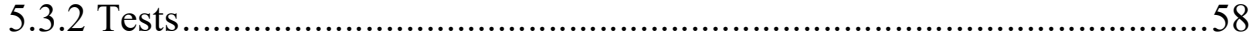

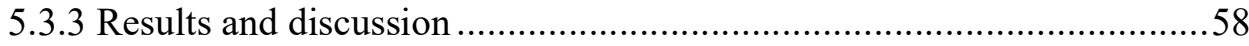

5.4 Effect of CNF on the hydration degree of cement paste ............................59

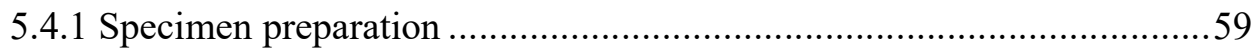

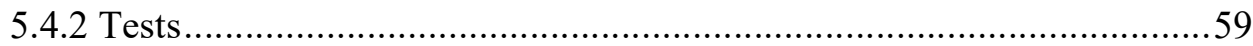

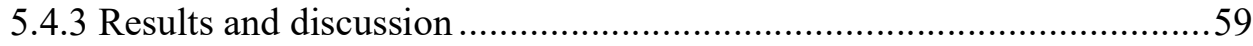

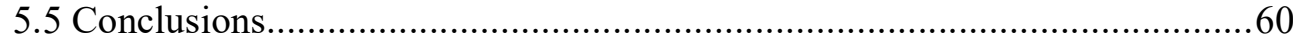

Chapter 6 CONCLUSIONS AND FUTURE WORKS ...................................61

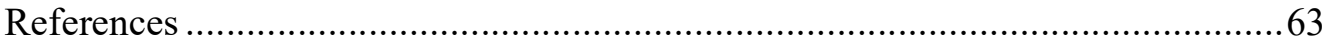




\section{SUMMARY}

A novel idea of using carbon nanofibers (CNFs) to strengthen the interface transition zone (ITZ) and to enhance the interface frictional bond strength between polyethylene (PE) fibers and cement matrix was proposed and realized by coating CNFs on surface of PE fibers through hydrophobic interactions. A strain hardening ultra-highperformance concrete (SHUHPC) incorporating such CNF-coated PE fibers was developed. The resulting CNF-SHUHPC has a compressive strength over $150 \mathrm{MPa}$ and exhibits $15 \%$ enhancement in tensile strength and 20\% improvement in tensile strain capacity as compared to the control SHUHPC. Single fiber pullout tests showed the interface frictional bond strength of the CNF-coated PE fiber was increased by $22 \%$, which is attributed to CNFs strengthen the ITZ by filling nano-pores and bridging nano-cracks resulting in denser microstructure and higher crack resistance against fiber pullout as revealed by the micrographs and Nanoindentation test results. 


\section{LIST OF TABLES}

Table 2.1 Comparison of SHUHPC products. ................................................. 11

Table 2.2 Typical properties of VGCNF, SWCNT, and MWCNT....................... 12

Table 2.3 Published results of studies related to CNTs/CNFs reinforced concrete .14

Table 3.1 Source and physical properties of the UHPC compounds......................16

Table 3.2 Chemical compositions of the UHPC compounds.................................16

Table 3.3 Geometry and mechanical/physical properties of the PE fibers .............. 17

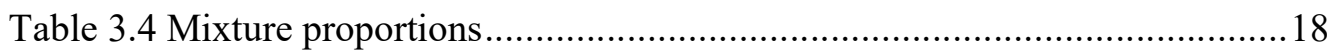

Table 3.5 Aspect ratios of the PE fibers...................................................... 19

Table 3.6 Average mechanical properties...................................................21

Table 3.7 Micromechanics parameters used as model input...............................25

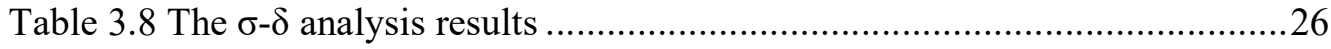

Table 4.1 Mixture compositions of SHUHPC [unit in $\left.\mathrm{kg} / \mathrm{m}^{3}\right]$.............................30

Table 4.2 Properties of the PE fibers (Spectra ${ }^{\circledR}$ 1000, Honeywell).........................30

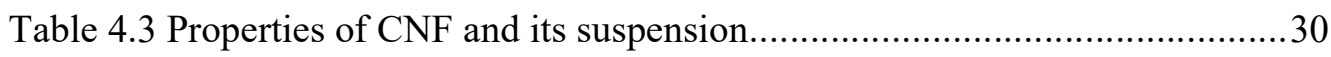

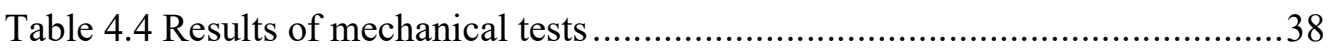

Table 4.5 Micromechanical parameters for model calculation and results..............46 


\section{LIST OF FIGURES}

Fig. 2.1 Overview of gradual increase in concrete strength ............................... 5

Fig. 2.2 Formation of multiple fine cracks ............................................... 9

Fig. 2.3 Conceptual bridging stress - crack opening $(\sigma-\delta)$ relation...................... 10

Fig. 3.1 Particle size distribution of ingredients............................................. 17

Fig. 3.2 (a) Single fiber pullout specimen and (b) experimental setup of the single

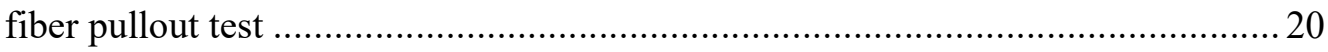

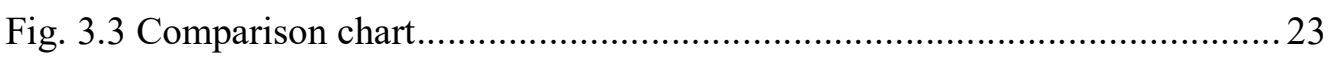

Fig. 3.4 Complete single fiber pullout test curves........................................ 24

Fig. 3.5 Crack patterns of selected sample ................................................ 27

Fig. 4.1 Illustration of hydrophobic interactions between PE fibers and CNFs in

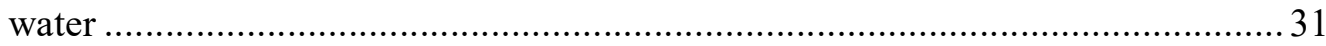

Fig. 4.2 Micrographs of (a) (c) (e) the pristine and (b) (d) (f) the CNF-coated PE

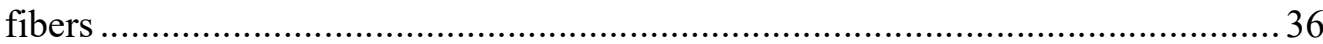

Fig. 4.3 (a) Optical microscope image and (b)(c)(d) SEM micrographs of CNF-

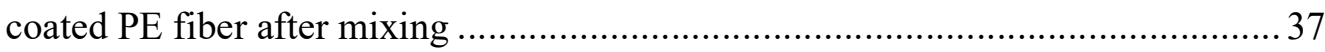

Fig. 4.4 Tensile stress-strain curves of (a) SHUHPC and (b) CNF-SHUHPC ........ 39

Fig. 4.5 Crack pattern of (a) SHUHPC and (b) CNF-SHUHPC [unit in cm]......... 40 Fig. 4.6 (a) Illustration of critical transfer distances $x d$ in SHUHPC and CNFSHUHPC, and (b) transfer distance $x d$ as a function of fiber-bridging stress $\sigma$ and

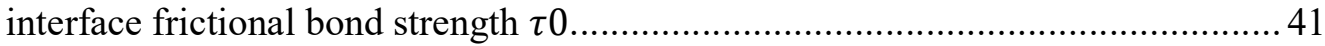

Fig. 4.7 Typical single fiber pullout curves of the pristine PE fiber and the CNFcoated PE fiber from the SHUHPC matrix with the same embedment length ........42 Fig. 4.8 SEM micrographs of fiber tunnel of (a), (c) the pristine and (b), (d)-(f) the CNF-coated PE fibers

Fig. 4.9 Schematic illustration of the hierarchical structure near ITZ in CNFSHUHPC 45

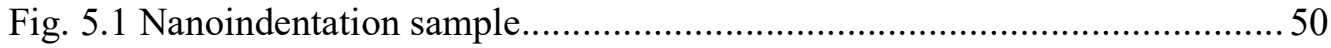

Fig. 5.2 A photograph the reflective sample surface after 4 hours of polishing......51 Fig. 5.3 AFM images and results: (a) topography of a $50 \times 50 \mu \mathrm{m}$ region, and (b) region histogram. 
Fig. 5.4 SEM images of the indentation area: (a) with CNF coating, and (b) w/o

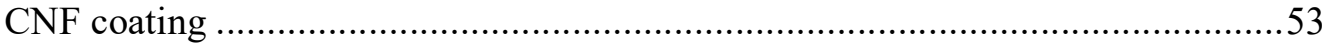

Fig. 5.5 Back-scattered electron images of the indentation area: (a) with CNF

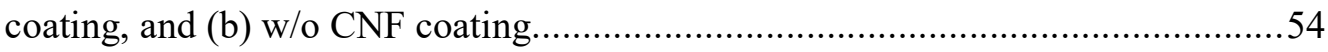

Fig. 5.6 Elastic modulus mappings of the indentation area: (a) with CNF coating,

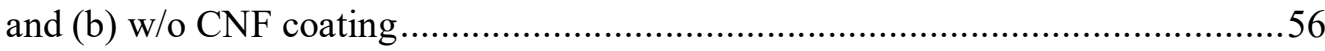

Fig. 5.7 Plot of indentation hardness versus elastic modulus: (a) with CNF coating, and (b) w/o CNF coating .57

Fig. 5.8 differential heat release plotted as a function of hydration time. .58

Fig. 5.9 Results of the thermal decomposition of pure cement paste and paste incorporating $\mathrm{CNF}$ .60 


\section{Chapter 1 INTRODUCTION}

\subsection{Background and motivation}

Concrete is the most abundant engineered material on earth. There are no known materials that can replace concrete in terms of cost and availability. Progress in investigating the fundamental mechanisms and in improving its performance has been reported constantly since it was invented. Today, properties of concrete has been explored and engineered from the macroscale to nanoscale [1]; this leads to the development of a series of remarkable functionalities such as ultrahigh compressive strength, tensile strain-hardening [2] and even self-healing [3]. It is believed that concrete is a material having limitless potential to be researched, engineered and innovated.

Ultra-high performance concrete (UPHC) represents a group of cement-based materials that achieves compressive strength exceeding $150 \mathrm{MPa}$ [4-6]. The ultrahigh strength of UHPC can effectively reduce the size of structural members and thus lowering the concrete usage, mitigating the environmental impact $[7,8]$ and also resulting in greater flexibility in architectural design [9]. Nevertheless, UHPC is often associated with increased brittleness and reduced cracking resistance. Short fibers have been used as reinforcement to mitigate brittle failure of concrete, to control the crack propagation, and even to impart ductility into cement-based materials. For example, strain hardening cementitious composites (SHCC) with tensile strain capacity exceeding $2 \%$ has been developed through tailoring of fiber-bridging under the guidance of micromechanics [10].

Adopting similar approach, Kamal et al. [11] and Ranade et al. [12, 13] developed strain hardening ultra-high performance concrete (SHUHPC) with tensile strain capacity over $2 \%$ and compressive strength of 96 and $166 \mathrm{MPa}$ respectively by using 1.5 to 2 vol.\% of high-strength high-modulus polyethylene (PE) fibers. Despite high fiber strength of $3000 \mathrm{MPa}$, PE fiber has smooth and hydrophobic surface, and thus 
interfacial bond between fiber and cementitious matrix is limited [14, 15]. As a result, higher fiber dosage and increased fiber length, which introduce significant processing and cost issues, are often required to ensure sufficient fiber-bridging. Furthermore, due to weak interfacial bond, larger crack width of few hundred micronmeters is often observed in PE fiber-reinforced SHUHPC $[12,16]$, which causes higher transport properties and loss of self-healing potential [17].

It is well known that the mechanical behaviour of material at a certain scale depends largely on its sub-structural elements and phenomena that are effective at a smaller scale. To strengthen the small but critical area around micro-fibers, nanomaterials are perfect candidates. Carbon nanotubes (CNTs) and carbon nanofibers (CNFs) have been incorporated into cementitious material to improve the mechanical properties at nanoscale [18-21]. The CNF, with comparable excellent properties of CNT including high stiffness [22] and high tensile strength [23], has even better performance in terms of nanofiber/matrix interaction. The cup-stacked structure of the CNFs contains more carbon edges that could prevent interfacial slip [21,24]. It is therefore plausible that CNF may be able to enhance interfacial bond between PE fiber and matrix by strengthening the ITZ, resulting in enhancement of the performance of the SHUHPC.

There are still many open questions, such as: (a) how to accurately deploy the CNFs to fiber/matrix interface without affecting the matrix; (b) how to characterize the status of the distribution of CNFs at the interface; (c) to what extend could the CNF affect the micro-scale interface properties and the macro-scale composite properties of SHUHPC; (d) what are the underlying mechanisms that deliver the response.

The purpose of this study is to clarify the above-mentioned questions. A novel idea of using carbon nanofibers (CNFs) to strengthen the interface transition zone (ITZ) and to enhance the interface frictional bond strength between polyethylene (PE) fibers and cement matrix was proposed and realized by coating CNFs on surface of PE fibers through hydrophobic interactions. A strain hardening ultra-high performance concrete (SHUHPC) incorporating such CNF-coated PE fibers was developed. The effects of such coating on the interface properties and composite properties of 
SHUHPC incorporating CNF-coated fiber (CNF-SHUHPC) have been studied. At last, the functioning mechanisms of CNFs at the scale where physical chemistry meets mechanics was attempted to explained.

\subsection{Research objectives and methodology}

This study aims to develop a strain-hardening ultra-high performance concrete (SHUHPC) with reduced fiber content and enhanced performance by strategically incorporating carbon nanomaterials into the system. The SHUHPC shall incorporeate moderate fiber dosage (less than 2 vol.\%) to reduce processing difficulty and material cost. The resulting SHUHPC shall also possess tight crack width in order to have reduced transport properties, increased potential of autogenous crack healing, and enhanced durability. The resultant SHUHPC is believed to be able to benefit both the sustainability and resilience of concrete infrastructure.

The major technical issue aims to resolve in this study is the weak interfacial bond between PE fiber and cement-based matrix of such SHUHPC, due to the smooth and hydrophobic surface of PE fiber. This study proposes to enhance the PE fiber/HUPC matrix interfacial bond though incorporating carbon nanomaterials to elevate the performance of SHUHPC with desired properties. This study presents an innovative approach to strategically use carbon nanomaterials in the critical region to enhance the performance of fiber-reinforced cement-based composites.

\subsection{Thesis organization}

This thesis is organized into six chapters. Chapter 1 introduces the background and motivation of the proposed research. Major objectives are specified, as well as the organization of the current report.

Chapter 2 gives a review of the historical development of concretes with high strength and high ductility is presented, and the state-of-the-art applications of nanomaterial in concrete are summarized. 
Chapter 3 concerns the design of a preliminary version of strain hardening ultra-highperformance concrete (SHUHPC) using locally available raw materials in Singapore. It aims to provide the next chapter with a matrix to be further modified by the Carbon Nanofibers (CNFs). Details about the selection of materials and the formulation of mix proportions are presented.

Chapter 4 presents the work of using CNF to improve the mechanical properties of the SHUHPC developed in the previous chapter. It aims to enhance the interfacial bond strength between PE fiber and UHPC matrix by introducing CNFs to the interface transition zone (ITZ) between fiber and matrix. The resultant CNFSHUHPC with improved mechanical properties and optimized cracking behavior was developed.

Chapter 5 includes the microstructural investigations on reinforcing mechanisms of CNF coating. The objective is to give more insights to the filling effects of the CNFs to the matrix.

Chapter 6 gives the conclusions of the current study, the findings that current study contributed to the literature, the discussion on the application of those findings, and the suggestions for future works. 


\section{Chapter 2 LITERATURE REVIEW}

2.1 Strain hardening ultra-high performance concrete

\subsubsection{Concrete with high strength}

Over the years, since the invention of Portland cement in the early $19^{\text {th }}$ century, concrete strength has been constantly increased (as shown Over the years, since the invention of Portland cement in the early $19^{\text {th }}$ century, concrete strength has been constantly increased (as shown in Fig. 2.1). A series of innovations repeatedly changed the design of concrete and eventually pushed the limit of its strength to 800 $\mathrm{MPa}$. Some of the notable materials such as the Reactive Powder Concrete were developed and categorized as a special class named as Ultra High Performance Concrete (UHPC). In 2004, the first application of a UHPC (Ductal) structure, the Shawnessy Light Rail Transit Station, was completed in Canada [25]; and now, UHPC has been widely accepted to be the ideal for architectural and structural creativity and renovation.

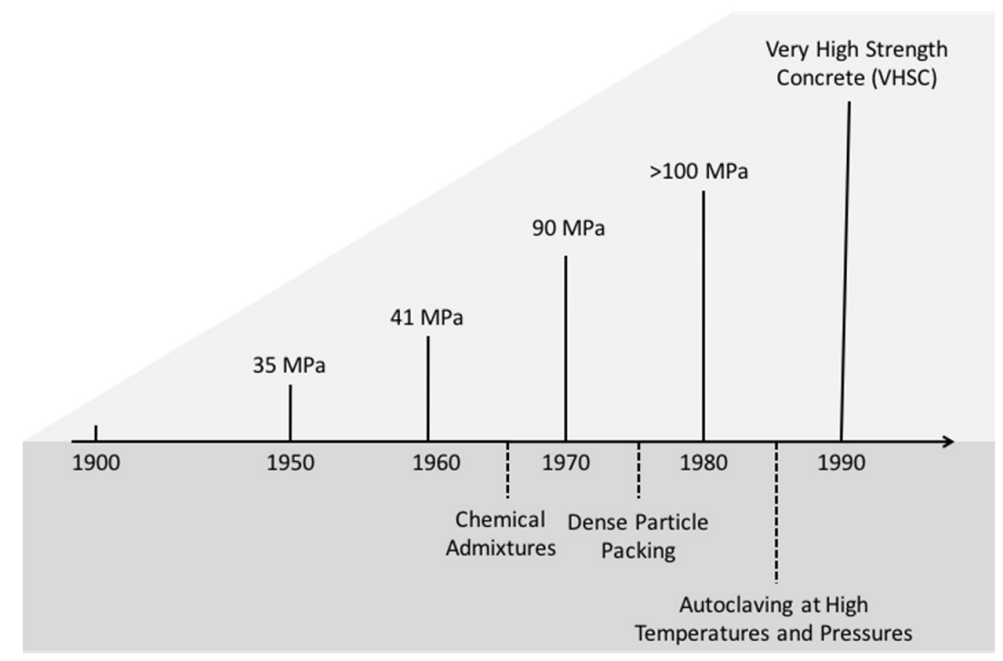

Fig. 2.1 Overview of gradual increase in concrete strength

Concrete is a porous solid material; the porosity and the strength of the solid collectively affect its overall performance. Strategies commonly applied could be 
classified by their objective: to reduce porosity, or to improve the strength of the solid. Specific strategies and leading studies that propose each strategy are summarized below:

1. Low water/cement ratio and rheological control

High-performance concretes usually have low water/cement ratio to ensure that water will be adsorbed as gel water thus the influence of capillary pores could be minimized. However, low water to cement ratio would affects the workability and may results in a situation where a considerably amount of air would be entrapped during mixing process. This issue could be solved by conducting the rheology control. The superplasticizers (SPs), which could emancipate the water wrapped by cement grains, could improve the flow characteristics of fresh paste and used to ensure the workability.

Polycarboxylates (PCs) based SP has been reported to be most effective for UHPC [26]. It is also found that length of the side chain mainly influenced retardation time and the density of the side chain controlled the workability [27]. The optimum addition procedure of SP [28], the effects of the SP to the microstructure of UHPC [29] and the compatibility between the superplasticizer and cementitious materials [26] have all been reported.

In addition, cement with coarse particle size $[12,30]$ and low calcium aluminate cement has been reported to require less water and are used to benefit the workability of the fresh paste.

\section{Optimization of particle packing}

An ideal cementitious matrix would be a highly dense matrix that contained no flaws or voids. The space between larger diameter particles would be filled with smaller when certain proportion between particles is reached. Silica fume, fly ash 
or inert filler have all been used to fill the spaces between cement particles [ 31 , 32].

Many packing model have been proposed to calculate and to increase the packing density of concrete. Having considered the interactions between size classes of the materials and the difference between ideal and random packing, leading models could precisely predate the density of UHPC made up of difference size particle [4, 32]. Another possibility for mixture design is based on the investigation of Andreasen \& Andersen particle packing model to match the optimal particle size distribution (PSD) of all the applied particle materials in the mixture [33]. One of the extreme examples in which the defects are aimed to be eliminated is the macro-defect-free concrete [34], which could have compressive strength over $400 \mathrm{MPa}$.

\section{Reduction in size of aggregates}

In concrete, there is a difference in modulus between cement matrix and aggregate. When stress is applied, the resultant differential strain would produce microcracks. Efforts to bring the moduli of all the component materials closer will reduce the differential strain. In addition, since the size of the micro-cracks developed under a given stress is a proportional to the size of the aggregate, the size of micro-cracks is also diminished by using fine aggregate [35]. High strength high ductility concrete (HSHDC) using quartz sand with maximum diameter of $600 \mu \mathrm{m}$ has been developed [12].

\section{The use of mineral admixtures}

Calcium Silicate Hydroxide (C-S-H) is the main product of the cement hydration reaction. The use of mineral admixtures creates more C-S-H. Pozzolans are a class of siliceous or aluminous materials that could react with calcium hydroxide to form compounds possessing cementitious properties. UHPC with strength of $200 \mathrm{MPa}$ was developed by replacing 30-35\% cement of silica fume. Yazici 
prepared RPC with Portland cement replaced with up to $60 \%$ granulated blast furnace slag (GGBS). Besides that, fly ash, metakaolin, rich husk ash has also been used to developed UHPC and conventional concrete.

\section{Heat and pressure treatment}

The mechanical properties of the C-S-H could be improved though high temperature and high-pressure treatment. It has been reported that heating the concrete to $90{ }^{\circ} \mathrm{C}$ significantly accelerates the formation of the C-S-H and results in the formation of hydrates with microstate differ from common C-S-H [35]. Heat and pressure treatment at a proper age (typically 4-7 days after casting) could converts the amorphous C-S-H into stronger crystalline tobermorite in the presence of an amorphous silica source (such as silica fume).

\subsubsection{Concrete with high ductility}

In early 1990s, Li and fellow researchers developed a micromechanics-based multiscale framework to achieve high tensile ductility in concrete, and pioneered the first high ductility concrete reinforced with short discontinuous fibers at low fiber volume, that is the Engineered Cementitious Composites (ECC) [36]. Polyethylene fiber, polyvinyl alcohol fibers, polypropylene fiber, natural fibers (wood and vegetable fibers) and steel fibers (hybridized with polymer fibers) have been investigated with their respective matrixes for use in various ECCs and their applications.

Lots of studies have been carried out to investigate the behaviors of ECC material. Fatigue resistance ECC [37], impact resistance ECC [38], ECC with waste materials [39] have all been developed. The mechanisms for the tensile strain hardening behavior [40], fatigue deterioration [41], self-healing [3], creep and rate dependence [42] have all been investigated. In addition, analytical models have also been developed to simulate the cracking process [43], to predict the ductility and even to guide the design of mixture compositions [40]. 
High tensile ductility of concretes is a result of sequential development of parallel steady-state cracks. There are two necessary micromechanics-based conditions [44] that facilitate the steady state multiple cracking. The first necessary condition is called the strength criterion or crack initiation criterion (Eq. 2.1). This condition implied that the matrix cracks initiate at stresses should not exceed the bridging capacity of the least-bridged crack. Crack initiation stress for the first can be computed from Irwin's fracture criterion and the bridging capacity can be determined from the crack bridging behavior shown in Fig 2.2.

$$
\sigma_{s s}=\sigma_{f c} \leq \min \left(\sigma_{0}\right)
$$

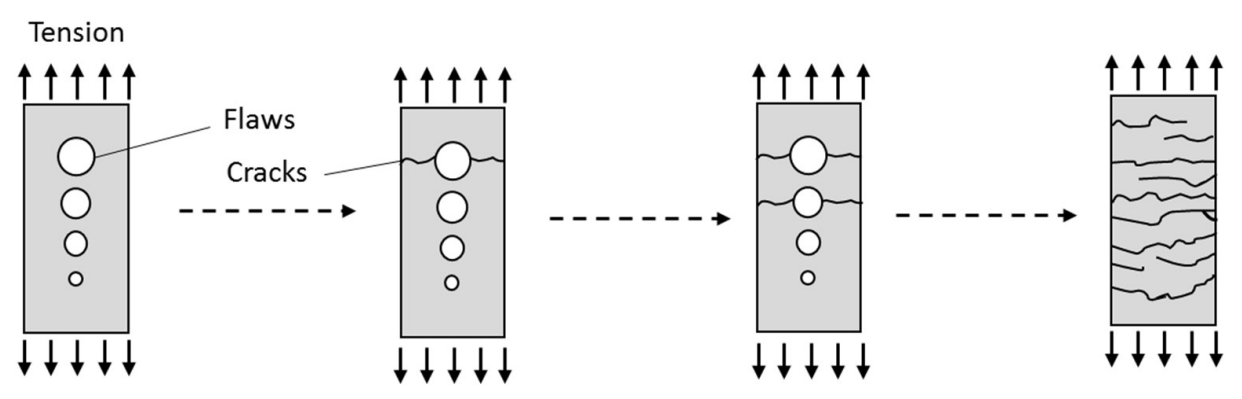

Fig. 2.2 Formation of multiple fine cracks

The second necessary condition is called the energy criterion or crack propagation criterion (Eq. 2.2). This condition is derived from path independent J-integral formulation of the steady-state crack propagation problem. In essence, the total available crack driving energy ( $\mathrm{J}_{\mathrm{b}}$ ' in Eq. 2.2) should be greater than the resistance of crack propagation ( $\mathrm{J}_{\text {tip }}$ in Eq. 2.2). $\mathrm{J}_{\mathrm{b}}$ ' or complementary energy of crack bridging can be determined from the $\sigma-\delta$ relation (Fig 2.3). It can be interpreted as net energy available from external work done to the body subtracting the energy absorbed by fibers from zero to steady state crack opening $\delta$ during steady-state crack propagation. $\mathrm{J}_{\text {tip }}$ can be approximated to $\mathrm{G}_{\mathrm{m}}$ (fracture energy of the matrix) in the case of brittle matrix composites. The crack propagation criterion ensures the flat crack formation, instead of forming oval-shaped Griffith cracks.

$$
\mathrm{G}_{m} \approx J_{\text {tip }} \leq J_{b}^{\prime}=\sigma_{0} \delta_{0}-\int_{0}^{\delta_{0}} \sigma(\delta) d \delta
$$


The crack bridging behavior ( $\sigma-\delta$ relation) can be either determined experimentally, from tension tests on notched specimens (forcing only one crack formation), or analytically, from single fiber pullout behavior.

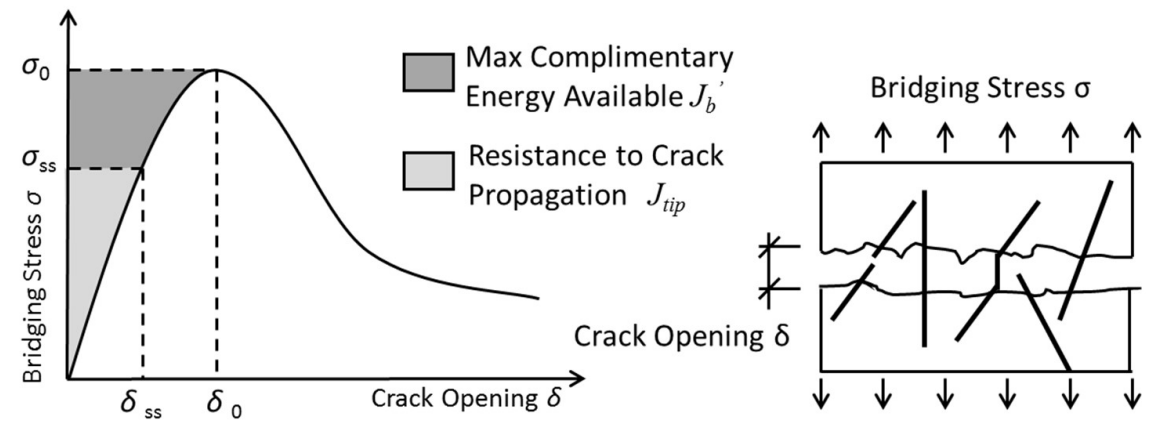

Fig. 2.3 Conceptual bridging stress - crack opening $(\sigma-\delta)$ relation

\subsubsection{Concrete with high strength and high ductility}

The integration of high compressive strength and high tensile ductility in concrete material is hard, for the rationales of designing the two properties are mutually exclusive. In the design of high strength concrete, the strategy is to minimize the flaws. In contrast, the principle mean by which ductile concrete is designed is to control the size and quantity of flaws within an optimum range to trigger multiple cracking. Nevertheless, several investigations focusing on combining high strength and high ductility have been reported since 2010. The development of such material was pioneered by Kamal et al. [45]: by matching a dense matrix with 1.5 vol. $\%$ of high strength polyethylene (PE) fiber, the first version of strain-hardening UHPC (SHUHPC) exhibits a compressive strength of $96 \mathrm{MPa}$ and a tensile strain of $2 \%$ [11]. Both targeted properties were largely improved in the next version of SHUHPC, in which Ranade et al. applied the special curing treatment to boost the strength to 166 $\mathrm{MPa}$ and enlarged the fiber content to 2.0 vol. $\%$ to enhance the strain capacity to $3.4 \%$ $[12,13]$. Curosu et al. took another path to advance strength over which most of the aggregates from the mixtures was removed to densify the matrix. Coupled with an increased fiber content $(2.1 \%$ by volume), this material exhibits a compressive strength of 139.5 MPa and shows an ultimate strain level exceeding 4\% [46]. Detailed 
information including the mix design, curing regime, and the mechanical performance of above products is summarized in Table 2.1.

Table 2.1 Comparison of SHUHPC products.

\begin{tabular}{|c|c|c|c|}
\hline & \multicolumn{2}{|c|}{ Mix Design } & Performance \\
\hline \multirow{3}{*}{$\begin{array}{l}\text { Kamal } \\
\text { et al. } \\
(2008) \\
{[11]}\end{array}$} & Water/binder ratio: & 0.18 & $f_{c}^{\prime a}(14$ days $)=96 \mathrm{MPa}$ \\
\hline & Silica fume/cement: & 0.25 & $\varepsilon_{u l t}^{b}(14$ days $)=2.8 \%$ \\
\hline & Silica sand ${ }^{\mathrm{d}} /$ cement: & 0.125 & $\sigma_{u l t}^{c}(14$ days $)=10 \mathrm{MPa}$ \\
\hline \multirow{2}{*}{$\begin{array}{l}\text { UHP- } \\
\text { SHCC }\end{array}$} & $\begin{array}{c}\text { Dyneema PE fiber } \\
6 \mathrm{~mm} \text { (length) } \\
12 \mu \mathrm{m} \text { (diameter) }\end{array}$ & $\begin{array}{l}1.5 \% \text { by } \\
\text { volume }\end{array}$ & \\
\hline & \multicolumn{2}{|c|}{ Curing: not mentioned } & \\
\hline \multirow{7}{*}{$\begin{array}{l}\text { Wille } \\
\text { et al. } \\
(2011) \\
{[47]}\end{array}$} & Water/binder ratio: & 0.176 & $f_{c}^{\prime}(28$ days $)=200 \mathrm{MPa}$ \\
\hline & Silica fume/cement: & 0.25 & $\varepsilon_{u l t}(28$ days $)=0.6 \%$ \\
\hline & Silica flour/cement: & 0.25 & $\sigma_{\text {ult }}(28$ days $)=14 \mathrm{MPa}$ \\
\hline & Fine sand $1 \mathrm{e} /$ cement : & 0.26 & \\
\hline & Fine sand $2^{\mathrm{f}} /$ cement : & 1.03 & \\
\hline & $\begin{array}{c}\text { Steel Fiber : } \\
13 \mathrm{~mm} \text { (length) } \\
0.20 \mathrm{~mm} \text { (diameter) }\end{array}$ & $\begin{array}{l}2.5 \% \text { by } \\
\text { volume }\end{array}$ & \\
\hline & \multicolumn{2}{|c|}{ Curing: No heat curing was used } & \\
\hline \multirow{6}{*}{$\begin{array}{c}\text { Ranade } \\
\text { et al. } \\
(2013) \\
{[12]} \\
\text { HSHDC }\end{array}$} & Water/binder ratio: & 0.15 & $f_{c}^{\prime}(28$ days $)=166 \mathrm{MPa}$ \\
\hline & Silica fume/cement: & 0.39 & $\varepsilon_{u l t}(28$ days $)=3.4 \%$ \\
\hline & Silica flour/cement: & 0.28 & $\sigma_{u l t}(28$ days $)=14.5 \mathrm{MPa}$ \\
\hline & Silica sand/cement: & 0.97 & \\
\hline & $\begin{array}{c}\text { Spectra } 1000 \text { PE fiber } \\
12 \mathrm{~mm} \text { (length) } \\
28 \mu \mathrm{m} \text { (diameter) } \\
\end{array}$ & $\begin{array}{l}2 \% \text { by } \\
\text { volume }\end{array}$ & \\
\hline & \multicolumn{2}{|c|}{$\begin{array}{l}\text { Curing: } \\
\text { Water curing for } 7 \text { days followed by } \\
\text { elevated-temperature curing for } 5 \text { days } \\
\text { (in water at } 90^{\circ} \mathrm{C} \text { ) and for } 3 \text { days (in air } \\
\text { at } 90^{\circ} \mathrm{C} \text { ). }\end{array}$} & \\
\hline $\begin{array}{l}f_{c}^{\prime} \\
\varepsilon_{u l t} \\
\sigma_{u l t} \\
\text { Maxi } \\
\text { Maxi }\end{array}$ & \multicolumn{2}{|l|}{$\begin{array}{l}=\text { Compressive strength } \\
=\text { Ultimate tensile strain } \\
=\text { Ultimate tensile stress } \\
\text { aum grain size } 0.2 \mathrm{~mm} . \\
\text { hum grain size } 0.8 \mathrm{~mm} .\end{array}$} & \\
\hline
\end{tabular}


2.2 Carbon nanofiber reinforced cementitious composite

The frontier of engineering the properties of concrete is to incoporate one or several kinds of nanomaterials. Among them, carbon nanomaterials, which have inherent excellent mechanical properties, have received the majority of attentions. Concretes with carbon nanotube, carbon nanofiber, and grephene have been developed; and the effects of those carbon nanomaterials to the ingredients of concrete have been studied extensively. It has been prove that a small amount of the nanomaterials is able to significantly improve the properties of concrete, as long as they are used in a right way.

\subsubsection{Carbon nanofiber and carbon nanotube}

Carbon nanotubes (CNTs) and carbon nanofibers (CNFs) have been incorporated into cementitious material to improve the mechanical properties at nanoscale [18-21]. It has been reported that these carbon-based fibrous materials could reinforce the matrix by bridging nano-cracks [20], filling nano-pores [48] and serving as seeds to promote hydration [49]. The CNF, with comparable excellent properties of CNT including high stiffness [22] and high tensile strength [23], has even better performance in terms of nanofiber/matrix interaction. The cup-stacked structure of the CNFs contains more carbon edges that could prevent interfacial slip [21, 24]. Table 2.2 summarizes some of the major properties of VGCNF, SWCNT, and MWCNT.

Table 2.2 Typical properties of VGCNF, SWCNT, and MWCNT.

\begin{tabular}{l|l|l|l}
\hline Property & VGCNF $^{\mathrm{a}}$ & SWCNT $^{\mathrm{b}}$ & MWCNT $^{\mathrm{b}}$ \\
\hline Diameter $(\mathrm{nm})$ & $50-200$ & $0.6-0.8$ & $5-50$ \\
\hline Aspect ratio & $250-2000$ & $100-10,000$ & $100-10,000$ \\
\hline Density $\left(\mathrm{g} / \mathrm{cm}^{3}\right)$ & 2 & $\sim 1.3^{\mathrm{c}}$ & $\sim 1.75^{\mathrm{d}}$ \\
\hline Tensile strength $(\mathrm{GPa})$ & 2.92 & $50-500^{\mathrm{e}}$ & $10-60^{\mathrm{e}}$ \\
\hline Tensile modulus $(\mathrm{GPa})$ & 240 & 1500 & 1000 \\
\hline
\end{tabular}

a From Refs. [50-52]

${ }^{b}$ From Refs. [53]

c From Refs. [54]

${ }^{\mathrm{d}}$ From Refs. [55]

e From Refs. [56] 


\subsubsection{The effects of $C N F s / C N T s$}

Interest and exploration work within the field of carbon materials have been ongoing for many years. Carbon nanofibers (CNFs) and carbon nanotubes (CNTs) have received widespread attention because of their remarkable mechanical and multifunctional properties [48]. In the past decade, the mechanical [18-20], thermal [57], electrical [58] and piezo-resistive properties [59, 60] of CNF/CNT reinforced cementitious composites have been studied extensively. The influences of specific properties of CNTs/CNFs including the concentration, aspect ratios, shapes, surface functional groups and the lattice defects to their reinforcement efficiency have also been reported [48]. Besides experimental works, numerical studies of the mechanical behavior of CNT reinforced cement composites, and molecular dynamic simulation of CNT reinforced calcium silica hydrate composite have also recently been reported $[61,62]$. Table 2.3 summarizes the results of selected research using different types and proportions of $\mathrm{CNT} / \mathrm{CNF}$ and resulting influences in the mechanical properties of the composites.

Although results abound, the published data is insufficient to conclude on the effects of $\mathrm{CNTs} / \mathrm{CNFs}$ addition on the macroscale properties of the composites. The dispersion issue is recognized to be blamed for this inconsistency [63]. The common approach to incorporate $\mathrm{CNFs} / \mathrm{CNTs}$ is to produce its suspension which will then be used to mix with the cement. However, research has recently proved that a homogeneous dispersion of CNTs/CNFs in the mix water could not ensure a uniform dispersion in the cement matrix, regardless of the dispersion method, dispersing agent dosage and CNF loading $[64,65]$. If the effect of the chemical environment generated during cement hydration on the stability and homogeneity of the dispersion could not be fully understood and be offset by other techniques, the properties of resulting composite must be hard to control when CNTs/CNFs is used in the aqueous suspension form. The dispersion issue, therefore, must be thoroughly solved, or be dodged. An effective way, instead, would be to strategically use carbon nanomaterials in the critical region to enhance the performance of material. 
There are two main questions: where is the critical region with the highest value to be reinforced by the carbon nanomaterial; and how to deploy highly-concentrated carbon nanomaterials to that targeted region in a simple way. This study aims to answer the two questions and to prove the feasibility of this idea by presenting a case study of using CNF as PE fiber coating to strengthen the fiber/matrix interface and to improve the overall performance of the SHUHPCs.

Table 2.3 Published results of studies related to CNTs/CNFs reinforced concrete

\begin{tabular}{|c|c|c|c|c|c|c|c|}
\hline $\begin{array}{l}\text { Research } \\
\text { Study }\end{array}$ & $\begin{array}{c}\text { CNT } \\
\text { (Length) }\end{array}$ & $\begin{array}{c}\text { CNT } \\
\text { Content }\end{array}$ & $\begin{array}{c}\text { Water/ } \\
\text { Cement } \\
\text { Ratio }\end{array}$ & $\begin{array}{c}\text { Compressive } \\
\text { Strength } \\
\text { Increase } \\
(\mathrm{MPa}) \\
\end{array}$ & $\begin{array}{c}\text { Flexural } \\
\text { Strength } \\
\text { Increase } \\
(\%) \\
\end{array}$ & $\begin{array}{c}\text { Yong's } \\
\text { Modulus } \\
\text { Increase } \\
(\%) \\
\end{array}$ & $\begin{array}{c}\text { Fracture } \\
\text { Toughness } \\
\text { Increase } \\
(\%)\end{array}$ \\
\hline \multirow{2}{*}{$\begin{array}{l}\text { Li et al., } \\
(2005)\end{array}$} & $\begin{array}{l}\text { Untreated-CF } \\
\quad(10-\mu \mathrm{m})\end{array}$ & $\begin{array}{c}0.5 \\
\text { wt } \%\end{array}$ & 0.45 & $\begin{array}{c}52.3 \text { to } 47.5 \\
(-9.1 \%)\end{array}$ & 17.0 & - & - \\
\hline & $\begin{array}{l}\text { Treated-CNT } \\
(0.5-500 \mu \mathrm{m})\end{array}$ & $\begin{array}{c}0.5 \\
\mathrm{wt} \%\end{array}$ & 0.45 & $\begin{array}{c}52.3 \text { to } 62.1 \\
(9.98 \%)\end{array}$ & 25.1 & - & - \\
\hline \multirow{3}{*}{$\begin{array}{l}\text { Musso et } \\
\text { al. } \\
(2009)\end{array}$} & $\begin{array}{c}\text { Pristine } \\
\text { MWCNTs } \\
(400-1000 \mu \mathrm{m}) \\
\end{array}$ & \multirow{3}{*}{$\begin{array}{c}0.5 \\
\mathrm{wt} \%\end{array}$} & \multirow{3}{*}{0.40} & $\begin{array}{l}104 \text { to } 115 \\
(+10 \%)\end{array}$ & 34 & - & - \\
\hline & $\begin{array}{c}\text { Annealed } \\
\text { MWCNTs } \\
(200-400 \mu \mathrm{m})\end{array}$ & & & $\begin{array}{l}104 \text { to } 122 \\
(+17.3 \%)\end{array}$ & +9.3 & - & - \\
\hline & \begin{tabular}{|c|} 
Carboxyl-group \\
functionalized \\
MWCNTs \\
$(0.1-10 \mu \mathrm{m})$
\end{tabular} & & & $\begin{array}{l}104 \text { to } 15 \\
(-85.5 \%)\end{array}$ & $-61 \%$ & - & - \\
\hline \multirow{2}{*}{$\begin{array}{l}\text { Konsta- } \\
\text { Gdoutos et } \\
\text { al. } \\
(2010)\end{array}$} & $\begin{array}{c}\text { Long MWCNT } \\
(10-100 \mu \mathrm{m})\end{array}$ & $\begin{array}{l}0.048 \\
w t \%\end{array}$ & 0.30 & - & 25.0 & 45.0 & - \\
\hline & $\begin{array}{c}\text { Short MWCNT } \\
(10-30 \mu \mathrm{m})\end{array}$ & $\begin{array}{l}0.08 \\
\text { wt } \%\end{array}$ & 0.30 & - & 35.0 & 35.0 & - \\
\hline $\begin{array}{l}\text { Metaxs et } \\
\text { al. (2010) }\end{array}$ & $\begin{array}{c}\text { CNF } \\
(10-30 \mu \mathrm{m})\end{array}$ & $\begin{array}{l}0.048 \\
w t \%\end{array}$ & 0.50 & - & 40.0 & 75.0 & 35.0 \\
\hline $\begin{array}{c}\text { Abu Al- } \\
\text { Rub et al. } \\
(2012)\end{array}$ & $\begin{array}{c}\text { Untreated CNT } \\
(1.5 \mu \mathrm{m})\end{array}$ & $\begin{array}{l}0.10 \\
w t \%\end{array}$ & 0.4 & - & 33 & 28.5 & 65 \\
\hline \multirow{2}{*}{$\begin{array}{c}\text { Sobolkina } \\
\text { et al. } \\
(2012)\end{array}$} & $\begin{array}{l}\text { Mixed CNT } \\
(20 \mu \mathrm{m})\end{array}$ & $\begin{array}{c}0.5 \\
\mathrm{wt} \%\end{array}$ & \multirow{2}{*}{\multicolumn{5}{|c|}{$\begin{array}{l}\text { In this research, several dispersion technologies were } \\
\text { investigated. A pronounced increase in its compressive } \\
\text { strength was determined under high strain rate loading. } \\
\text { However, no significant improvement in strength was } \\
\text { observed for quasi-static loading. }\end{array}$}} \\
\hline & $\begin{array}{c}\text { MWCNT } \\
(100-300 \mu \mathrm{m})\end{array}$ & $\begin{array}{c}0.5 \\
\text { wt } \%\end{array}$ & & & & & \\
\hline $\begin{array}{l}\text { Hu et al., } \\
\text { (2014) }\end{array}$ & $\begin{array}{c}\text { MWCNT- } \\
\mathrm{COOH}\end{array}$ & $\begin{array}{c}0.1 \\
\mathrm{wt} \%\end{array}$ & 0.20 & $\begin{array}{l}93.8 \text { to } 100.8 \\
(+7 \%)\end{array}$ & - & - & 19.2 \\
\hline
\end{tabular}




\section{Chapter 3 MATRIX DESIGN OF STRAIN HARDENING ULTRA- HIGH PERFORMANCE CONCRETE (SHUHPC)}

\subsection{Introduction}

This chapter concerns the design of a strain hardening ultra-high-performance concrete (SHUHPC) using locally available raw materials in Singapore. It aims to provide the next chapter with a basic mix design. Details about the selection of materials and the formulation of mix proportions are presented. Ten mixture proportions were tested to determine the optimum water-to-binder ratio, the filler-tobinder ratio, the proportioning of two types of filler, the fiber type, and the fiber content. The results of uniaxial compression test, uniaxial direct tension test and single fiber pullout test were documented. A micromechanics-based analytical model was applied to acquire insights into the tensile behavior of the SHUHPCs. At the end, the mixture proportion with the most balanced performance between compressive strength and tensile ductility was selected.

\subsection{Material and experimental program}

\subsubsection{Materials}

The raw materials of high performance concrete typically comprise cementitious components, fine fillers, superplasticizer and fibers. The cementitious components consist of mainly cement; but supplementary cementitious materials are also used to partially replace cement when there is a particular concern for greenness, workability, or durability. To reach high strength, cement with moderate water demand and very high strength development is preferred. The CEM I 52.5, which has and a low $\mathrm{C}_{3} \mathrm{~A}-$ content, low to medium fineness, is therefore used in current research. Silica fume is incorporated to reach high strength by filling voids in the next larger granular class, enhancing mix lubrication, and producing secondary hydrates through pozzolanic reactions. Elkem Microsilica ${ }^{\circledR}$ Grade $940 \mathrm{U}$ (Undensified) silica fume, which has the 
highest silica content and the smallest mean diameter among most of the commercial products, is selected for current research.

Having well-proportioned fillers is a key factor for a good and durable concrete. Fillers in hardened concrete serve as a skeleton to resist loading and to make up the space where cement otherwise would fill in. In this research, two types of filler, silica flour and silica sand, are used; and their proportion are determined experimentally. The information related to the type, source, range of particle size and density of mentioned ingredients above are summarized in Table 3.1. The chemical compositions of the ingredients are included in Table 3.2. The particle size distribution of all the granular ingredients involved are plotted in Fig. 3.1.

Table 3.1 Source and physical properties of the UHPC compounds

\begin{tabular}{ccccc}
\hline Material & Supplier & type & $\begin{array}{c}\text { Particle } \\
\text { size range } \\
(\mu \mathrm{m})\end{array}$ & $\begin{array}{c}\text { Specific } \\
\text { gravity } \\
\left(\mathrm{kg} / \mathrm{m}^{3}\right)\end{array}$ \\
\hline Cement & Asia Cement & CEM I 52.5 & $10-25$ & 3150 \\
Silica fume & Elkem & Undensified 940U & $0.1-1$ & $200-350$ \\
Filler-1 & Sibelco Europe & Microsil M4 & 5 to 100 & 2650 \\
Filler-2 & from China & $\mu$-silica sand & $100-150$ & 2650 \\
Fibers & Honeywell & Spectra 1000 & - & 970 \\
Superplasticizer & Grace & Polycarboxylate-based & - & 1100 \\
\hline
\end{tabular}

Table 3.2 Chemical compositions of the UHPC compounds

\begin{tabular}{lcccccc}
\hline Compositions (wt.\%) & $\mathrm{CaO}$ & $\mathrm{SiO}_{2}$ & $\mathrm{Al}_{2} \mathrm{O}_{3}$ & $\mathrm{Fe}_{2} \mathrm{O}_{3}$ & $\mathrm{SO}_{3}$ & LOI \\
\hline Cement & 67.17 & 22.14 & 3.12 & 2.51 & 2.13 & 1.68 \\
Silica fume & & $>90$ & & & & \\
Silica flour & & 99.40 & 0.10 & 0.03 & & 0.15 \\
\hline
\end{tabular}




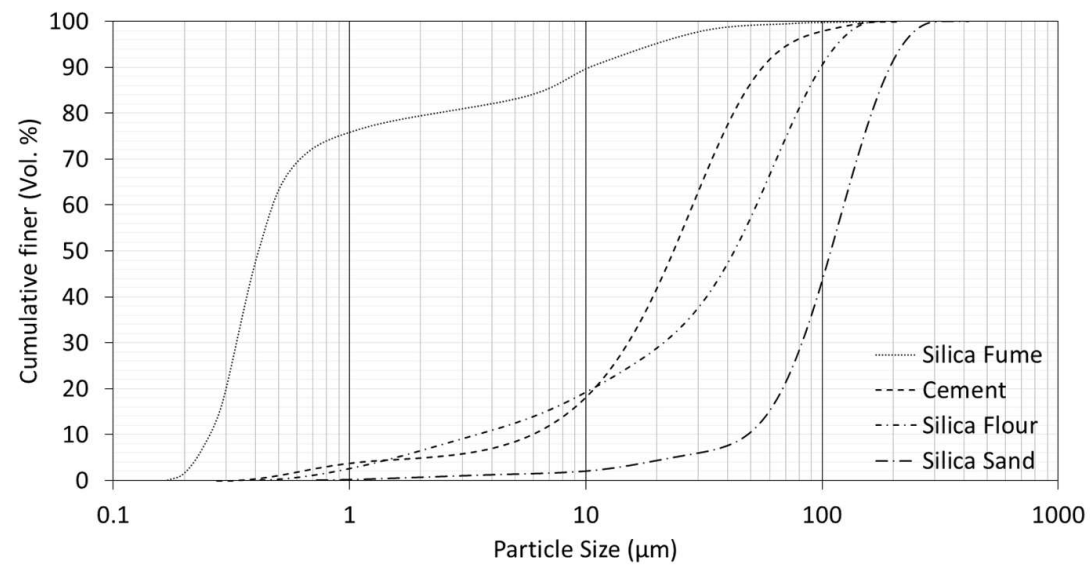

Fig. 3.1 Particle size distribution of ingredients.

Two types of fiber are explored to achieve high ductility. Designed with tough matrix, UHPC could only by reinforced by fibers with high tensile strength in order to avoid extensive fiber rupture during fiber pullout. Ultrahigh molecular weight polyethylene (UHMWPE) fiber, manufactured by Honeywell Inc with brand name as Spectra ${ }^{\circledR}$ fiber, is obtained by a gel-spinning technique and shows ultrahigh tensile strength and modulus. The mechanical properties of both types of fiber are detailed in Table 3.3 .

Table 3.3 Geometry and mechanical/physical properties of the PE fibers

\begin{tabular}{cccccc}
\hline & $\begin{array}{c}\text { Diameter } \\
(\mu \mathrm{m})\end{array}$ & $\begin{array}{c}\text { Tensile } \\
\text { strength } \\
(\mathrm{MPa})\end{array}$ & $\begin{array}{c}\text { Elastic } \\
\text { modulus } \\
(\mathrm{GPa})\end{array}$ & $\begin{array}{c}\text { Elongation } \\
(\%)\end{array}$ & $\begin{array}{c}\text { Melting } \\
\text { Temp } \\
\left({ }^{\circ} \mathrm{C}\right)\end{array}$ \\
\hline $\begin{array}{c}\text { Spectra } 900 \\
(\text { PE1 })\end{array}$ & 38 & 2500 & 75 & 3.1 & 150 \\
\cline { 1 - 3 } $\begin{array}{c}\text { Spectra } 1000 \\
(\text { PE2 })\end{array}$ & 23 & 3250 & 100 & 3.6 & \\
\hline
\end{tabular}

\subsubsection{Mix proportions}

Table 3.4 shows the mix proportions of 10 mixtures explored in this chapter. M1, the control mix, is a UHPC mix developed previously [66]. The ingredient proportions that are changed from successive mixtures are underlined to highlight. 
Table 3.4 Mixture proportions

\begin{tabular}{|c|c|c|c|c|c|c|c|c|c|c|}
\hline \multirow{2}{*}{$\begin{array}{l}\text { Mixture } \\
\text { Name }\end{array}$} & \multirow[b]{2}{*}{ Cement } & \multirow{2}{*}{$\begin{array}{l}\text { Silica } \\
\text { Fume }\end{array}$} & \multirow{2}{*}{$\begin{array}{l}\text { Silica } \\
\text { Flour }\end{array}$} & \multirow{2}{*}{$\begin{array}{l}\text { Silica } \\
\text { Sand }\end{array}$} & \multirow[b]{2}{*}{$\mathrm{w} / \mathrm{b}$} & \multirow{2}{*}{$\begin{array}{c}\text { HRW } \\
\text { RA }\end{array}$} & \multicolumn{4}{|c|}{ Fiber $^{\mathrm{a}}$} \\
\hline & & & & & & & Type & $\begin{array}{l}V_{\mathrm{f}} \\
(\%)\end{array}$ & $\begin{array}{c}\mathrm{L}_{\mathrm{f}} \\
(\mathrm{mm})\end{array}$ & $\begin{array}{c}\mathrm{d}_{\mathrm{f}} \\
(\mu \mathrm{m})\end{array}$ \\
\hline M1 & $0.9^{\mathrm{b}}$ & 0.1 & 0.4 & 0.1 & 0.22 & $1.60 \%$ & PE1 & 2 & 12 & 38 \\
\hline M2 & 0.9 & 0.1 & 0.4 & 0.1 & $\underline{0.20}$ & $1.66 \%$ & PE1 & 2 & 12 & 38 \\
\hline M3 & $\underline{0.85}$ & $\underline{0.15}$ & 0.4 & 0.1 & $\underline{0.19}$ & $1.76 \%$ & PE1 & 2 & 12 & 38 \\
\hline M4 & 0.9 & 0.1 & 0.4 & $\underline{0.3^{\mathrm{c}}}$ & 0.20 & $2.10 \%$ & PE1 & 2 & 12 & 38 \\
\hline M5 & 0.9 & 0.1 & $\underline{0.3}$ & 0.1 & 0.20 & $1.50 \%$ & PE1 & 2 & 12 & 38 \\
\hline M6 & 0.9 & 0.1 & $\underline{0.5}$ & 0.1 & 0.20 & $1.70 \%$ & PE1 & 2 & 12 & 38 \\
\hline M7 & 0.9 & 0.1 & 0.3 & 0.1 & 0.20 & $1.80 \%$ & $\underline{\text { PE2 }}$ & 2 & 12 & $\underline{23}$ \\
\hline M8 & 0.9 & 0.1 & 0.3 & 0.1 & 0.20 & $1.63 \%$ & $\underline{\text { PE2 }}$ & $\underline{1.5}$ & $\underline{19}$ & 23 \\
\hline M9 & 0.9 & 0.1 & 0.3 & $\underline{0.1}$ & 0.20 & $1.63 \%$ & PE2 & 1.5 & 19 & 23 \\
\hline M10 & 0.9 & 0.1 & 0.3 & $\underline{0.1}$ & 0.20 & $1.60 \%$ & PE2 & 1.5 & 19 & 23 \\
\hline
\end{tabular}

${ }^{\text {a }}$ Proportion of fiber in each mix is given in terms of volume fraction $\left(\mathrm{V}_{\mathrm{f}}\right)$ of the total $\operatorname{mix}$ volume. $\mathrm{L}_{\mathrm{f}}$ and $\mathrm{d}_{\mathrm{f}}$ are fiber length and fiber diameter, respectively. The naming of fiber type is abbreviated as follows: 'PE1' = polyethylene 1 (Spectra 900); 'PE2' $=$ polyethylene 2 (Spectra 1000).

${ }^{b}$ Except fiber, all mixture proportions are by weight of binder (cement + silica fume).

c The ingredient proportions that are changed between successive mixtures are underlined.

The main parameter compared between the first three mixture is the water-to-binder ratio $(\mathrm{w} / \mathrm{b}$ ratio). The aim is to determine the minimum boundary of its range in which the workability would not deteriorate by much. From M4 to M6, the purpose is to determine the effect of the filler-to-binder ratio ( $\mathrm{f} / \mathrm{b}$ ratio). The total amount of fillers to the amount of binder ranges from $0.7,0.6$, to 0.4 . In M7, fiber with increased aspect ratio was applied for higher ductility; while in M8, the amount of fiber was reduced 
to compensate the deterioration in workability caused by the increased water demand of the new fiber (the geometrical information of fibers is summarized in Table 3.3). In the end, attempts have also been made to investigate the effects of filler size in M9 and M10.

Table 3.5 Aspect ratios of the PE fibers

\begin{tabular}{c|c|c|c}
\hline Type & Length $(\mathrm{mm})$ & Diameter $(\mu \mathrm{m})$ & Aspect ratio \\
\hline PE1 & 12 & 38 & 316 \\
\hline PE2 & 12 & 23 & 521 \\
\hline PE2 & 19 & 23 & 826 \\
\hline
\end{tabular}

\subsubsection{Specimen preparation}

For each mix, the mixing, casting and curing process were keep as content. Cement, silica fume, silica flour, and micro silica sand were dry-mixed by a planetary mixer for 5 minutes first. Water pre-mixed with $80 \%$ of superplasticizer was slowly added into the mixture and mixed until the fresh paste was homogenous and consistent. Fibers were then gradually added and mixed for another 5 minutes. Meanwhile, the remaining $20 \%$ SP was added into the mixture to compensate rheological loss due to the addition of fibers. Afterward, the mixture was cast into $50 \mathrm{~mm}$ cubic and dog bone (150 $\mathrm{mm} \times 35 \mathrm{~mm} \times 15 \mathrm{~mm}$ in gauge length area) molds while moderate vibration was applied to remove entrapped air and to improve consolidation. The molds were covered with plastic sheets and cured in air at room temperature for one day. The hardened specimens were then removed from the molds and cured in limesaturated water for another 27 days in the laboratory at a temperature of $23 \pm 3{ }^{\circ} \mathrm{C}$ before testing.

Preparation of single fiber pullout specimens followed the suggestion of reference [67]. A long fiber was cut into about $150 \mathrm{~mm}$ in length and embedded into the cementbased matrix as shown in Fig. 3.2a. The hardened specimen was demolded after one day and cured in the same condition as described above. The specimens were sawed into thin specimens with a single fiber extruded out from one side. 


\subsubsection{Tests}

Compressive strength test was conducted in accordance with ASTM C 109. The loading of compression test was controlled at the rate of $100 \mathrm{kN} / \mathrm{min}$. Uniaxial tension tests were performed using a MTS hydraulic testing machine with $250 \mathrm{kN}$ capacity under displacement control with a rate of $0.2 \mathrm{~mm} / \mathrm{min}$. Two linear variable differential transducers (LVDTs) were attached to both sides of the tensile specimens to monitor the deformation of the sample with a gage length of $150 \mathrm{~mm}$. At least three samples were tested for each mixture and the average and the standard deviation were reported.

Single fiber pullout test was carried out to determine the interface frictional bond strength between fiber and matrix. The setup of single fiber pullout test is shown in Fig. 3.2b. The free end of the fiber was glued onto an aluminum plate, which was held by the upper gripper of a universal testing machine (UTM). The single fiber pullout specimen was glued to a pedestal which was screwed into a high-precision load cell with a maximum capacity of $10 \mathrm{~N}$. The load cell was attached to an $\mathrm{x}-\mathrm{y}$ displacement stage that was held by the bottom grip of the UTM.

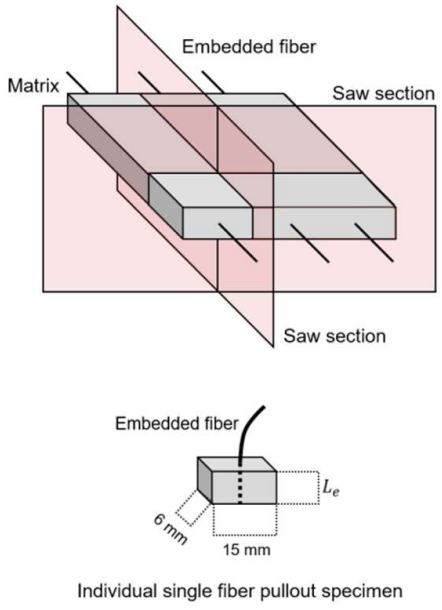

(a)

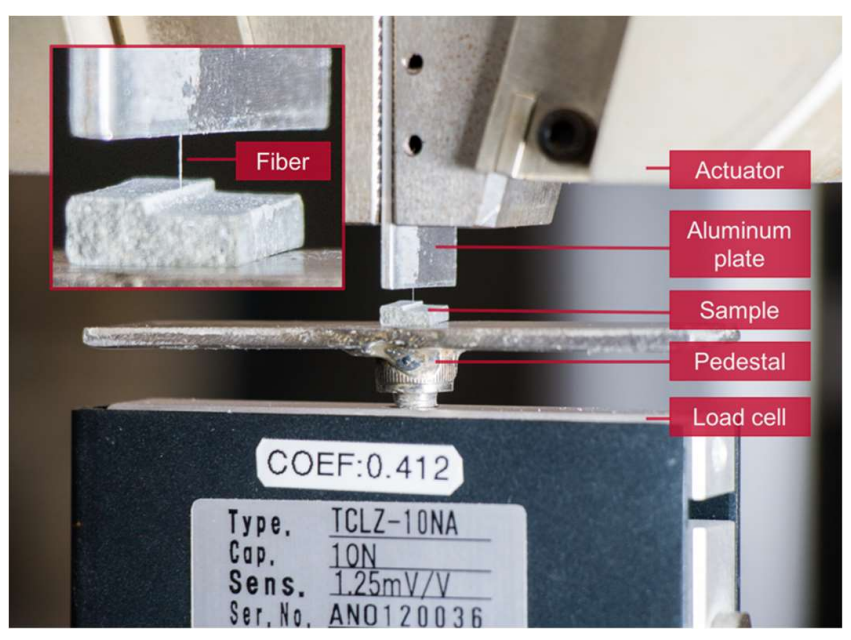

(b)

Fig. 3.2 (a) Single fiber pullout specimen and (b) experimental setup of the single fiber pullout test 


\subsection{Results and discussion}

The average of the mechanical properties of all mixtures (M1-M10) are presented in Table 3.6. A comparative chart plotting tensile ductility versus compressive strength of all mixtures M1-M10 is shown in Fig 3.3. Fiber bridging calculations and the pseudo strain hardening (PSH) indices are engaged to explain the tensile performances of selected mixtures.

Table 3.6 Average mechanical properties

\begin{tabular}{c|c|c|c|c|c|c}
\hline $\begin{array}{c}\text { Mixture } \\
\text { Name }\end{array}$ & $\begin{array}{c}\text { Brief Mixture } \\
\text { Description }\end{array}$ & $\begin{array}{c}f_{c}^{\prime} \\
(\mathrm{MPa})\end{array}$ & $\begin{array}{c}\text { COV } \\
\text { in } f_{c}^{\prime}\end{array}$ & $\begin{array}{c}\sigma_{u l t} \\
(\mathrm{MPa})\end{array}$ & $\begin{array}{c}\varepsilon_{u l t} \\
(\%)\end{array}$ & $\begin{array}{c}\text { COV } \\
\text { in } \varepsilon_{u l t}\end{array}$ \\
\hline M1 & Control & 138.67 & 2.83 & 7.70 & 1.23 & 19.16 \\
\hline M2 & $\mathrm{w} / \mathrm{b}=0.20$ & 142.72 & 0.32 & 7.44 & 1.33 & 29.31 \\
\hline M3 & w/b $=0.19$ & 135.73 & 4.12 & 7.03 & 1.42 & 24.32 \\
\hline M4 & $\mathrm{f} / \mathrm{b}=0.7 \mathrm{~b}$ & 132.00 & 1.82 & 7.48 & 1.34 & 29.78 \\
\hline M5 & $\mathrm{f} / \mathrm{b}=0.4$ & 154.70 & 4.41 & 8.03 & 1.14 & 18.69 \\
\hline M6 & $\mathrm{f} / \mathrm{b}=0.6$ & 138.22 & 3.36 & 6.68 & 1.65 & 24.88 \\
\hline M7 & With $12 \mathrm{~mm}$ PE2 ${ }^{\mathrm{c}}$ & 128.65 & 3.11 & 9.92 & 3.15 & 27.74 \\
\hline M8 & With 19mm PE2 & 144.44 & 5.38 & 9.60 & 2.55 & 22.63 \\
\hline M9 & Finer-sized sand & 143.49 & 8.56 & 10.30 & 2.60 & 13.80 \\
\hline M10 & Coarser-sized sand & 147.03 & 4.51 & 10.35 & 2.46 & 37.33 \\
\hline
\end{tabular}

a Only for quick reference - for complete description, refer Table 3.4.

${ }^{b}$ All mixtures following M3 utilize w/b ratio of 0.2 .

c All mixtures following M7 utilize Spectra1000 (PE2) fiber.

\subsubsection{Direct uniaxial compression test}

An optimum water/binder ratio was determined to be 0.2. Among M1-M3, the compressive strength of mix M2 is the highest. It may recall that the water-to-cement ratio determines the porosity of the hardened concrete at any stage of hydration; however, this trend would cease to continue when the water to cement ratio is 
excessively reduced, given that the full compaction is no longer possible. This could be the reason why the compressive strength of M3 is lower than that of M2.

From M4 to M6, the filler-to-binder ratio (f/b ratio) decreased from 0.7 to 0.4 . It was found the compressive strength increases with decreasing $f / b$ ratio. The $f / b$ ratio controls the volume fraction of the solid of fresh paste and in turn influences the workability. High content of water in any given suspension system implies lower viscosity and higher flowability. By decreasing the $\mathrm{f} / \mathrm{b}$ ratio from 0.7 to 0.4 , the volume fraction of the solid particles reduces from $88.5 \%$ to $86.4 \%$, benefiting the overall workability of the fresh paste and strength of harden specimens. Therefore, the $\mathrm{f} / \mathrm{b}$ ratio was fixed at 0.4 for following mixtures.

\subsubsection{Direct uniaxial tension test}

In mixtures M7-M10, the Spectra 900 fiber (abbreviated as PE1 in Table 3.3) used in M1-M5 was changed to Spectra 1000 fiber (PE2) with higher tensile strength and higher elastic modulus. In M7, 2 vol.\% 12-mm-long PE2 fiber led to a dramatic rise in the ductility from $1.14 \%$ of M5 to $3.15 \%$, albeit with significant loss in compressive strength. The loss in strength can be attributed to the increase of aspect ratio of fibers, as shown by Table 3.6. In M8, a balance was achieved by using 1.5 vol.\% 19-mm-long PE2 fiber, resulting in the most balanced combination of high strength (144 MPa) and high ductility (2.55\%).

In M9 and M10, it was found that the use of finer sand or coarser sand could only

slightly influence the ductility. The particle size of the aggregates was also observed to have opposite influence on compressive strength and tensile ductility. While mix M9 showed improved strength and reduced ductility, M10 exhibited lower strength and higher ductility. This results also suggested that, to meet specific engineering requirements, the combination of high strength and high ductility could be tailored by using different aggregates. 
To summary, considering the mechanical properties of all mixture, it can be observed that the mixture M8 has the best combination of compressive strength and tensile strain capacity as illustrated by Fig. 3.3. This unique performance is made possible by the micromechanically tailored interaction between the high strength PE fiber (of carefully chosen aspect ratio and volume fraction) and the densely-packed matrix. The crack patterns showing the multiple cracking performance of selected samples are shown in Fig 3.5.

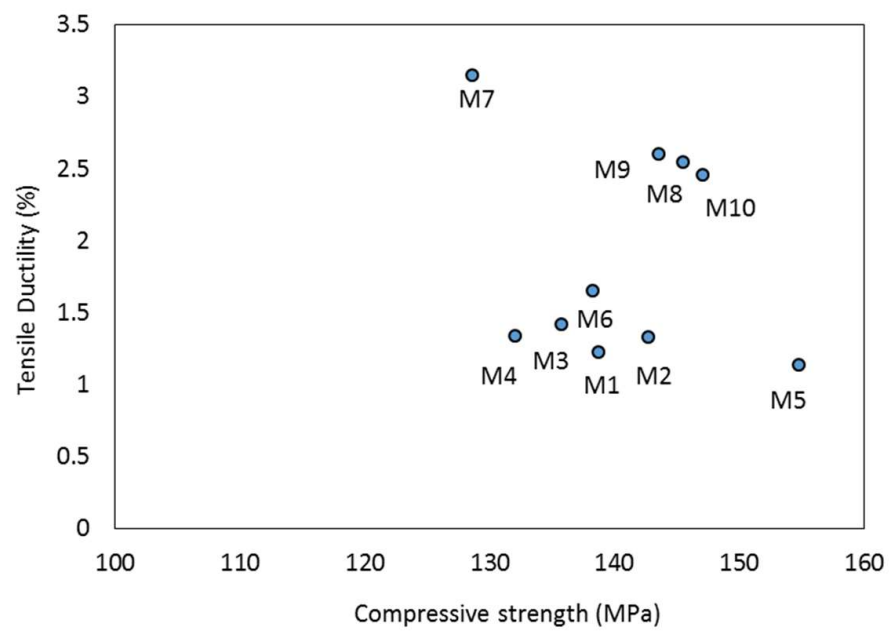

Fig. 3.3 Comparison chart

\subsubsection{Micromechanics-based modeling of strain hardening potential}

A microscale investigation was performed to acquire insights into the material behavior, which is used to explain the uniaxial tension behaviors of M5, M7 and M8. Single fiber pullout tests were conducted with varying embedment lengths. The fiber/matrix interaction properties and mechanisms inferred from the single fiber pullout test results were used in a statistical scale-linking model [10] to analytically compute the bridging stress-crack opening $(\sigma-\delta)$ relation of SHUHPC. The $\sigma-\delta$ was finally used to check the two necessary conditions of multiple cracking [68] to explain the different tensile performances. 
The single fiber pullout test curves of four representative specimens with varying embedment lengths are shown in Fig 3.4. Two distinct phases can be observed in the test curves, which are debonding (pre-peak, monotonically increasing) and pullout (post-peak). The fiber/matrix interfacial bond properties of chemical bond $G_{d}$, frictional bond $\tau_{0}$, and slip hardening parameter $\beta$ were determined by analyzing the single-fiber pullout curves.

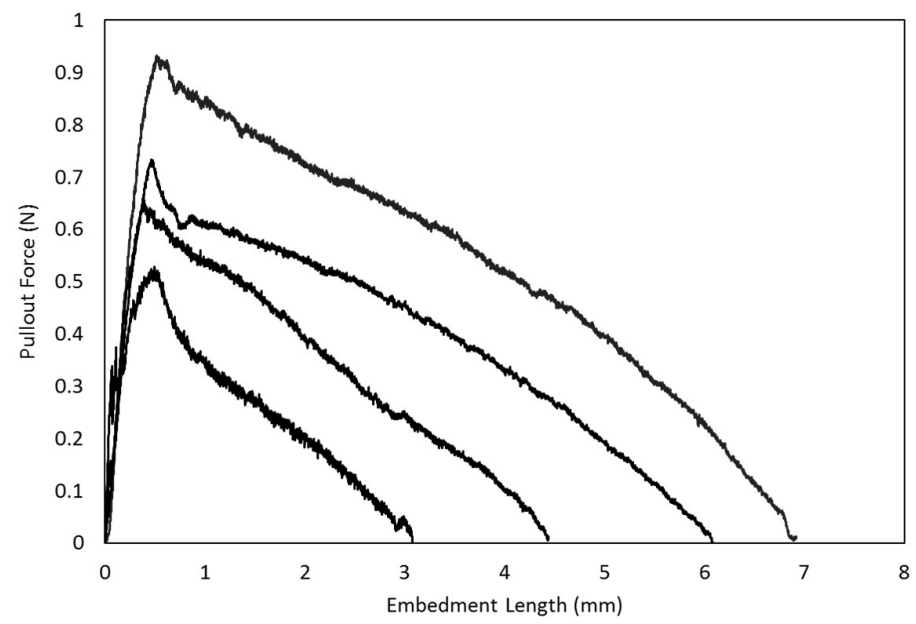

Fig. 3.4 Complete single fiber pullout test curves

The chemical bond is approximately equal to $0 \mathrm{~J} / \mathrm{m} 2$, which is as expected with PE due to its hydrophobic nature. This is verified by the pullout curves that show no sudden drop in load after the peak. In this case of nonchemically bonded fibers, the frictional bond strength $\tau_{0}$ could be calculated from the peak debond load by using Eq. 3.1. It was computed equal to $1.52 \mathrm{MPa}$. Next, the slop hardening parameter $\beta$ is determined from the post peak curvatures of the aligned fiber pullout curves. The average $\beta$ value was calculated to be 0.003 using Eq. 3.2.

$$
\begin{gathered}
\tau_{0}=P_{\text {peak }} / \pi d_{f} L_{e} \\
\beta=\left(\frac{d_{f}}{l_{f}}\right)\left[\left.\left(\frac{1}{\tau_{0} \pi d_{f}}\right)\left(\frac{\Delta \mathrm{P}}{\Delta S^{\prime}}\right)\right|_{S^{\prime} \rightarrow 0}+1\right]
\end{gathered}
$$

Besides the interfacial properties, $\sigma-\delta$ curve is also governed by the snubbing coefficient $f$, the matrix Young's modulus $E_{m}$, matrix tensile strength $\sigma_{m}$, matrix 
spalling coefficient $k$, fiber content $V_{f}$, fiber diameter $d_{f}$, length $L_{f}$, and Young's modulus $E_{f}$, apparent fiber strength $\sigma_{f u}$, and Cook-Gordon parameter $\alpha$. However, in terms of the high strength matrix used in this study, the matrix spalling effect and the Cook-Gordon effect were left out from considerations.

In order to calculate the $\sigma-\delta$ curve, micromechanics parameters were independently measured or deduced. Table 3.7 summarized the values of those micromechanics parameters for mixture M5, M7 and M8 used in the model calculation. Among them, the apparent fiber strength was measured by in-situ strength test. Matrix Young's modulus $E_{m}$ was approximately determined from Eq. 3.3:

$$
E_{c}=3.65\left(f_{c}^{\prime}\right)^{0.5}
$$

The values of snubbing coefficient $\beta$ and the fracture toughness of a reported mixture developed by Ranade $[12,13]$, which with similar strength and same type of PE fiber, was adopted in this study.

Table 3.7 Micromechanics parameters used as model input.

\begin{tabular}{|c|c|c|c|c|c|}
\hline & \multicolumn{5}{|c|}{ Fiber parameters } \\
\hline & $\begin{array}{c}V_{f} \\
(\text { vol. \%) }\end{array}$ & $\begin{array}{c}d_{f} \\
(\mu \mathrm{m})\end{array}$ & $\begin{array}{c}L_{f} \\
(\mathrm{~mm})\end{array}$ & $\begin{array}{c}E_{f} \\
(\mathrm{GPa})\end{array}$ & $\begin{array}{c}\sigma_{f u} \\
(\mathrm{MPa})\end{array}$ \\
\hline Mix 5 & 2 & 38 & 12 & 75 & 1357 \\
\hline Mix 7 & 2 & 23 & 12 & 100 & 1765 \\
\hline \multirow[t]{3}{*}{ Mix 8} & 1.5 & 23 & 19 & 100 & 1765 \\
\hline & \multicolumn{4}{|c|}{ Interface parameters } & \\
\hline & $\begin{array}{c}\tau_{0} \\
(\mathrm{MPa}) \\
\end{array}$ & $\begin{array}{c}G_{d} \\
\left(\mathrm{~J} / \mathrm{m}^{2}\right)\end{array}$ & $\beta$ & $f$ & \\
\hline Mix 5 & \multirow{3}{*}{1.52} & \multirow{3}{*}{0} & \multirow{3}{*}{0.003} & \multirow{3}{*}{0.59} & \\
\hline Mix 7 & & & & & \\
\hline \multirow[t]{3}{*}{ Mix 8} & & & & & \\
\hline & \multicolumn{3}{|c|}{ Matric parameters } & & \\
\hline & $\begin{array}{c}E_{m} \\
(\mathrm{GPa}) \\
\end{array}$ & $\begin{array}{c}K_{m} \\
\left(\mathrm{MPa} \cdot \mathrm{m}^{0.5}\right)\end{array}$ & $\begin{array}{c}\sigma_{m} \\
(\mathrm{MPa})\end{array}$ & & \\
\hline Mix 5 & \multirow{3}{*}{43} & \multirow{3}{*}{1.1} & \multirow{3}{*}{6.1} & & \\
\hline Mix 7 & & & & & \\
\hline Mix 8 & & & & & \\
\hline
\end{tabular}


The results of the $\sigma-\delta$ analysis for the three mixtures are summarized in Table 3.8. It was observed the M7 satisfy the strength criterion and the energy criterion comfortably while the M5 narrowly meet the two criteria. The analysis results successfully correlated with the ductility of the three mixtures, providing a rational basis for the observed composite tensile performance. It is further concluded that in spite of the fiber volume fraction of M8 was reduced to only $1.5 \%$, the ductility of the M8 could be maintained within an acceptable range by using 19-mm-long fiber.

Table 3.8 The $\sigma-\delta$ analysis results

\begin{tabular}{c|c|c|c}
\hline & Mix5 & Mix7 & Mix8 \\
\hline$J_{b}^{\prime}$ & 33.64 & 37.46 & 33.86 \\
\hline$J_{t i p}$ & 28.14 & 28.14 & 28.14 \\
\hline PSH energy & 1.20 & 1.33 & 1.20 \\
\hline$\sigma_{0}$ & 6.55 & 9.12 & 7.50 \\
\hline$\sigma_{f c}$ & 6.3 & 6.1 & 6.2 \\
\hline PSH strength & 1.039 & 1.495 & 1.170 \\
\hline Ductility & $1.14 \%$ & $3.15 \%$ & $2.55 \%$ \\
\hline
\end{tabular}




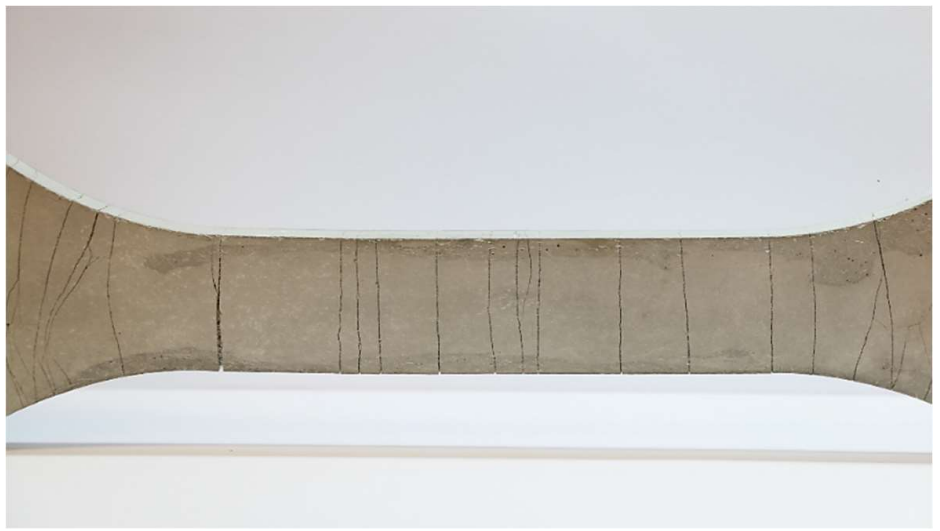

(a) Dogbone sample

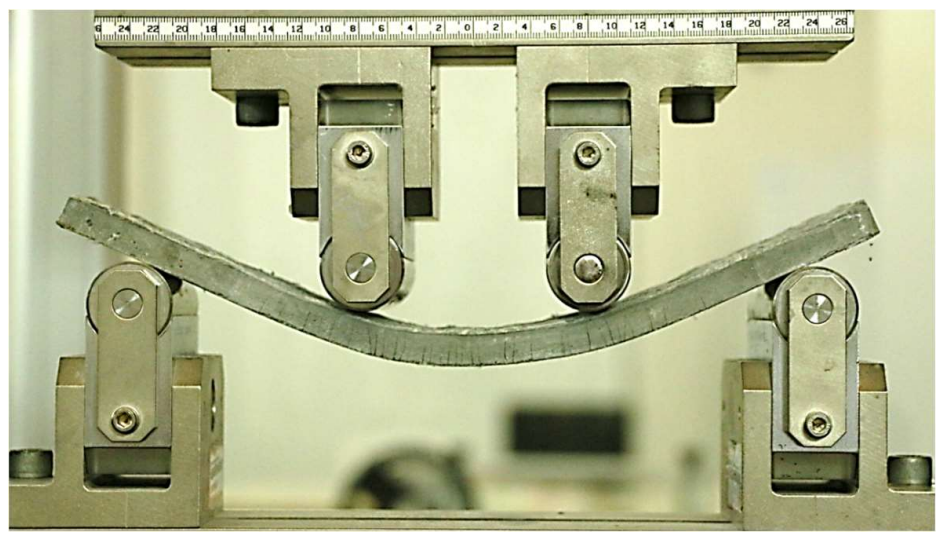

(b) Front view of a coupon sample

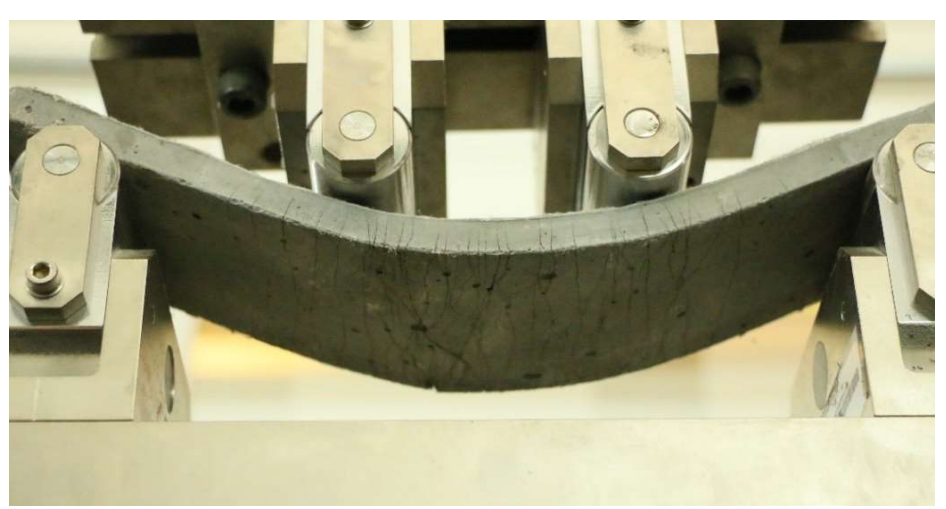

(c) Bottom view of a coupon sample

Fig. 3.5 Crack patterns of selected sample 


\subsection{Conclusions}

A set of fiber reinforced cementitious composites were investigated in this chapter. It led to the development of a preliminary version of the SHUHPC using locally available raw materials in Singapore. The mixture utilizes an ultrahigh molecular weight Polyethylene fiber (UHMWPE fiber) and a densely-packed matrix to reach both high tensile ductility and compressive strength. Compared with other SHUHPCs with similar performance, this material requires only standard water curing, which would benefit its application in the future. However, like all the PE fiber reinforced UHPC, the cracking width is large, visually estimated to be around several hundred micrometers, current material has the drawback related to its durability. Therefore, it is of great need to further engineer the material to eliminate the mentioned concerns. 


\section{Chapter 4 SHUHPC INCORPORATION CNF-COATED PE FIBERS (CNF-SHUHPC)}

\subsection{Introduction}

This chapter concerns the use of CNF to improve the mechanical properties of the SHUHPC developed in last chapter. It aims to enhance the interfacial bond strength between PE fiber and UHPC matrix by introducing CNFs to the interface transition zone (ITZ) between fiber and matrix. In accordance with this plan, a new idea of coating CNFs on the surface of PE fibers through hydrophobic interaction was proposed. The resultant CNF-SHUHPC has a compressive strength over $150 \mathrm{MPa}$ and exhibits $15 \%$ enhancement in tensile strength, $20 \%$ improvement in tensile strain capacity, and reduced cracking spacing. Single fiber pullout tests showed that the interface frictional bond strength of the CNF-coated PE fiber was increased by $22 \%$, which leads to higher tensile strength and increased strain capacity as predicted by the micromechanical model. At the end, an explanation on the possible mechanism by which the CNFs work is also presented.

\subsection{Experimental program}

\subsubsection{Mix design and materials}

Table 4.1 shows the mix compositions of the SHUHPC developed in last chapter. The SHUHPC matrix has a water-to-binder ratio of below 0.2 and a filler-to-binder ratio of 0.4 to achieve ultra-high strength. The binder consists of 90 wt.\% of CEM I 52.5N Portland cement and $10 \mathrm{wt} . \%$ of silica fume (Elkem Microsilica Grade 940U). Silica fume was used to strengthen the interface transition zone. The filler comprises $75 \%$ of silica flour and $25 \%$ of micro silica sand. Silica flour is powdered crystalline silica with a particle size distribution ranging from 0.1 to $100 \mu \mathrm{m}$, while micro silica sand has an average particle size of $150 \mu \mathrm{m}$. The finely graded fillers increase the packing density and thus improve rheological properties of fresh paste. A polycarboxylate- 
based superplasticizer (SP) produced from Grace with 30.0\% solid content by mass was used to reach desired workability.

Table 4.1 Mixture compositions of SHUHPC [unit in $\mathrm{kg} / \mathrm{m}^{3}$ ]

\begin{tabular}{ccccccccc}
\hline \multirow{2}{*}{ Mixture ID } & \multirow{2}{*}{ Cement } & $\begin{array}{c}\text { Silica } \\
\text { fume }\end{array}$ & $\begin{array}{c}\text { Silica } \\
\text { flour }\end{array}$ & $\begin{array}{c}\mu \text {-silica } \\
\text { sand }\end{array}$ & Water & SP & $\begin{array}{c}\text { PE fiber } \\
(1.5 \text { vol. \%) })\end{array}$ & $\begin{array}{c}\text { CNF } \\
\text { coating }\end{array}$ \\
\hline SHUHPC & 1289 & 143 & 430 & 143 & 284 & 22 & 14 & No \\
CNF-SHUHPC & 1289 & 143 & 430 & 143 & 284 & 22 & 14 & Yes \\
\hline
\end{tabular}

To achieve high ductility, 1.5 vol.\% of 19-mm-long high-strength high-modulus PE fibers (Spectra ${ }^{\circledR} 1000$, Honeywell) with a diameter of $23 \mu \mathrm{m}$ were used to produce SHUHPC. Table 4.2 summarizes the physical properties and geometry of PE fibers used in this study. As can be seen, Spectra ${ }^{\circledR} 1000$ PE fiber has a very high tensile strength of $3250 \mathrm{MPa}$ due to the use of ultra-high-molecular-weight PE resin for the production of fibers through a gel-spinning process.

Table 4.2 Properties of the PE fibers (Spectra ${ }^{\circledR}$ 1000, Honeywell)

\begin{tabular}{ccccc}
\hline $\begin{array}{c}\text { Diameters } \\
(\mu \mathrm{m})\end{array}$ & $\begin{array}{c}\text { Length } \\
(\mathrm{mm})\end{array}$ & $\begin{array}{c}\text { Tensile strength } \\
(\mathrm{MPa})\end{array}$ & $\begin{array}{c}\text { Elastic modulus } \\
(\mathrm{GPa})\end{array}$ & $\begin{array}{c}\text { Density } \\
\left(\mathrm{g} / \mathrm{cm}^{3}\right)\end{array}$ \\
\hline 23 & 19 & 3250 & 113 & 0.96 \\
\hline
\end{tabular}

CNFs used in this study were sourced locally (ceEntek Pte Ltd). Table 4.3 summarizes the properties of CNF and its suspension. CNFs are produced by catalytic chemical vapor deposition of a hydrocarbon over a surface of a metal catalyst. The resulting CNFs have diameters of 50 to $200 \mathrm{~nm}$ and an average length of $10 \mu \mathrm{m}$. CNFs were then dispersed in distilled water through ultrasonication without surface modification and addition of surfactant. The resulting suspension has a concentration of 0.3 and a $\mathrm{pH}$ around 6.

Table 4.3 Properties of CNF and its suspension

\begin{tabular}{cccccc}
\hline \multicolumn{1}{c}{ CNF } & & \multicolumn{2}{c}{ CNF suspension } \\
\cline { 1 - 2 } \cline { 6 - 7 } $\begin{array}{c}\text { Diameter } \\
(\mathrm{nm})\end{array}$ & $\begin{array}{c}\text { Ave. length } \\
(\mu \mathrm{m})\end{array}$ & $\begin{array}{c}\text { Surface area } \\
\left(\mathrm{m}^{2} / \mathrm{g}\right)\end{array}$ & & $\begin{array}{c}\text { Concentration } \\
\left(\mathrm{kg} / \mathrm{m}^{3}\right)\end{array}$ & $\mathrm{pH}$ \\
\hline $50-200$ & 10 & $120-130$ & & & $5.6-6.2$ \\
\hline
\end{tabular}




\subsubsection{Specimen preparation}

CNFs were coated to the surface of PE fibers through hydrophobic interaction [69], where PE fibers were immersed in CNF suspension and manually shaken for 5 minutes. After which, the solution was filtered and fibers were collected and dried in an oven at $80^{\circ} \mathrm{C}$ for 6 hours. It was observed that hydrophobes tend to clump up together in a water medium so that they may have minimal contact with water to reach a lower energy status and thus an attractive force was created between the hydrophobes. Strong attractive force has been reported between CNF and PE in aqueous solution [70]. When PE fibers and CNFs are simultaneously immersed in aqueous environment, the loss of hydrogen bonds near the two extended hydrophobic surfaces could cause water to move away from the hydrophobic surfaces and thus produce thin vapor layers between the two substances resulting in strong adhesion between PE fibers and CNFs as depicted in Fig. 4.1. Similar approaches have been applied to produce electrically conductive flexible films. CNT-coated polyethylene terephthalate (PET) and polyethylene naphthalate (PEN) were developed by dipping the polymer substrates into CNT suspension $[71,72]$. It was concluded the thickness of CNT coating is directly proportional to the hydrophobicity of the substrate [71]. It should be noted that the process conditions adopted in current study may not necessarily be the optimum conditions. Further study is needed to understand factors, such as CNF suspension concentration, $\mathrm{pH}$ value, fiber surface zeta potential, and the hydrophobicity of CNFs, govern the properties of the coating layer.
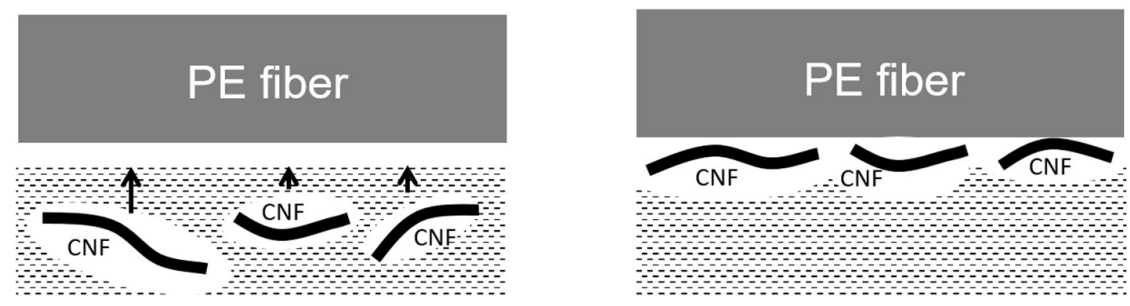

Fig. 4.1 Illustration of hydrophobic interactions between PE fibers and CNFs in water

To prepare SHUHPC, cement, silica fume, silica flour, and micro silica sand were dry-mixed by a planetary mixer for 5 minutes first. Water pre-mixed with $80 \%$ of SP 
was slowly added into the mixture and mixed until the fresh paste was homogenous and consistent. Fibers were then gradually added and mixed for another 5 minutes. Meanwhile, the remaining $20 \%$ SP was added into the mixture to compensate rheological loss due to the addition of fibers. Afterward, the mixture was cast into 50 $\mathrm{mm}$ cubic and dog bone (150 $\mathrm{mm} \times 35 \mathrm{~mm} \times 15 \mathrm{~mm}$ in gauge length area) molds while moderate vibration was applied to remove entrapped air and to improve consolidation. The molds were covered with plastic sheets and cured in air at room temperature for one day. The hardened specimens were then removed from the molds and cured in lime-saturated water for another 27 days in the laboratory at a temperature of $23 \pm 3{ }^{\circ} \mathrm{C}$ before testing.

Preparation of single fiber pullout specimens followed the suggestion of reference [67]. A long PE fiber was cut into about $150 \mathrm{~mm}$ in length and embedded into the SHUHPC matrix (same mix composition as in Table 4.1 but without the addition of PE fiber). The hardened specimen was demolded after one day and cured in the same condition as described above. The specimens were sawed into thin specimens (0.6-9 $\mathrm{mm}$ in thickness) with a single fiber extruded out from one side.

\subsubsection{Tests}

Compressive strength test was conducted in accordance with ASTM C 109. The loading of compression test was controlled at the rate of $100 \mathrm{kN} / \mathrm{min}$. Uniaxial tension tests were performed using a MTS hydraulic testing machine with $250 \mathrm{kN}$ capacity under displacement control with a rate of $0.2 \mathrm{~mm} / \mathrm{min}$. Two linear variable differential transducers (LVDTs) were attached to both sides of the tensile specimens to monitor the deformation of the sample with a gage length of $150 \mathrm{~mm}$. At least three samples were tested for each mixture and the average and the standard deviation were reported.

Single fiber pullout test was carried out to determine the interface frictional bond strength between the PE fiber (pristine and CNF-coated) and the SHUHPC matrix. The free end of the fiber was glued onto an aluminum plate, which was held by the upper gripper of a universal testing machine (UTM). The single fiber pullout 
specimen was glued to a pedestal which was screwed into a high-precision load cell with a maximum capacity of $10 \mathrm{~N}$. The load cell was attached to an $\mathrm{x}-\mathrm{y}$ displacement stage that was held by the bottom grip of the UTM. 24 specimens with different embedment lengths of 0.6 to $9 \mathrm{~mm}$ of each mixture were tested. The interface frictional bond strength $\tau_{0}$ can be determined by the following equation,

$$
\tau_{0}=P_{\text {peak }} / \pi d_{f} L_{e}
$$

where $P_{\text {peak }}$ is the peak pullout force, $L_{e}$ is the fiber embedment length and $d_{f}$ is the fiber diameter.

Optical microscope (OLYMPUS BX51) and field emission scanning electron microscope (FESEM, JEOL JSM-7600F) were used to investigate the CNF coating on the surface of PE fiber and to study the microstructure of interface between PE fiber and SHUHPC matrix from the single fiber pullout specimens. After the single fiber pullout tests, the specimens were cleaved through the fiber tunnel so that the fiber/matrix interface was exposed and examined under SEM.

\subsubsection{Micromechanics-based modeling of strain hardening potential}

Tensile strain hardening of cement-based material is a result of sequential development of parallel steady-state cracks $[10,73]$. The condition for steady-state cracking was quantitatively analyzed by Marshal and Cox [74] based on the J-integral method, which can be expressed as Eqn. 2.

$$
\frac{K_{m}^{2}}{E_{m}}=J_{t i p} \leq \sigma_{0} \delta_{0}-\int_{0}^{\delta_{0}} \sigma(\delta) d \delta \equiv J_{b}^{\prime}
$$

It indicates that the complementary energy of fiber-bridging $J_{b}^{\prime}$ must exceed the crack tip toughness $J_{\text {tip }}$, which is approximately equal to the matrix toughness $K_{m}{ }^{2} / E_{m}$ at small fiber content, where $K_{m}$ is the matrix fracture toughness and $E_{m}$ is the matrix Young's modulus. The $\sigma(\delta)$ curve, which can be viewed as the constitutive law of fiber-bridging behavior, is expressible as a function of a set of micromechanics parameters including interface frictional bond strength $\tau_{0}$ and snubbing coefficient $f$ accounting for the interaction between fiber and matrix when pulled at an inclined angle. Besides interfacial properties, the $\sigma(\delta)$ curve is also governed by the matrix 
Young's modulus $E_{m}$, fiber content $V_{f}$, fiber diameter $d_{f}$, fiber length $L_{f}$, and fiber Young's modulus $E_{f}$. A numerical procedure followed Qiu et al. [41] were used to calculated the $\sigma(\delta)$ curve. In addition, the fiber-bridging strength $\sigma_{0}$ along the crack plane must be higher than the matrix cracking strength $\sigma_{c}$ to allow the initiation of crack propagation from a matrix flaw. This consideration leads to the second criterion for strain hardening as Eqn. 4.3.

$$
\sigma_{c} \leq \sigma_{0}
$$

Equations 4 and 5 are referred to as the energy criterion and the strength criterion of pseudo strain hardening, respectively. Satisfaction of both is necessary to achieve tensile strain hardening behavior. The pseudo strain hardening (PSH) performance indices are often used to quantitatively evaluate the likelihood and robustness of strain hardening behavior [75].

$$
\begin{aligned}
& P S H_{\text {energy }}=\frac{J_{b}^{\prime}}{J_{\text {tip }}} \\
& P S H_{\text {strength }}=\frac{\sigma_{0}}{\sigma_{c}}
\end{aligned}
$$

Theoretically, strain hardening behavior would occur given both PSH indices are larger than unity. Due to random nature of pre-existing flaw size and fiber distribution in cement composites, however, large margins are preferred to ensure saturated multiple cracking and high tensile strain capacity. In this study, the measured interface frictional bond strength from the single fiber pullout tests together with other fiber and matrix properties were used to calculate fiber-bridging constitutive law and to determine the PSH indices of the SHUHPC and CNF-SHUHPC mixes.

\subsection{Results and discussion}

\subsubsection{CNF coating on PE fiber}

Fig. 4.2a shows the optical microscopy image of pristine PE fibers which are white in nature with a high degree of transparency. As compared to the pristine fibers, $\mathrm{PE}$ fibers treated with CNFs are black as shown in Fig. 4.2b indicating CNFs are adhered to the surface of PE fibers (Figs. 4.2c to 4.2f). As observed in the figure, densely packed CNFs are found on the surface of treated PE fibers. A positive correlation has 
been observed between the transparency of the CNF film and its thickness [72]. CNF films with a thickness of 50-250 nm and a corresponding transmittance of 90-50\% were reported [76]. The drastic change in visual transparency suggests the CNF layer on the PE fiber is dense with a thickness of at least $250 \mathrm{~nm}$. Further study should be carried out to characterize the coating layer.

The thick CNF coating on PE fiber surface may be attributed to the long range of hydrophobic interaction. Perturbation caused by the presence of hydrophobes generally occurs only at the interface between hydrophobes and water. The threedimensional hydrogen-bonding network of water; however, makes perturbations from the interface transmit over a long range [77]. It has been reported that the range of attractive force from hydrophobic interaction are measured up to $3.5 \mu \mathrm{m}$ [78] which is several order higher than the diameter of CNF. As a result, when PE fiber was immersed in the CNF suspension, a large volume of water surrounding the PE fibers would be perturbed causing dense and thick CNF coating on the surface of PE fibers. 


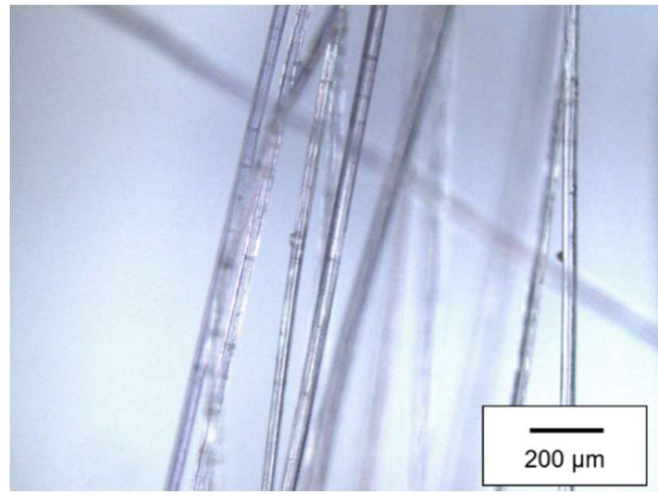

(a)

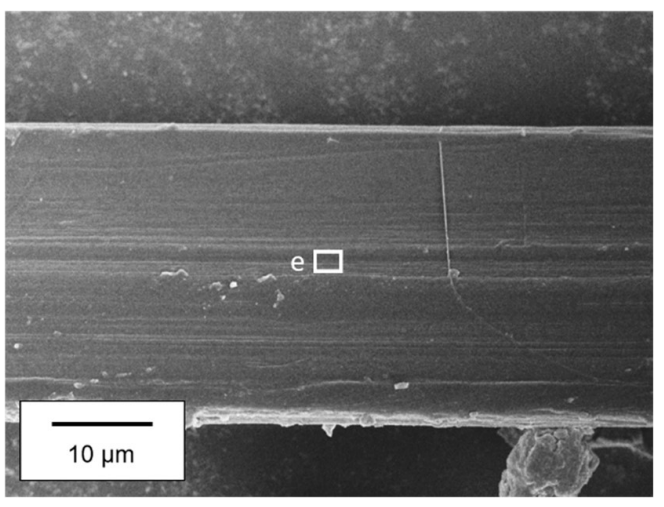

(c)

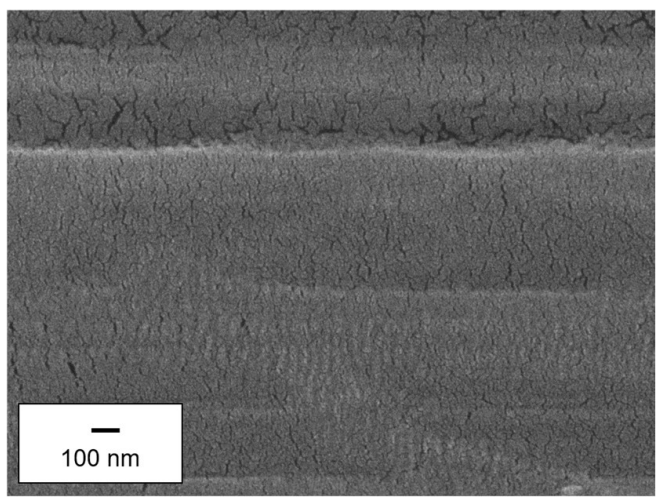

(e)

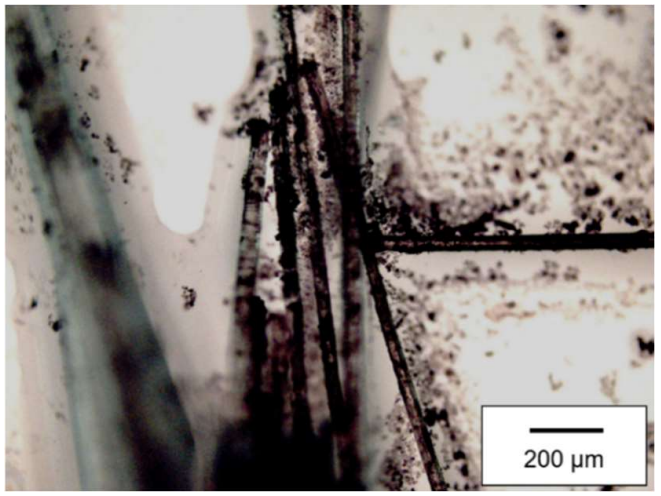

(b)

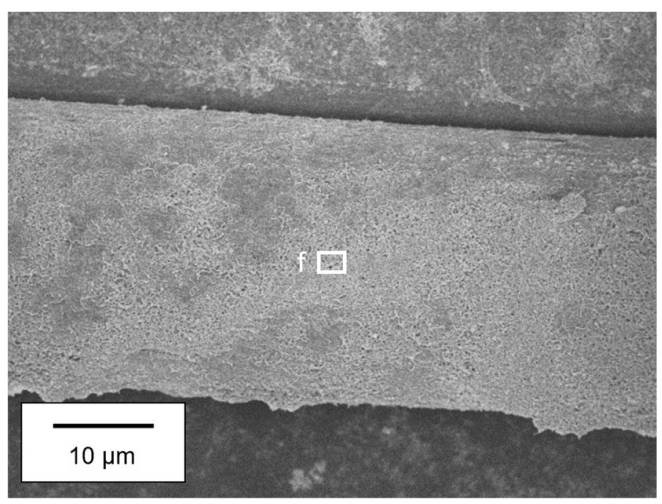

(d)

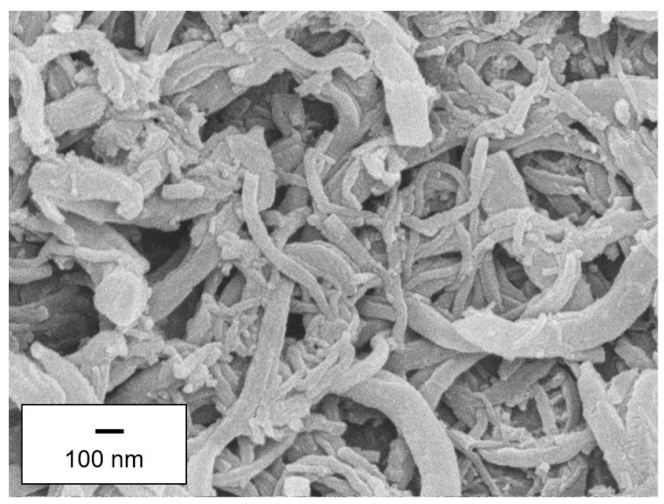

(f)

Fig. 4.2 Micrographs of (a) (c) (e) the pristine and (b) (d) (f) the CNF-coated PE fibers 
CNF-coated PE fibers were collected from the fresh CNF-SHUHPC paste after mixing. After collection, the CNF-coated fibers were washed by running water for few minutes to remove fresh cement paste and then stored in isopropanol to terminate cement hydration before microscopic imaging. As can be seen, the washed fibers remained black as shown in Fig. 4.3a suggesting CNFs stay on the surface of PE fibers even after mixing and washing. While the thickness of CNF layer may reduce, a larger number of CNFs remains on the surface of PE fibers (Fig. 4.3b) and interlace with silica fume particles (Figs. 4.3c and 4.3d).

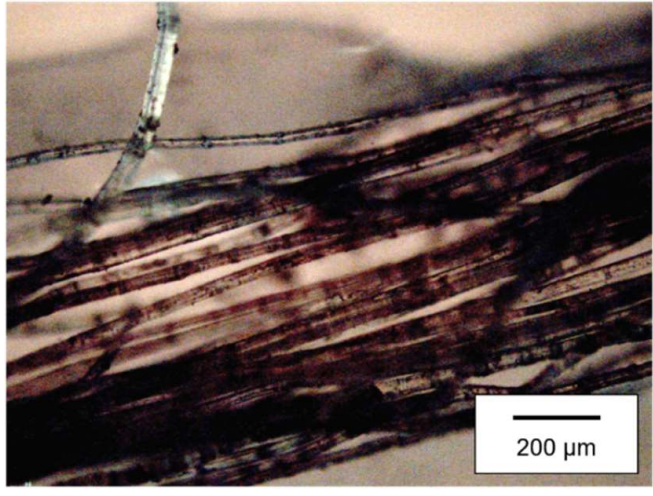

(a)

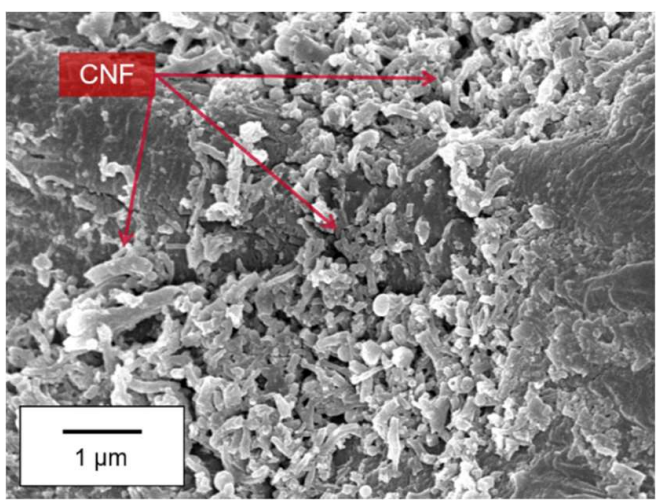

(c)

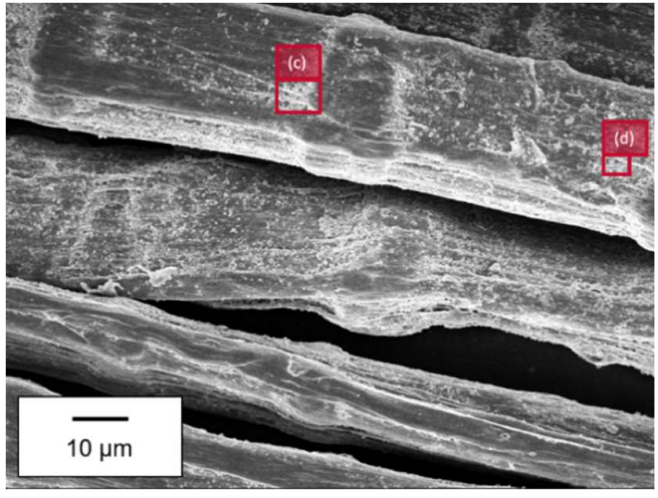

(b)

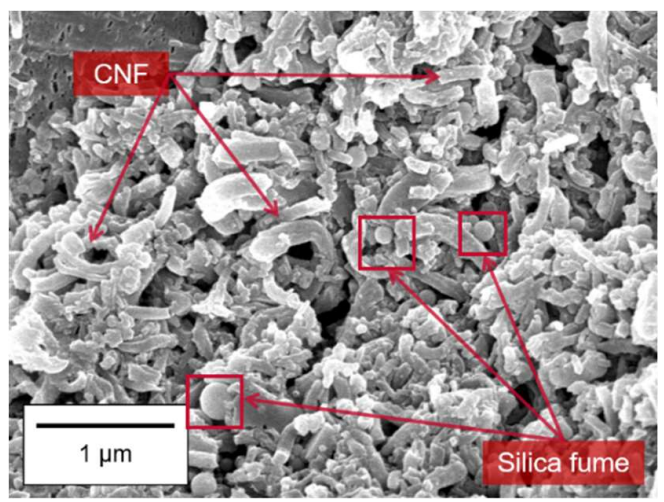

(d)

Fig. 4.3 (a) Optical microscope image and (b)(c)(d) SEM micrographs of CNFcoated PE fiber after mixing

\subsubsection{Mechanical properties of CNF-SHUHPC}

Table 4.4 summarizes the mechanical properties of CNF-SHUHPC incorporating CNF-coated PE fibers and the corresponding control mix SHUHPC where pristine 
PE fibers were used. As can be seen, the composite has a compressive strength over $150 \mathrm{MPa}$. The use of CNF-coated fiber slightly increases the compressive strength which may be attributed to strengthening of ITZ between fiber and matrix with CNF as discussed in the next section.

Table 4.4 Results of mechanical tests

\begin{tabular}{lcccccc}
\hline \multirow{3}{*}{ Mixture ID } & $\begin{array}{c}\text { Compressive } \\
\text { strength } \\
(\mathrm{MPa})\end{array}$ & $\begin{array}{c}1^{\text {st }} \text { cracking } \\
\text { strength } \\
(\mathrm{MPa})\end{array}$ & $\begin{array}{c}\text { Tensile } \\
\text { strength } \\
(\mathrm{MPa})\end{array}$ & $\begin{array}{c}\text { Ultimate } \\
\text { strain } \\
(\%)\end{array}$ & $\begin{array}{c}\text { Crack } \\
\text { Nos. }\end{array}$ & $\begin{array}{c}\text { Crack } \\
\text { width } \\
(\mu \mathrm{m})\end{array}$ \\
\hline SHUHPC & $144 \pm 2$ & $7.6 \pm 1.0$ & $13.1 \pm 1.2$ & $1.9 \pm 0.3$ & 16.3 & $142 \pm 67$ \\
CNF-SHUHPC & $153 \pm 4$ & $8.8 \pm 0.7$ & $15.0 \pm 0.5$ & $2.3 \pm 0.3$ & 38.3 & $71 \pm 42$ \\
\hline
\end{tabular}

Fig. 4.4 shows the tensile stress-strain curves of the two mixes. As can be seen, both mixes exhibit tensile strain hardening behavior. Three distinctive phases can be observed in the tensile behavior of the composites. A linear line with a slope equal to the elastic modulus of the material can be observed in the initial elastic stretching phase. After matrix first cracking, the load continues to increase without damage localization. The sequential formation of multiple parallel cracks contributes to the inelastic straining during the strain hardening stage. Fracture occurs once the fiberbridging is exhausted which defines the ultimate strength of the material.

As summarized in Table 4.4, CNF-SHUHPC shows a 20\% improvement in strain capacity from 1.9 to $2.3 \%$ and a $15 \%$ enhancement in tensile strength from 13 to 15 MPa as compared to the control SHUHPC. The enhanced tensile strength indicates a stronger fiber-bridging while the improved tensile strain capacity is a direct result of formation of more multiple cracks in the CNF-SHUHPC specimen. As can be seen in Fig. 4.5, the cracking pattern of SHUHPC is very different from that of CNFSHUHPC. More cracks with close spacing and tight crack width in CNF-SHUHPC could be observed. The crack spacing determined by the critical stress transfer distance $\left(x_{d}\right)$ in CNF-SHUHPC is much reduced. 


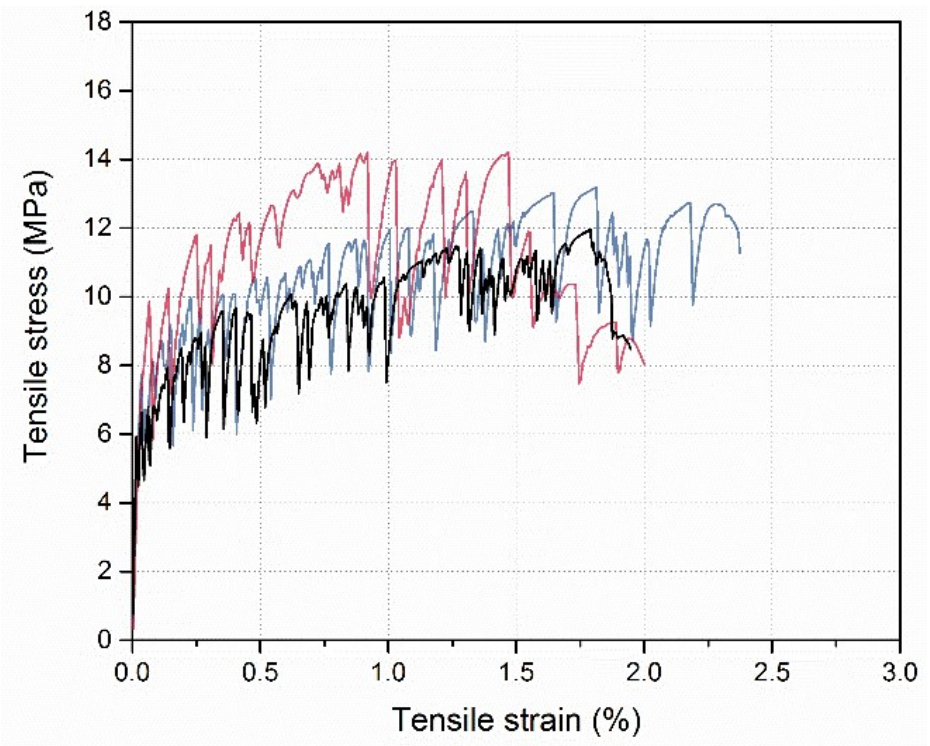

(a)

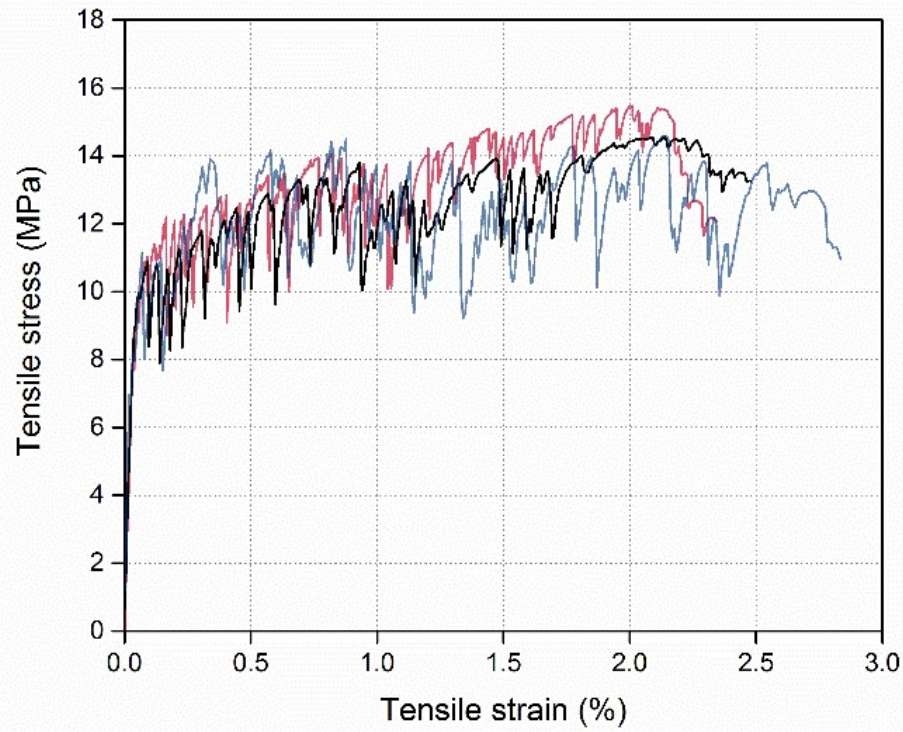

(b)

Fig. 4.4 Tensile stress-strain curves of (a) SHUHPC and (b) CNF-SHUHPC 


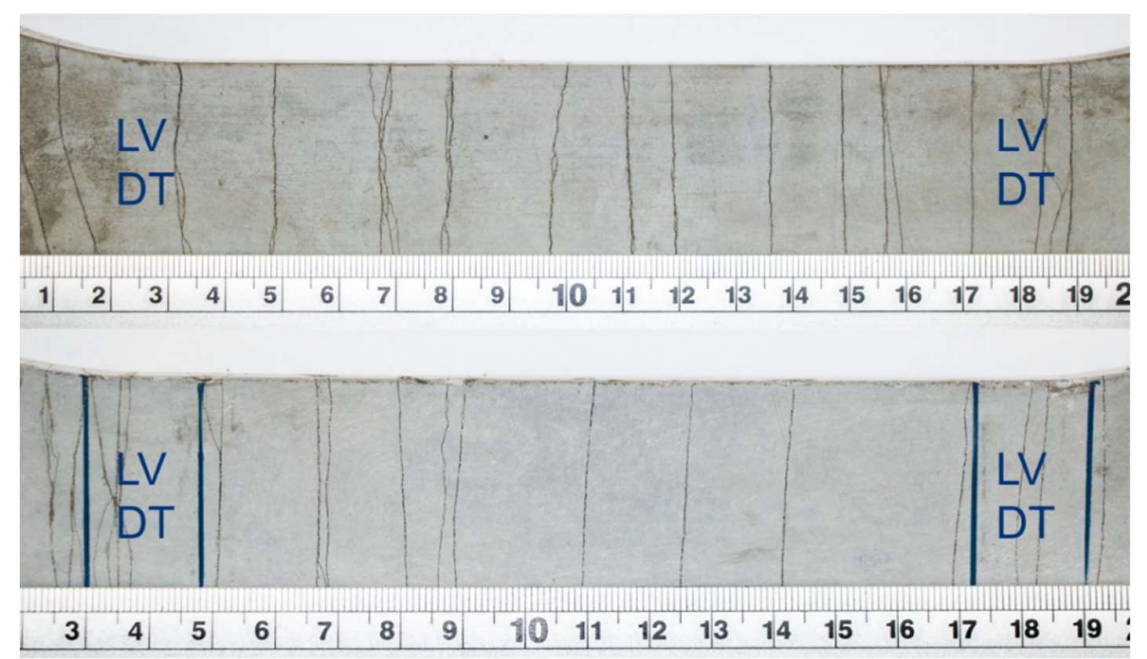

(a)
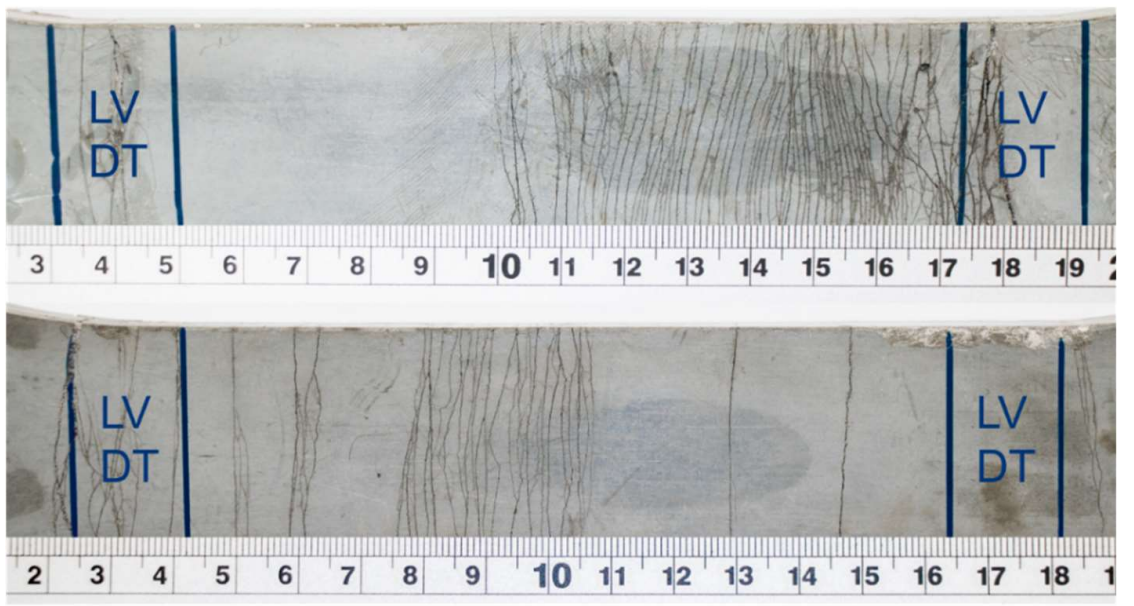

(b)

Fig. 4.5 Crack pattern of (a) SHUHPC and (b) CNF-SHUHPC [unit in $\mathrm{cm}$ ]

The stress transfer distance was first derived by Aveston et al. [2] for continuous aligned fibers and was later extended for randomly distributed short fibers [79]. In the analysis, when crack forms, matrix along the crack plane becomes stress-free and the applied load is carried by the bridging fibers across the crack plane to maintain equilibrium. The stress carried by the fibers is then transferred back to the matrix through fiber/matrix interfacial friction. The matrix stress is gradually increased with distance away from the crack plane as illustrated in Fig. 4.6a. At a critical transfer 
distance, the matrix stress reaches the matrix cracking strength resulting in the formation of another crack plane.

A micromechanics-based analytical model was developed to calculate the transfer distance $x_{d}$ as a function of crack opening $\delta$ at different interfacial frictional bond strength of 1 to $2 \mathrm{MPa}$ as Fig. 4.6b [43]. Input parameters for the calculation include fiber diameter, fiber length, fiber Young's modulus, and fiber strength as shown in Table 4.2; fiber volume (1.5 vol.\%) according to Table 4.1; and matrix strength of 8.2 $\mathrm{MPa}$ was experimentally determined. As can be seen, the required transfer distance reduces with increasing fiber-bridging stress. Furthermore, transfer distance reduces with increasing interface frictional bond strength at a given fiber-bridging stress level. Thus, the reduced crack spacing in CNF-SHUHPC suggest higher interfacial frictional bond strength and a more effective load transfer from the fiber back to the matrix through the interface due to the use of CNF-coated PE fibers.

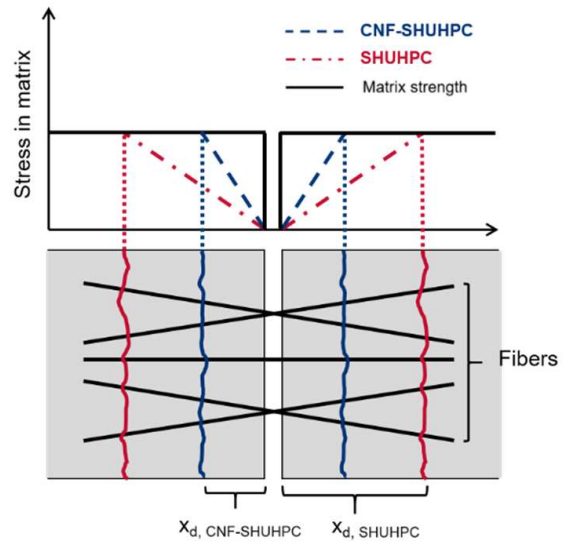

(a)

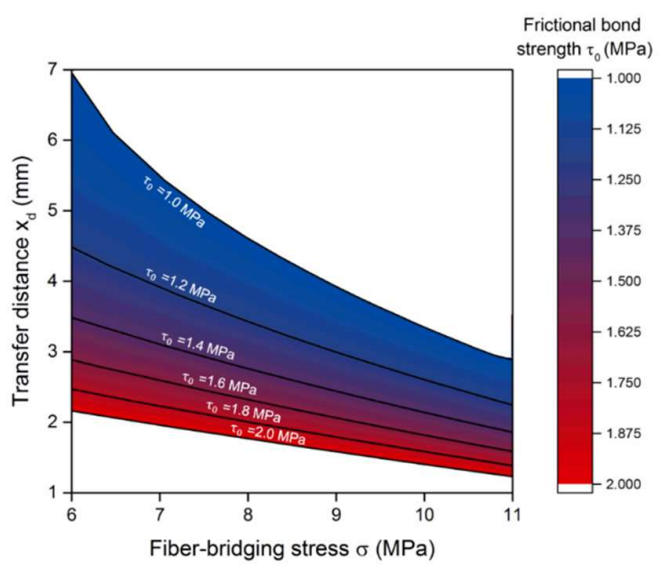

(b)

Fig. 4.6 (a) Illustration of critical transfer distances $x_{d}$ in SHUHPC and CNFSHUHPC, and (b) transfer distance $x_{d}$ as a function of fiber-bridging stress $\sigma$ and interface frictional bond strength $\tau_{0}$

Furthermore, crack width in CNF-SHUHPC is much reduced which again can be attributed to higher interface frictional bond strength which restrains the slippage of the fiber. This is consistent with the previous work which reported that the increase of fiber/matrix interface frictional bond in is responsible for the tight crack width in 
SHCC [39]. Tight crack width in CNF-SHUHPC greatly reduces transport properties, increases the potential of autogenous crack healing, and enhances durability.

\subsubsection{Fiber/matrix interface properties of CNF-SHUHPC}

Fig. 4.7 presents the typical single fiber pullout curve of the pristine PE fiber and CNF-coated PE fiber from the SHUHPC matrix. The interface frictional bond strength can be derived from the peak pullout force for a given fiber diameter and embedment length. The average interface frictional bond strength was $1.36 \pm 0.39$ $\mathrm{MPa}$ for the pristine PE fiber and 1.66 $\pm 0.40 \mathrm{MPa}$ for the CNF-coated PE fiber. The CNF coating results in $22 \%$ enhancement of the interface frictional bond strength.

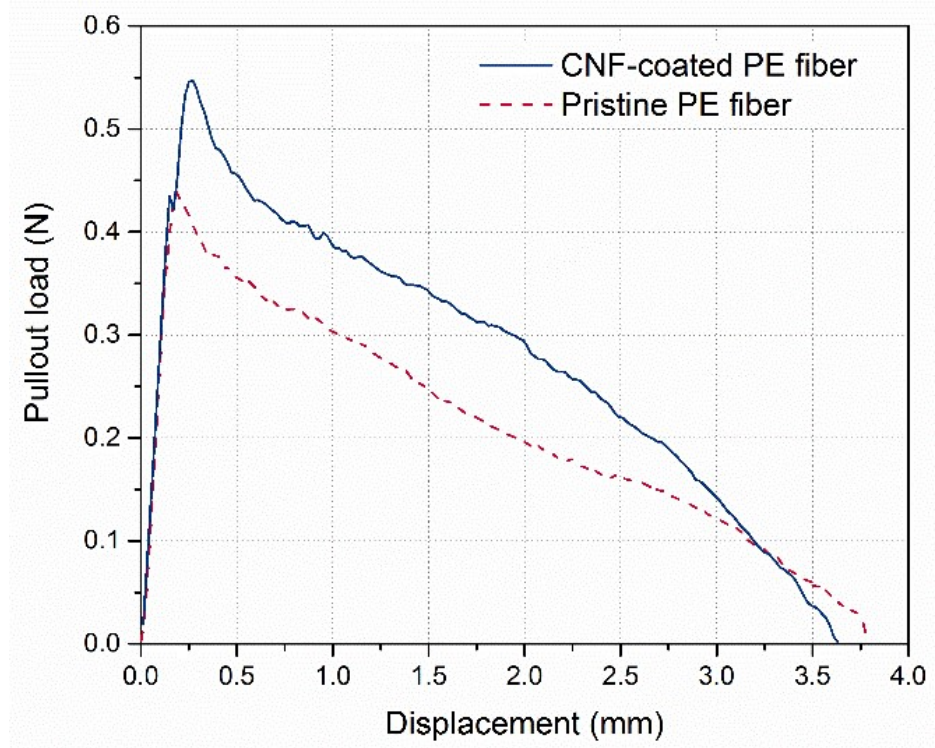

Fig. 4.7 Typical single fiber pullout curves of the pristine PE fiber and the CNFcoated PE fiber from the SHUHPC matrix with the same embedment length

$$
(\mathrm{Le}=3.4 \mathrm{~mm})
$$

Figs. $4.8 \mathrm{a}$ and $4.8 \mathrm{~b}$ show the micrograph of fiber tunnel of the pristine PE fiber and the CNF-coated PE fiber. Longitudinal cracks along the tunnel, which are caused by matrix shrinkage, are found in both cases. However, transverse cracks, which result from fiber pullout during the test, are only observed in the pristine PE fiber single fiber pullout specimen. This suggests specimen incorporating the CNF-coated PE 
fiber has higher crack resistance against fiber pullout. As can be seen, the ITZ of the specimen with the CNF-coated PE fiber (Fig. 4.8d) is much denser than that of the specimen with the pristine PE fiber (Fig. 4.8c). This may be attributed to the filling of nano-pores in the ITZ with CNFs as shown in the inset of Fig. 4.8d. It is plausible some CNFs coated on the PE fibers may move away from the fibers to the surrounding matrix due to mixing and thus densify the surrounding ITZ as shown in the schematic illusion of Fig. 4.9. Furthermore, a mixture of cement paste and CNFs can be found in the fiber/matrix interface (Fig. 4.8e) and CNFs bridge nano-cracks in cement paste (Fig. 4.8f), which suggest hydration products penetrate the CNF network so a weak transition zone is no longer present as illustrated in Fig. 4.9. The highly-concentrated CNFs layer on the PE fiber surface thus creates a hierarchical structure near ITZ in CNF-SHUHPC, i.e. fiber, CNF network-reinforced C-S-H layer, CNF filled ITZ, and bulk matrix (Fig. 4.9). These mechanisms result in the enhancement of interface frictional bond strength between PE fiber and UHPC matrix.

This highlights strategic use of carbon nanomaterials in the critical region to enhance the performance of composites. As compared to previous studies where carbon nanomaterials are either added directly into the matrix or grew on the fiber surface through high temperature in-situ grafting, current approach is simple while effective, efficient, and economical. 


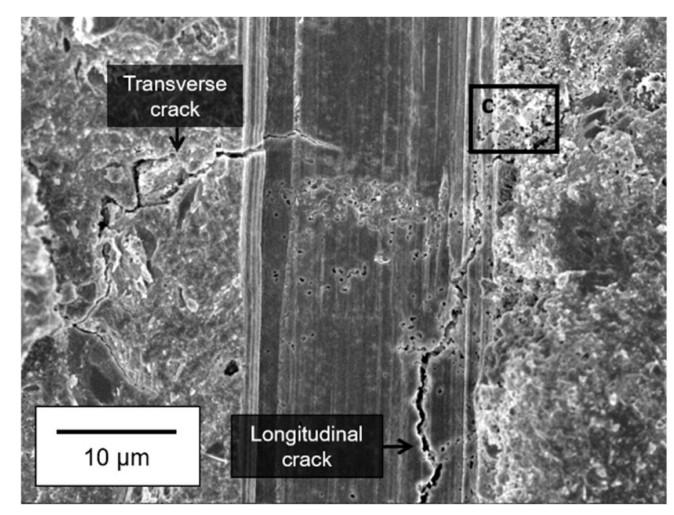

(a)

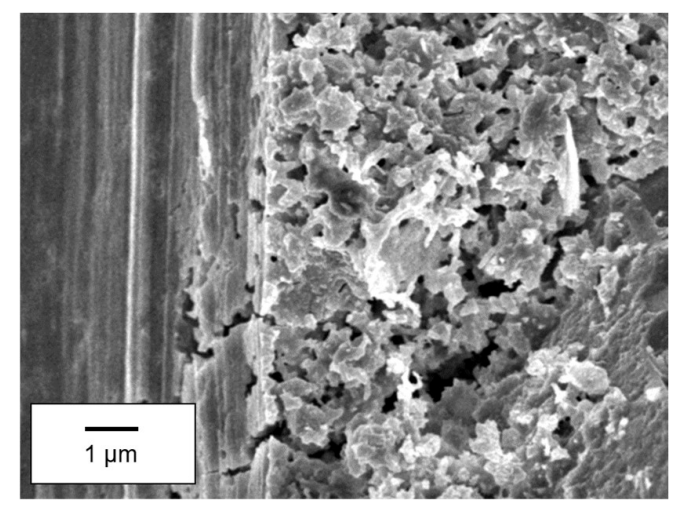

(c)

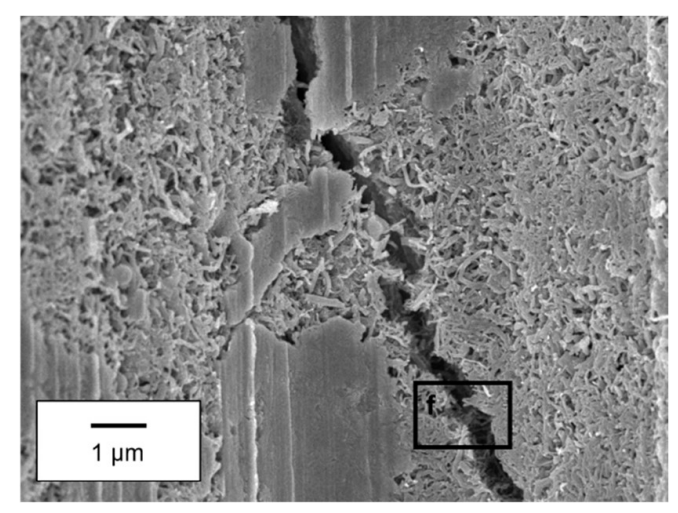

(e)

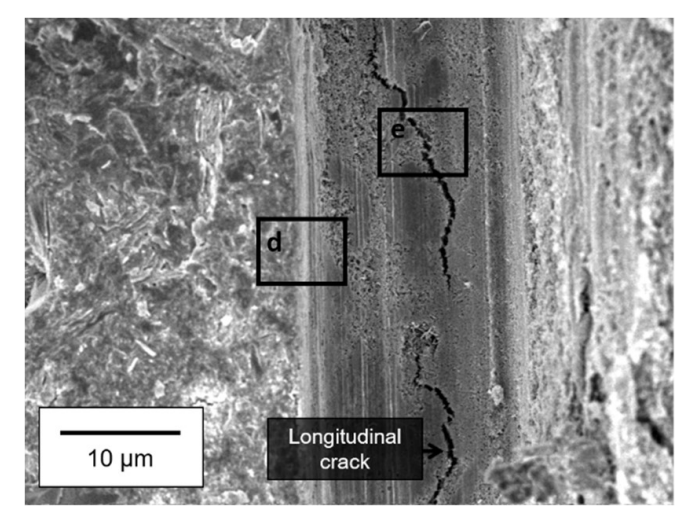

(b)

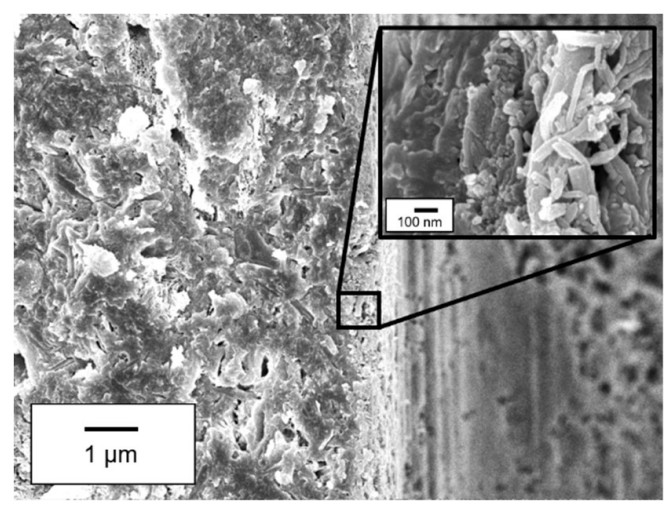

(d)

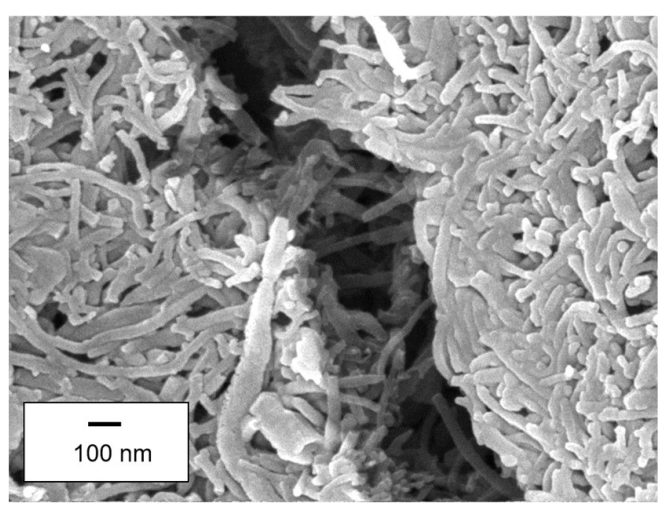

(f)

Fig. 4.8 SEM micrographs of fiber tunnel of (a), (c) the pristine and (b), (d)-(f) the CNF-coated PE fibers 


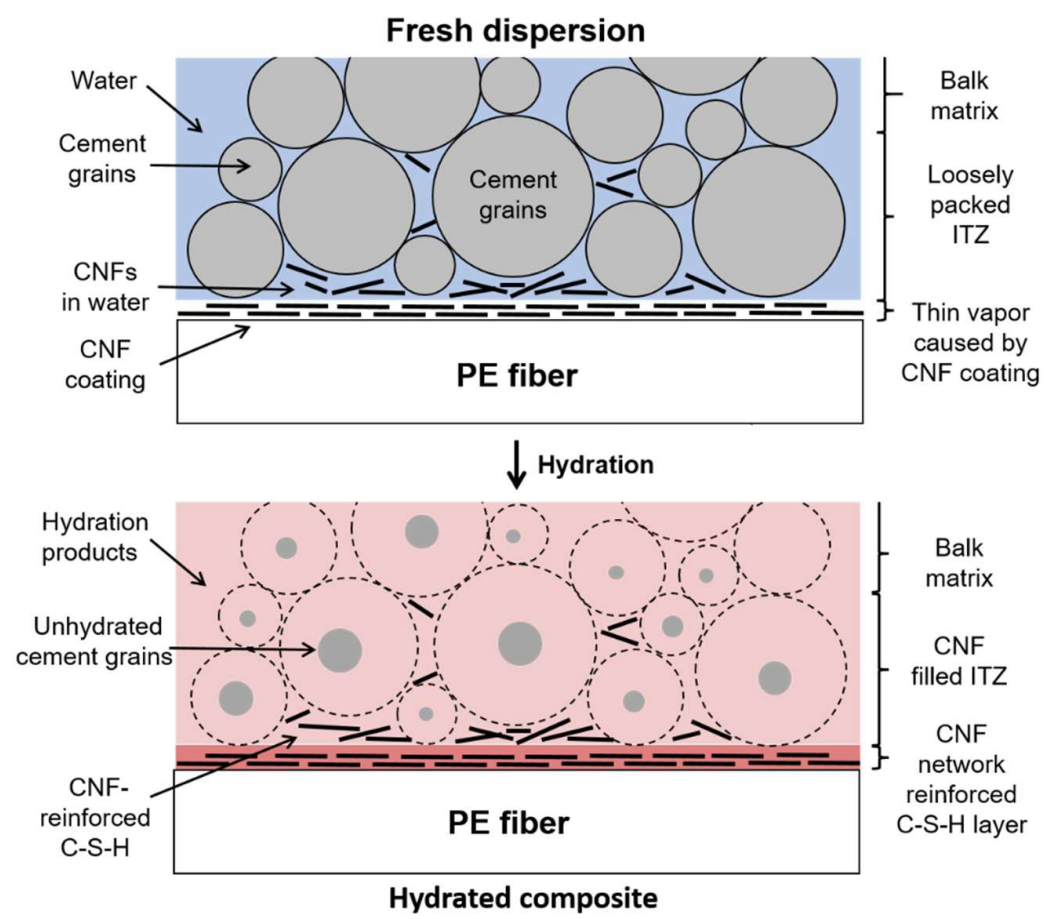

Fig. 4.9 Schematic illustration of the hierarchical structure near ITZ in CNFSHUHPC

4.4 Micromechanics-based modeling of strain hardening potential

Table 4.5 summarizes inputs for the calculation of complementary energy $J_{b}^{\prime}$, peak fiber-bridging strength $\sigma_{0}$ and the two PSH indices based on the micromechanical model. The fiber parameters including fiber diameter $d_{f}$, fiber length $L_{f}$, fiber Young's modulus $E_{f}$, and apparent fiber strength $\sigma_{f u}$ are nominal values provided by the manufacturer. Matrix cracking strength $\sigma_{m}$ was experimentally determined and matrix fracture toughness $K_{m}$ was deduced based on the wedge splitting test. Matrix Young's modulus $E_{m}$ and snubbing coefficient $f$ were assumed to be the same as another PE fiber-reinforced UHPC with similar matrix composition and compressive strength reported in [13]. The interface frictional bond strengths $\tau_{0}$ was derived from the single fiber pullout tests in the previous section. 
Table 4.5 Micromechanical parameters for model calculation and results

\begin{tabular}{|c|c|c|c|c|c|c|c|c|c|c|c|c|c|}
\hline \multirow[b]{2}{*}{$\begin{array}{l}\text { Mixture } \\
\text { ID }\end{array}$} & \multicolumn{4}{|c|}{ Fiber } & \multicolumn{3}{|c|}{ Matrix } & \multicolumn{2}{|c|}{ Interface } & \multicolumn{4}{|c|}{ Model results } \\
\hline & $\begin{array}{c}d_{f} \\
(\mu \mathrm{m})\end{array}$ & $\begin{array}{c}L_{f} \\
(\mathrm{~mm})\end{array}$ & $\begin{array}{c}\sigma_{f u} \\
(\mathrm{MPa})\end{array}$ & $\begin{array}{c}E_{f} \\
(\mathrm{GPa})\end{array}$ & $\begin{array}{c}E_{m} \\
(\mathrm{GPa})\end{array}$ & $\begin{array}{c}\sigma_{m} \\
(\mathrm{MPa})\end{array}$ & $\begin{array}{c}K_{m} \\
\left(\mathrm{MPa}-\mathrm{m}^{1 / 2}\right)\end{array}$ & $f$ & $\begin{array}{c}\tau_{0} \\
(\mathrm{MPa})\end{array}$ & $\begin{array}{c}J_{b}^{\prime} \\
\left(\mathrm{J} / \mathrm{m}^{2}\right)\end{array}$ & $\begin{array}{c}\sigma_{0} \\
(\mathrm{MPa})\end{array}$ & $P S H_{\text {energy }}$ & $P S H_{\text {strength }}$ \\
\hline SHUHPC & 23 & 19 & 3250 & 113 & 48.4 & 8.2 & 1.5 & 0.59 & 1.36 & 449 & 14.4 & 9.8 & 1.7 \\
\hline $\begin{array}{c}\text { CNF- } \\
\text { SHUHPC }\end{array}$ & 23 & 19 & 3250 & 113 & 48.4 & 8.2 & 1.5 & 0.59 & 1.66 & 514 & 16.5 & 11.2 & 2.0 \\
\hline
\end{tabular}

Model results are also reported in Table 4.5. CNF-SHUHPC possesses higher fiber bridging strength $\sigma_{0}(15 \%$ higher than SHUHPC), which is consistent with the experimental results that the tensile strength of CNF-SHUHPC is higher than that of control. A higher peak fiber bridging strength $\sigma_{0}$ is favorable to the satisfaction of the strength criterion (Eqn. 3). The complementary energy $J_{b}^{\prime}$ of CNF-SHUHPC increases from 449 to $514 \mathrm{~J} / \mathrm{m}^{2}$, which is in favor of the energy criterion (Eqn. 2). Both improvements can be attributed to the increased interface frictional bond strength $\tau_{0}$ when CNF-coated PE fibers were included in the material. The $P S H_{\text {energy }}$ and the $P S H_{\text {strength }}$ indices increase by $14 \%$ and $18 \%$, respectively. Material with higher values of PSH indices should have more chance of saturated multiple cracking and often leads to higher tensile ductility [75]. As a result, CNF-SHUHPC possesses higher tensile strength as well as increased tensile ductility as shown in Fig. 4.5.

\subsection{Conclusions}

In this chapter, a SHUHPC incorporating CNF coated PE fiber (CNF-SHUHPC) was developed. The resultant CNF-SHUHPC exhibits 15\% enhancement in tensile strength, $20 \%$ improvement in tensile strain capacity, and largely reduced cracking spacing and width. Two micromechanics-based models were adopted to confirm that the improvements are direct results of having improved interface frictional bond strength between PE fiber and cement-based matrix. It is expected that the concerns over the cost and the durability of the SHUHPC materials can be largely mitigated.

The issue of the weak interfacial bond between fiber with hydrophobic surface and cement-based matrix has also been solved. Instead of aiming to change the hydrophobicity of the fiber surface, current studies fully utilized this hydrophobic 
nature. Through the hydrophobic interactions, CNFs are coated on the surface of PE fiber to strengthen the interface transition zone. Unlike plasms treatment, in which high energy and temperature are required, current method is much feasible and simple. It is also expected that this method of strengthening the ITZ could be applied to a wide range fibers such as polypropylene fiber and steel fiber.

This study highlights strategic use of carbon nanomaterials in the critical region to enhance the performance of material. The high unit cost and the extremely small size of the carbon nanomaterials imply that they should be used with care for a critical application. However, most previous studies added (dispersed) carbon nanomaterials directly into concrete. This method, where a lot of nanomaterials is required, is costly; and its effect is unstable due to the dispersion issue. In contrast, current study proves that only a small amount of nanomaterial would be sufficient to boost the performance of concrete, as long as it is used in a right way. A simple method to coat CNFs on the surface of PE fibers through hydrophobic interactions was proposed. As compared to previous studies where carbon nanomaterials are either added directly into the matrix or grew on the fiber surface through high temperature in-situ grafting, current approach is simple while effective, efficient, and economical.

In addition, it is found that the highly-concentrated CNFs layer on the PE fiber surface could create a sub-structure around the fiber. By this means, the CNFs reinforce the region near the PE fibers, which are reinforcing the overall composite at a higher scale. A hierarchical structure is therefore created; and the exceptional performance of the resultant composite is believed to due to the contribution of all level of hierarchy. Further study should be carried out to characterize the coating layer, e.g. layer thickness, and to understand factors, such as CNF suspension concentration, $\mathrm{pH}$ value, fiber surface zeta potential, and the hydrophobicity of CNFs, govern the properties of the coating layer. 


\section{Chapter 5 MICROSTRUCTURAL INVESTIGATIONS ON REINFORCING MECHANISMS OF CNF COATING}

\subsection{Introduction}

In last chapter, a new idea of using the CNFs to strengthen the ITZ and enhance the interface frictional bond strength between PE fibers and cement-based matrix was proposed and was realized through a coating process. A CNF-SHUHPC incorporating such CNF-coated PE fibers was developed. Compared with the control SHUHP, the CNF-SHUHPC exhibits enhanced tensile strength, improved tensile strain capacity, and reduced cracking spacing. Single fiber pullout test results confirmed that a more effective load transfer between fiber and matrix was accomplished due to the reinforced ITZ, delivering those the responses under tensile loading.

By creating a hierarchical structure around the fiber, the CNFs at different positions may behave differently. While the SEM micrographs of the fiber tunnel clearly demonstrated that the CNFs could form a mixture with cement hydration products at the interface, the results also point to the possibility that some of CNFs coated on the fiber may move away to the surrounding matrix and thus densify the surrounding ITZ. This chapter, therefore, aims to give more insights to this filling behavior by investigating the microstructure of the ITZ.

The mechanical behavior of the ITZ is hard to test directly due to the dimension of the ITZ. Nanoindentation test could provide quantitative information about concrete at nanoscale. Hardness test generally reflect the mesoscale mechanical properties of materials. None of them is suitable to study the ITZ. Therefore, in this study, an indirect measurement was adopted by conducting grid nanoindentation test, in which a large number of indents would be carried out to test the proportions of different phases composing the material. 
It may recall the hydration process where the cement clinker reacts with water and thus create the hydration product. At any time, the hydration degree of cement clinker is proportional to the water content previously available around the clinker. Thus, if the CNFs could fill the place where otherwise the water would, more of residue clinker in the matrix may present due to insufficient amount of water for hydration. To fulfill this purpose, grid nanoindentation test is carried out to determine the proportions of the components in the matrix.

It has also been reported the carbon nanomaterial itself could influence the hydration of the cement; but this property is largely determined by the type and manufacture process of the CNFs. Thus, to verify that the change in the proportion between residual clinker and hydration product is the consequence of the filling, the effects of the CNF used in current research to the hydration have also been studied by the thermogravimetric analysis and isothermal calorimetric test.

In summary, in this chapter, grid nanoindentation test was conducted to study the filling effect of the CNFs by analyzing the hydration degree of cement clinkers in the ITZ. To support the results of the nanoindentation test, thermogravimetric analysis and isothermal calorimetric test were also conducted. It is expected that, by understanding the reinforcing mechanism of the CNF coating, the efficiency of the coating could be further increased in the future.

5.2 Effect of CNF on the nanoscale mechanical properties of the interface transition zone (ITZ) between polyethylene (PE) fiber and cement paste

\subsubsection{Specimen preparation}

CNF coated PE fiber yearn and pristine yarn were cut into $100 \mathrm{~mm}$ in length and embedded into the pure cement paste with 0.2 water to cement ratio as shown in Fig. 5.1. The geometry of this cylindrical specimen is designed to fit the sample holders of the polishing machine and the nano-indenter. The hardened specimen was demolded after one day and cured in the same condition as described in Chapter 4 for 
7 days. The specimens were sliced into samples of $10 \mathrm{~mm}$ thickness and were immersed into isopropanol to stop the process of hydration.

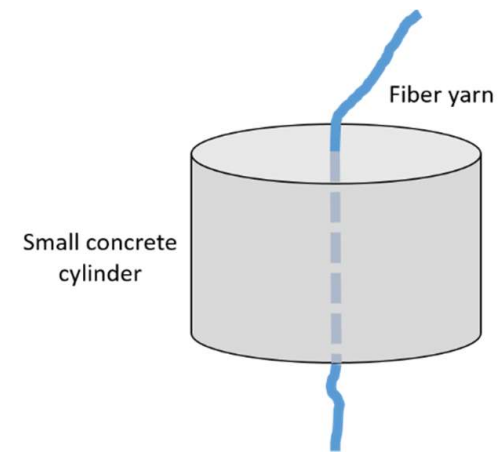

Fig. 5.1 Nanoindentation sample

It is well known that surface finish has a significant influence on the test results. The presence of significant surface roughness tends to increase the scatter in measured indentation modulus and indentation hardness, along with an overall reduction in these properties [80]. There are three primary goals of the surface preparation procedure: (1) to achieve as flat a surface as possible, (2) to obtain repeatable results, and (3) to minimize the sample disturbance. The procedure described here is optimized to satisfy these goals:

1. The first step is coarse grinding step. The goal of this step is to make sure the top of the sample to be parallel with its bottom, so that there is no tilt to the surface during indentation.

2. The second and final step is the polishing step. After much trial and error with a variety of polishing compounds and polishing cloths, one combination gave us repeated success. A TexMet P (Buehler) polishing cloth which with a hard, perforated, and non-woven surface, was charged with diamond paste containing angular polycrystalline diamonds particles with $1 \mu \mathrm{m}$ diameter. Polishing was then performed for 4 hours $(35 \mathrm{~N}$, 50rpm, complimentary rotation). Using only one size of diamond media aids in the repeatability of the procedure, as there is no need for the extensive cleaning required if the sample were polished by a series of successive smaller diamond media. While 
this may result in a longer polishing time, it requires much less operator intervention, and therefore increases the reparability of the procedure. After 4 hours polishing, inspection of the clean surface by the naked eye reveals a mirror-like finish as shown in Fig. 5.2. Atomic Force Microscope (AFM) analysis reveals that the resulting surface finish. The root-mean-squared average (RMS) of topography of the surface is only 45.59 as shown by Fig 5.3, which fulfill the surface roughness criteria established by Miller et al. [80].

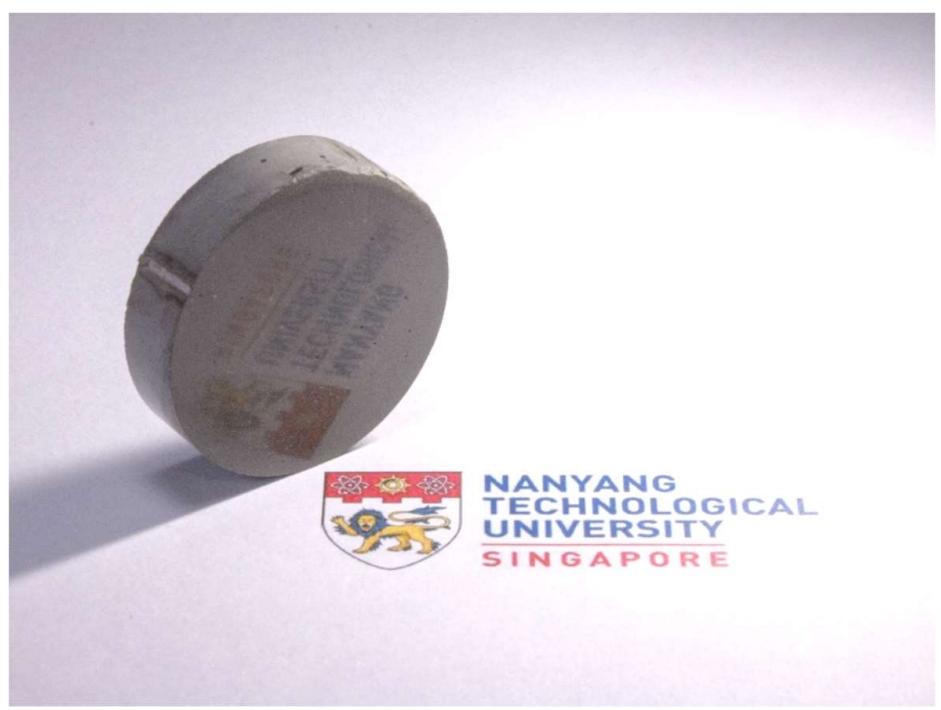

Fig. 5.2 A photograph the reflective sample surface after 4 hours of polishing 


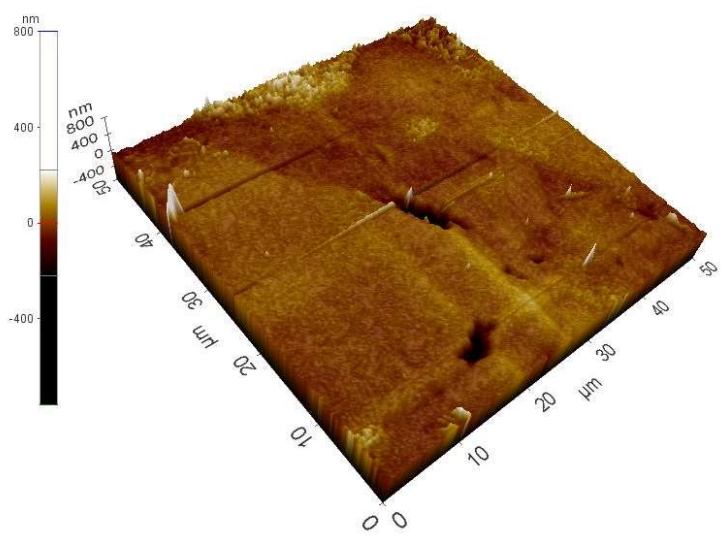

(a)

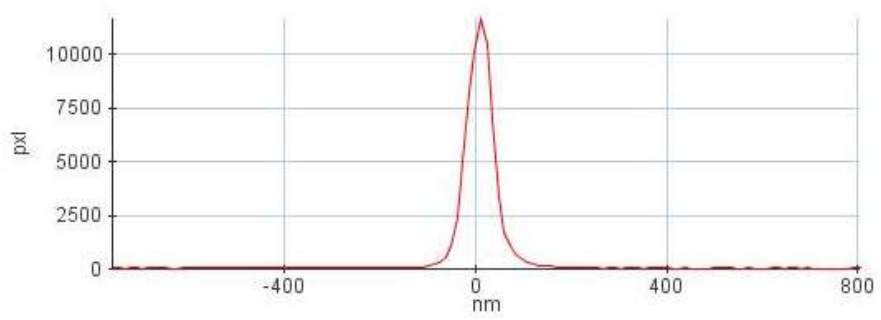

(b)

Fig. 5.3 AFM images and results: (a) topography of a 50×50 $\mu \mathrm{m}$ region, and (b) region histogram.

\subsubsection{Tests}

Grid nanoindentation experiments were performed using a device (Agilent G200) fitted with a Berkovitch tip. Tests were carried out in continuous stiffness mode to a predetermined depth $(500 \mathrm{~nm})$ with a target strain rate of $50 \mathrm{~nm} / \mathrm{s}$. Mechanical properties were automatically determined from the unloading segment through methods described by Oliver and Pharr [81]. To account for possible surface roughness, head repositioning was carried out before every indent. Each load/displacement diagram was plotted and inspected for signs of problems due to surface roughness, such as abnormal or discontinuous shapes. 


\subsubsection{Results and discussion}

Fig. 5.4 shows the SEM images of residual impression of nanoindentation tests on the two samples, in which the indentation area and PE fiber are marked. In order to measure the properties of the ITZ whose dimensions are not clear, a grid of indents $(10 \times 10$ grid with grid spacing of $5 \mu \mathrm{m})$ were performed to obtain the dataset for statistical analysis.

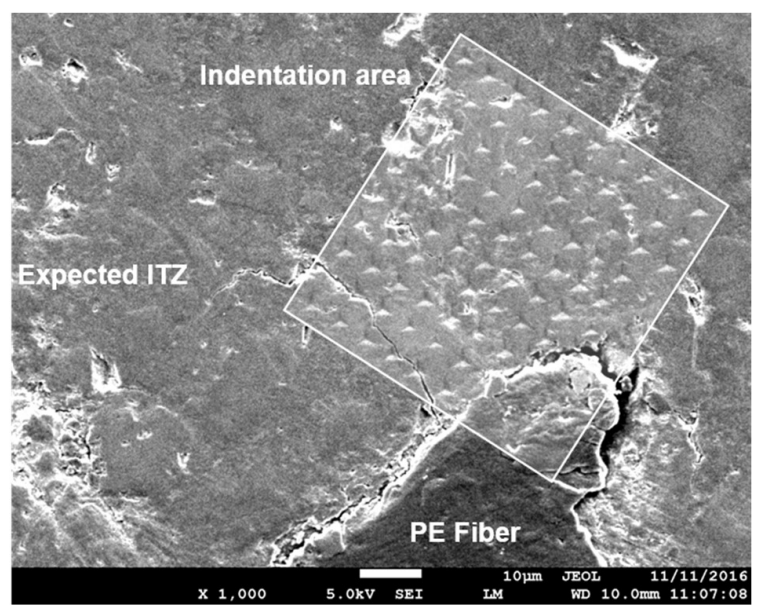

(a)

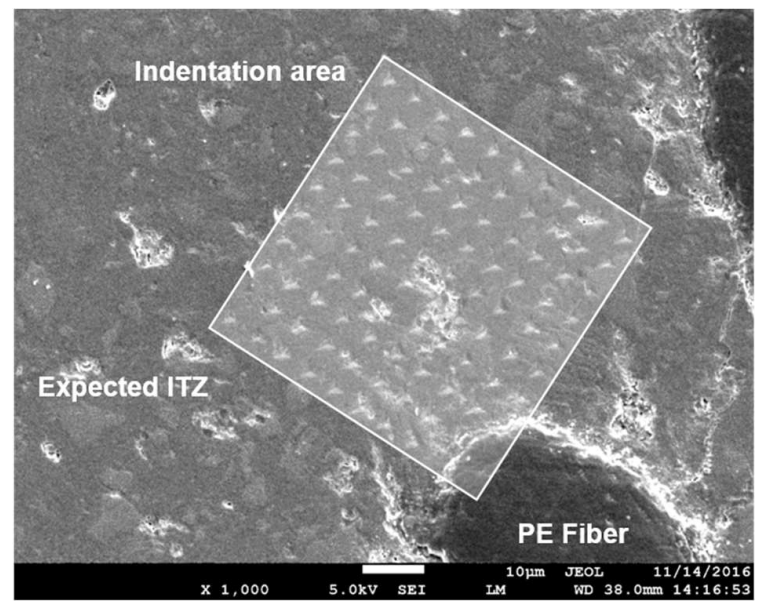

(b)

Fig. 5.4 SEM images of the indentation area: (a) with CNF coating, and (b) w/o CNF coating 
Fig. 5.5 are back-scattered electron (BSE) images of the indented area. Backscattered electrons are electrons from the incident beam which are scattered through large angles so that they re-emerge from the specimen. The intensity of the BSE signal is mainly a function of the average atomic number of the local area of the sample. The incorporation of water during hydration leads to hydrates which have much lower average atomic numbers than the anhydrous materials, and thus strong contrast is obtained between unreacted (anhydrous) and reacted material (hydrates). Within the hydrates, Portlandite $(\mathrm{CH})$ is significantly brighter than the other hydrates. It could be seen that the ITZ between PE fiber and the cement paste is composed of several phases including unhydrated clinker and hydration products.

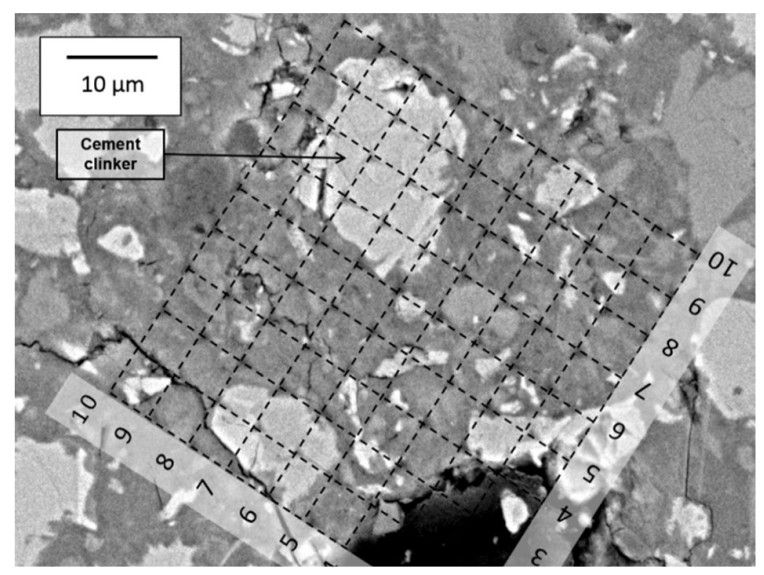

(a)

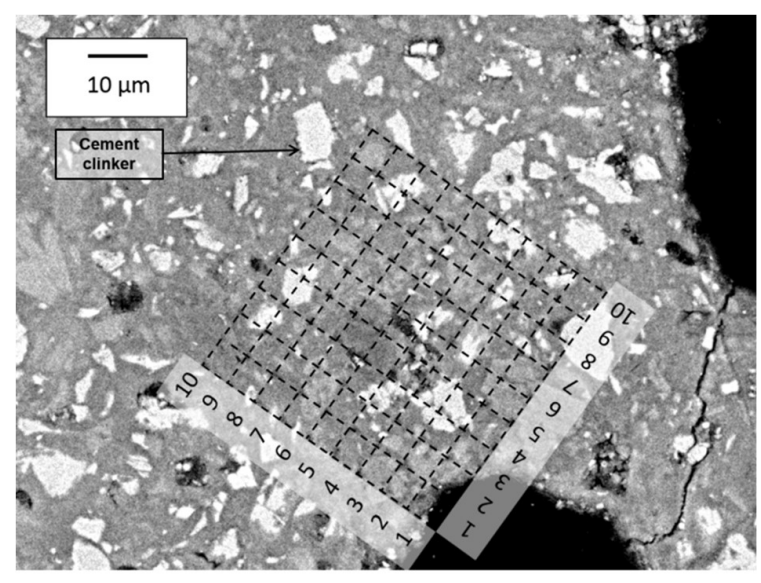

(b)

Fig. 5.5 Back-scattered electron images of the indentation area: (a) with CNF coating, and (b) w/o CNF coating 
Elastic modulus mappings of respective region of each sample are shown in Fig 5.6. The elastic modulus of each point in the grid acquired by individual indentation test was rated using a continuous scale where warm colors indicated higher levels of elastic modulus. The heterogeneity of the concrete is graphically illustrated by the chromatic mappings, where anhydrous cement grains, hydration products and fiber could be distinguished by the contrast between red, green and blue.

A good correspondence between the elastic modulus maps and the SEM-BSE observations is observed. It is found that the positions of the un-hydrated grains are clearly identified in ITZ between cement matrix and CNF-coated PE fiber as shown by a larger proportion of elements with warm colors. Thus, the presence of larger proportion of the clinker suggests the hydration degree is low, indicating the content of free water previously stayed in this region is insufficient. This could be attributed to the filling effects of CNF. In this scenario, the CNFs filled the place where otherwise the water would, resulting in insufficient amount of water for hydration. As a result, more of residue clinker in the matrix present.
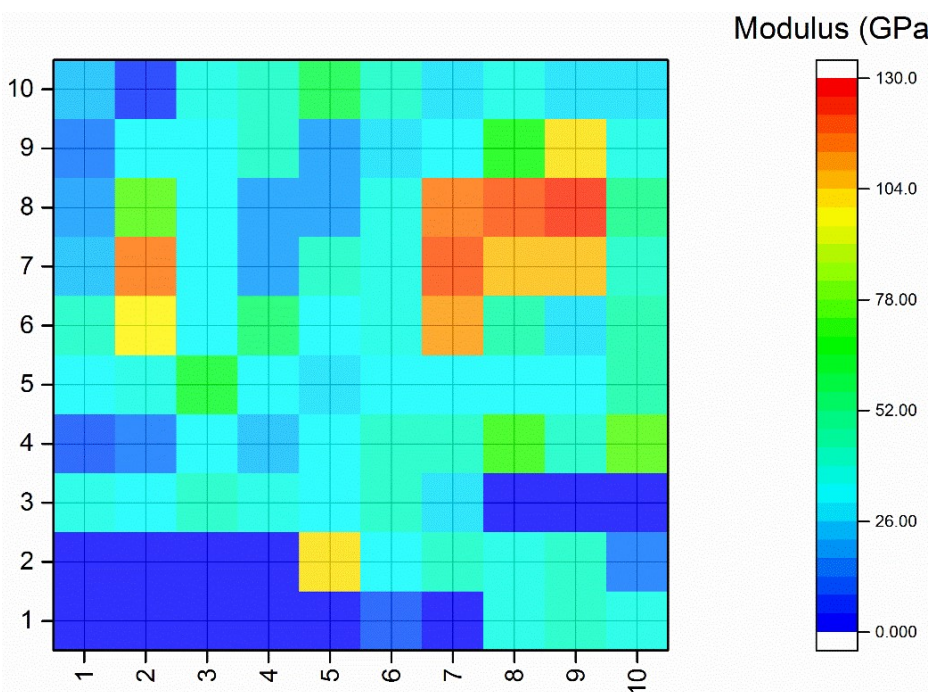

(a) 


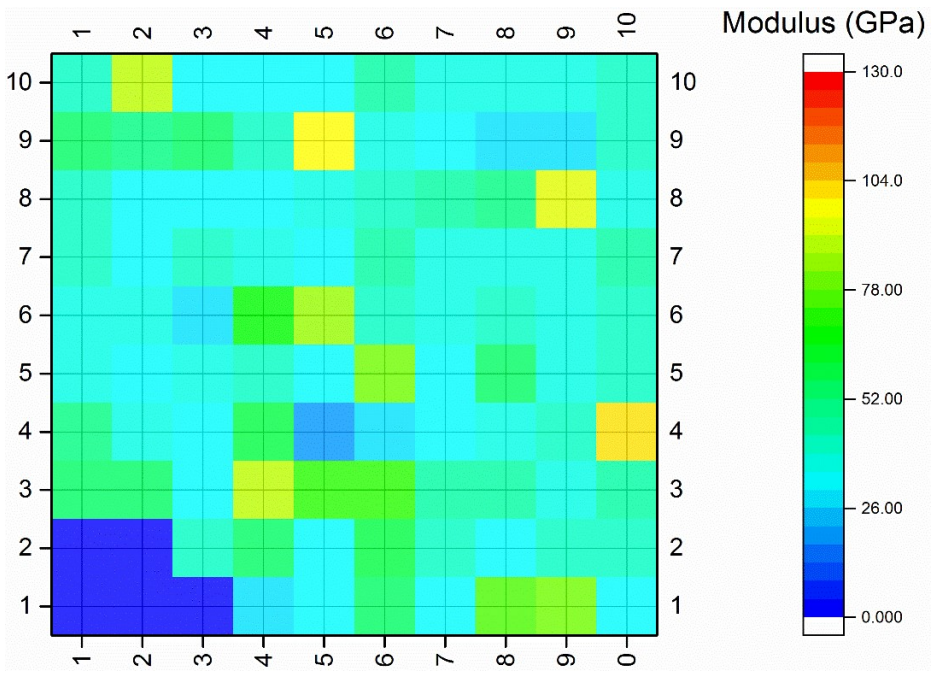

(b)

Fig. 5.6 Elastic modulus mappings of the indentation area: (a) with CNF coating, and (b) w/o CNF coating

Fig. 5.7 is the plots of indentation hardness versus elastic modulus. It could be observed that for a given modulus value, the corresponding hardness values are scattered and vice-versa. It is possible that some indents landed on the boundaries of multiphase. It is also possible that a few indents were performed on a thin layer of one phase which has another phase underneath. Fig. 5.7 shows the same trend as Fig. 5.6. More points can be found at the upper right part of the plot area in Fig. 5.7a, indicating more indents on the unhydrated cement grains. The presence of clinkers suggests that the content of free water content in this region is not enough for fully hydration. This imply that the CNFs have filled the pores where otherwise the water would occupy. 


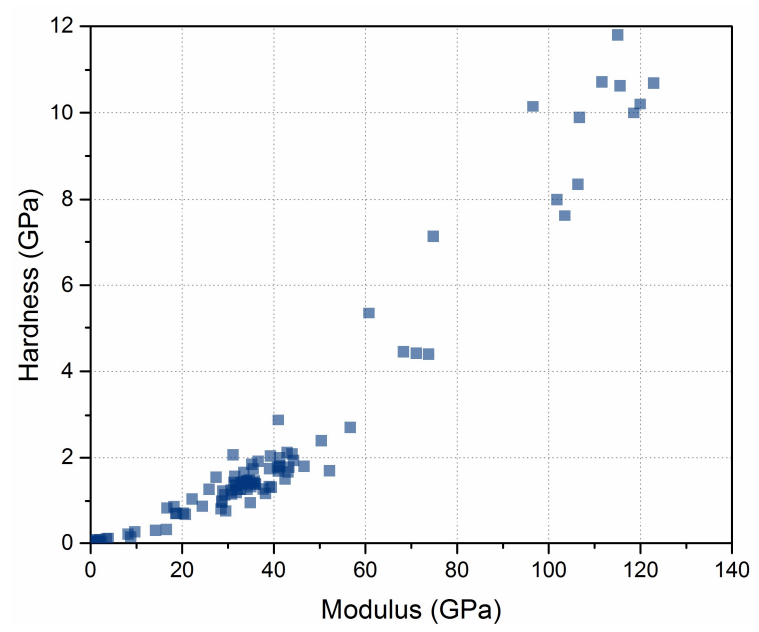

(a)

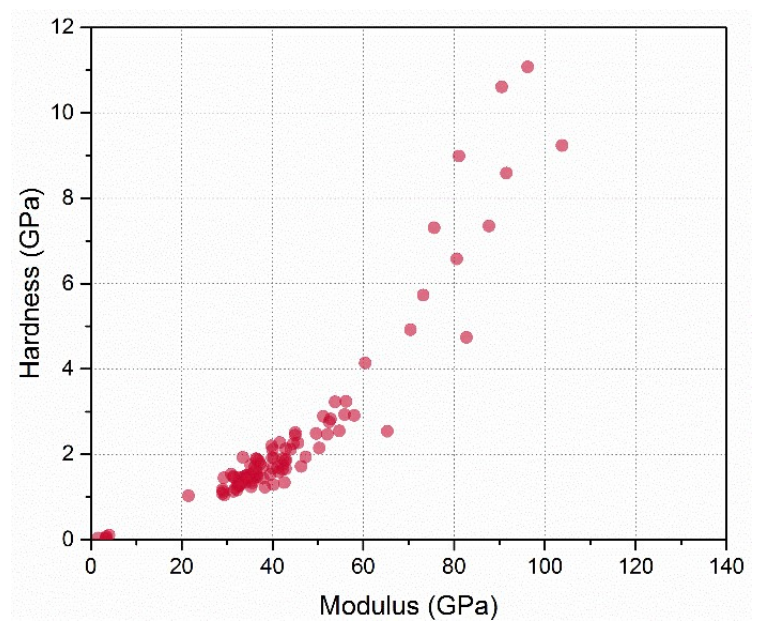

(b)

Fig. 5.7 Plot of indentation hardness versus elastic modulus: (a) with CNF coating, and (b) w/o CNF coating

\subsection{Effect of CNF on the heat of hydration of cement paste}

\subsubsection{Specimen preparation}

The sample preparation follows the same set of procedures of the nanoindentation samples. CNF was directly added into the cement paste to investing the effects of the CNF to the hydration process. For sample with CNF, the CNF suspension with a concentration of $0.5 \%$ is used, which represents a $0.5 \mathrm{wt} \%$ of CNF to cement. 


\subsubsection{Tests}

The I-Cal 2000 HPC calorimeter from Calmetrix was used in this study. The water or aqueous CNF suspension were weight and placed into the calorimeter to equilibrate for 24 hours at a temperature of $23^{\circ} \mathrm{C}$ before mixing with cement grains. 72 hours of reaction were recorded and the results are plotted in Fig. 5.8.

\subsubsection{Results and discussion}

Fig 5.8 shows the differential heat release plotted as a function of hydration time. It is found that the presence of CNF did not change the rate of the hydration at any stage. Though an extremely slight acceleration effect was observed starting from the induction period, the difference become less noticeable as the reaction continuing. This may attribute to the smaller amount of the CNF.

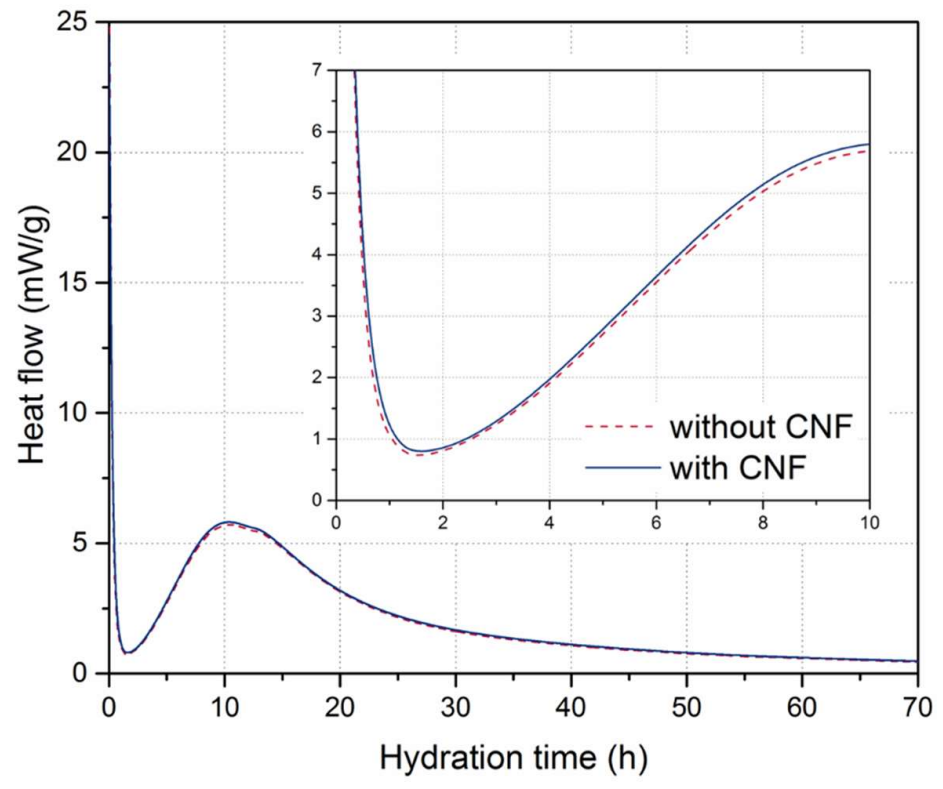

Fig. 5.8 differential heat release plotted as a function of hydration time. 
5.4 Effect of CNF on the hydration degree of cement paste

\subsubsection{Specimen preparation}

Hardened samples collected from the isothermal calorimetric test was assessed by thermogravimetric analysis (TGA). The samples were crushed in powder and stored in an over at 60 degrees for 24 for drying. Then, samples were kept in hermetic flasks before test

\subsubsection{Tests}

The sample preparation follows the same set of procedures of the nanoindentation samples. Samples was dried in an oven at 60 degrees for 24 hours. In the thermal analysis, about $30 \mathrm{mg}$ of a sample was put in an alumina top-opened crucible and heated from room temperature to $900{ }^{\circ} \mathrm{C}$ at a rate of $10{ }^{\circ} \mathrm{C} / \mathrm{min}$. The weight loss data was determined and recorded for further analysis. Nitrogen gas was chosen as the dynamic atmosphere, and corundum as the reference material.

\subsubsection{Results and discussion}

Fig. 5.9 presents the results of the thermogravimetric analysis representing the mass variations of the two samples from 20 to $900{ }^{\circ} \mathrm{C}$. With the temperature elevation, the mass loss increased. Three important mass losses at 100, 450 and $700{ }^{\circ} \mathrm{C}$ which could be associated to the evaporation of free water, decompositions of portlandite and calcium carbonate were observed. It is found that, the mass loss corresponding to the evaporation of free water for paste containing CNF is higher than the pure paste. This result may indicate a higher porosity of cement paste mixed with CNF. It is also found that more of calcium carbonate has formed in CNF sample, which may be attributed to the higher transportation properties caused by the high porosity. More capillary pores would facilitate the transport of carbon dioxide and thus encourage the carbonation. However, the general trends of the two sample are identical, suggesting the CNF may have little effects on the cement hydration. 


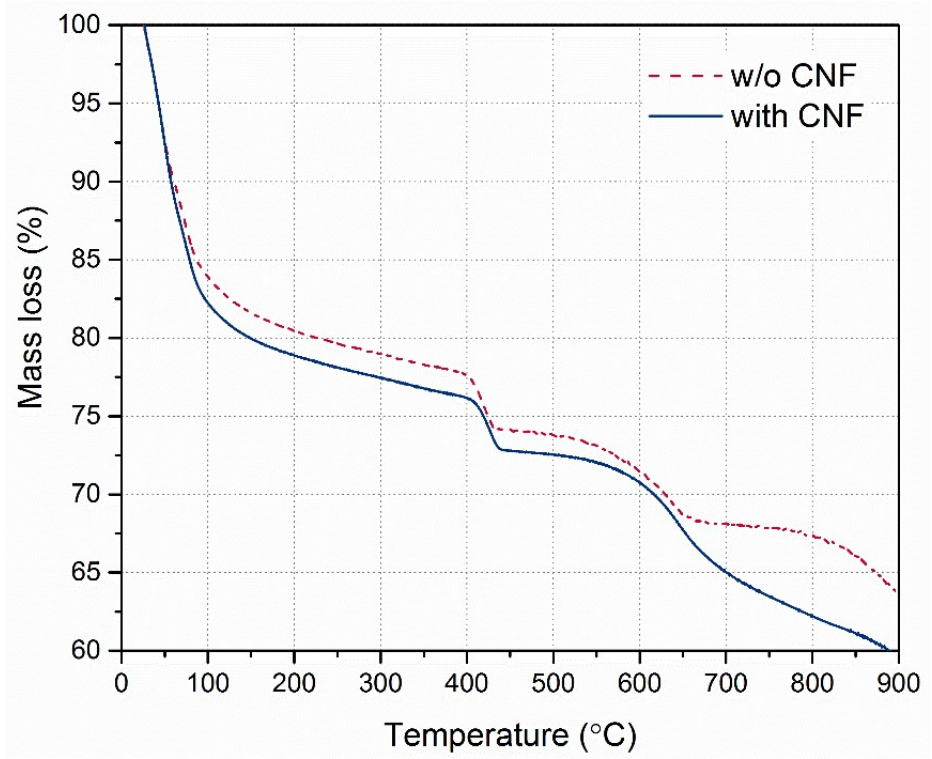

Fig. 5.9 Results of the thermal decomposition of pure cement paste and paste incorporating $\mathrm{CNF}$.

\subsection{Conclusions}

In this chapter, grid nanoindentation test was conducted to study the filling effect of the CNFs. In the matrix surrounding CNF coated-fiber, it is found that the proportion of unhydrated cement clinker to hydration products is larger than that of the control. The presence of clinkers suggests that the content of free water content in this region is not enough for fully hydration, indicating that the CNFs have filled the pores where otherwise the water would occupy. Thermogravimetric analysis and isothermal calorimetric test were also conducted. Results show that the CNF itself does not influence the hydration process and the hydration product. Therefore, it could be concluded that the change in the composition of the matrix is a consequence of having difference amount of water, validating the filling effect of the CNF coating. 


\section{Chapter 6 CONCLUSIONS AND FUTURE WORKS}

In this study, a strain-hardening ultra-high performance concrete (SHUHPC) material with high compressive strength and tensile ductility was first developed using locally available raw material and then further improved by incorporating CNF coated PE fibers. The resultant CNF-SHUHPC exhibits $15 \%$ enhancement in tensile strength, $20 \%$ improvement in tensile strain capacity, and largely reduced cracking spacing and cracking width. Micromechanical models were involved in revealing the improvement with the use of the CNF coated PE fibers. It is found that both the improved tensile performance and cracking behavior are direct results of having more effective load transfer between PE fiber and surrounding cement-based matrix. Compared with other SHUHPC materials, the CNF-SHUPC requires less processing effort and has reduced material cost, increased potential of autogenous crack healing, and enhanced durability. It is expected that the concerns over the cost and the durability of the SHUHPC materials can be largely mitigated.

The issue of the weak interfacial bond between fiber with a hydrophobic surface and cement-based matrix has also been attempted to solve. Instead of modifying the hydrophobicity of the fiber surface, CNFs are coated on the surface of PE fiber through the hydrophobic interaction to strengthen the interface transition zone. Unlike plasma treatment, in which high energy and temperature are required, the current method requires much less effort and energy. It is also expected that this method of strengthening the ITZ could be applied to reinforce ITZ between cementbased matrix and a wide range of fibers with an inert surface such as polypropylene and steel fibers.

This study highlights the strategic use of carbon nanomaterials in the critical region to enhance the performance of the material. The high unit cost and the extremely small size of the carbon nanomaterials imply that they should be used with care an only for critical application. However, most previous studies added (dispersed) carbon nanomaterials directly into concrete. This method, where a large number of 
nanomaterials are required, is costly and not efficient and effective. In contrast, the current study proves that only a small amount of nanomaterial is sufficient to boost the performance of concrete, as long as it is used in a proper way. A simple method to coat CNFs on the surface of PE fibers through hydrophobic interactions was proposed. As compared to previous studies where carbon nanomaterials are either added directly into the matrix or grew on the fiber surface through high-temperature in-situ grafting, the current approach is simple while effective, efficient, and economical.

SEM micrographs revealed that the highly-concentrated CNFs layer on the PE fiber surface could create a sub-structure around the fiber. By this means, the CNFs reinforce the region near the PE fibers, which are reinforcing the overall composite at a higher scale. A hierarchical structure is therefore created, and the exceptional performance of the resultant composite is believed to due to the contribution of all level of the hierarchy. Nanoindentation test confirms that the CNFs could fill the pores around the fiber and thus reduce the regional free water content. By reacting with less water, the cement hydration product is expected to be with higher density at a later age. In future, it is essential to precisely characterize the geometrical boundaries of the loosely packed ITZ region to determine the appropriate amount of CNF that would be required in that region.

The CNF-SHUHPC material developed in this study is believed to be able to benefit both the sustainability and resilience of the concrete infrastructure. However, to fully utilize the techniques adopted in the development of the material, further studies should be carried out to characterize the coating layer, e.g. layer thickness, and to understand factors, such as CNF suspension concentration, $\mathrm{pH}$ value, fiber surface zeta potential, and the hydrophobicity of CNFs. 


\section{References}

1. Abdolhosseini Qomi, M.J., et al., Combinatorial molecular optimization of cement hydrates. Nat Commun, 2014. 5: p. 4960.

2. Aveston, J. and A. Kelly, Theory of multiple fracture of fibrous composites. Journal of Materials Science, 1973. 8(3): p. 352-362.

3. Yang, Y., et al., Autogenous healing of engineered cementitious composites under wet-dry cycles. Cement and Concrete Research, 2009. 39(5): p. 382390.

4. de Larrard, F. and T. Sedran, Optimization of ultra-high-performance concrete by the use of a packing model. Cement and Concrete Research, 1994. 24(6): p. 997-1009.

5. Shi, C., et al., A review on ultra high performance concrete: Part I. Raw materials and mixture design. Construction and Building Materials, 2015. 101: p. 741-751.

6. Wang, D., et al., A review on ultra high performance concrete: Part II. Hydration, microstructure and properties. Construction and Building Materials, 2015. 96: p. 368-377.

7. Ulm, F.-J., Concrete innovation potential: from atoms to green infrastructure. BETON-UND STAHLBETONBAU, 2012. 107(8): p. 504-U79.

8. Van Vliet, K., et al., Set in stone? A perspective on the concrete sustainability challenge. MRS bulletin, 2012. 37(04): p. 395-402.

9. Batoz, J.F. and M. Behloul, UHPFRC Development: Experience with Ductal ${ }^{\circledR}$ Over the Past Two Decades. Designing and Building with UHPFRC, 2009: p. 43-62.

10. Yang, E.-H., et al., Fiber-bridging constitutive law of engineered cementitious composites. Journal of advanced concrete technology, 2008. 6(1): p. 181-193.

11. Kamal, A., et al., Evaluation of crack opening performance of a repair material with strain hardening behavior. Cement and Concrete Composites, 2008. 30(10): p. 863-871. 
12. Ranade, R., et al., Composite properties of high-strength, high-ductility concrete. ACI Materials Journal, 2013. 110(4): p. 413-422.

13. Ranade, R., et al., Micromechanics of high-strength, high-ductility concrete. ACI Materials Journal, 2013. 110(4): p. 375-384.

14. $\mathrm{Wu}$, H.-C. and V.C. Li, Fiber/cement interface tailoring with plasma treatment. Cement and Concrete Composites, 1999. 21(3): p. 205-212.

15. Zheng, Z., et al., Surface modification of ultrahigh-molecular-weight polyethylene fibers. Journal of Polymer Science Part B: Polymer Physics, 2004. 42(3): p. 463-472.

16. Choi, J.-I., et al., Ultra-high-ductile behavior of a polyethylene fiberreinforced alkali-activated slag-based composite. Cement and Concrete Composites, 2016. 70: p. 153-158.

17. Wittman, F., Durability of Strain-Hardening Fibre-Reinforced Cement-Based Composites (SHCC). Vol. 4. 2010: Springer Science \& Business Media.

18. Abu Al-Rub, R.K., et al., Mechanical properties of nanocomposite cement incorporating surface-treated and untreated carbon nanotubes and carbon nanofibers. Journal of Nanomechanics and Micromechanics, 2011. 2(1): p. 16.

19. Brown, L. and F. Sanchez, Influence of carbon nanofiber clustering on the chemo-mechanical behavior of cement pastes. Cement and Concrete Composites, 2016. 65: p. 101-109.

20. Konsta-Gdoutos, M.S., Z.S. Metaxa, and S.P. Shah, Multi-scale mechanical and fracture characteristics and early-age strain capacity of high performance carbon nanotube/cement nanocomposites. Cement and Concrete Composites, 2010. 32(2): p. 110-115.

21. Metaxa, Z.S., M.S. Konsta-Gdoutos, and S.P. Shah, Carbon nanofiber cementitious composites: Effect of debulking procedure on dispersion and reinforcing efficiency. Cement and Concrete Composites, 2013. 36: p. 25-32.

22. Lawrence, J.G., L.M. Berhan, and A. Nadarajah, Elastic properties and morphology of individual carbon nanofibers. ACS nano, 2008. 2(6): p. 12301236. 
23. Mordkovich, V., Carbon nanofibers: a new ultrahigh-strength material for chemical technology. Theoretical Foundations of Chemical Engineering, 2003. 37(5): p. 429-438.

24. Lawrence, J.G., L.M. Berhan, and A. Nadarajah, Structural transformation of vapor grown carbon nanofibers studied by HRTEM. Journal of Nanoparticle Research, 2008. 10(7): p. 1155-1167.

25. Perry, V. and D. Zakariasen, The first use of UHPC technology for an innovative LRT station canopy Shawnessy, Calgery, Alberta. Special Publication, 2005. 228: p. 1119-1132.

26. Schröfl, C., M. Gruber, and J. Plank, Preferential adsorption of polycarboxylate superplasticizers on cement and silica fume in ultra-high performance concrete (UHPC). Cement and Concrete Research, 2012. 42(11): p. 1401-1408.

27. Feylessoufi, A., et al., Controlled rate thermal treatment of reactive powder concretes. Advanced cement based materials, 1997. 6(1): p. 21-27.

28. Tue, N.V., J. Ma, and M. Orgass. Influence of addition method of superplasticizer on the properties of fresh UHPC. in Proceedings of Second International Symposium on Ultra High Performance Concrete, University of Kassel, Germany. 2008.

29. Courtial, M., et al., Effect of polycarboxylate and crushed quartz in UHPC: microstructural investigation. Construction and Building Materials, 2013. 44: p. 699-705.

30. O'Neil, E.F., On engineering the microstructure of high-performance concretes to improve strength, rheology, toughness, and frangibility. 2009, Northwestern University: Evanston, IL.

31. Yu, R., P. Spiesz, and H.J.H. Brouwers, Mix design and properties assessment of Ultra-High Performance Fibre Reinforced Concrete (UHPFRC). Cement and Concrete Research, 2014. 56: p. 29-39.

32. De Larrard, F. and T. Sedran, Mixture-proportioning of high-performance concrete. Cement and concrete research, 2002. 32(11): p. 1699-1704. 
33. Funk, J.E. and D. Dinger, Predictive Process Control of Crowded Particulate Suspensions: Applied to Ceramic Manufacturing. 1993: Springer Science \& Business Media.

34. Donatello, S., M. Tyrer, and C. Cheeseman, Recent developments in macrodefect-free (MDF) cements. Construction and Building Materials, 2009. 23(5): p. 1761-1767.

35. Richard, P. and M. Cheyrezy, Composition of Reactive Powder Concrexes. Cement and Concrete Research, 1995. 25(7).

36. Li, V.C., On engineered cementitious composites (ECC). Journal of advanced concrete technology, 2003. 1(3): p. 215-230.

37. Qiu, J., Designing fatigue-resistant engineered cementitious composites. 2016.

38. Yang, E.-H. and V.C. Li, Tailoring engineered cementitious composites for impact resistance. Cement and Concrete Research, 2012. 42(8): p. 1066-1071.

39. Yang, E.-H., Y. Yang, and V.C. Li, Use of high volumes of fly ash to improve ECC mechanical properties and material greenness. ACI materials journal, 2007. 104(6): p. 620-628.

40. Li, J., Mix design of strain hardening cementitious composites through multiscale and multiphysics models. 2016, Nanyang Technological University, Singapore.

41. Qiu, J. and E.-H. Yang, A micromechanics-based fatigue dependent fiberbridging constitutive model. Cement and Concrete Research, 2016. 90: p. 117-126.

42. Boshoff, W.P. and G.P. Van Zijl, Time-dependent response of ECC: Characterisation of creep and rate dependence. Cement and concrete research, 2007. 37(5): p. 725-734.

43. Lu, C. and C.K. Leung, A new model for the cracking process and tensile ductility of Strain Hardening Cementitious Composites (SHCC). Cement and Concrete Research, 2016. 79: p. 353-365.

44. Li, V.C. and C.K. Leung, Steady-state and multiple cracking of short random fiber composites. Journal of Engineering Mechanics, 1992. 118(11): p. 22462264. 
45. Kunieda, M., et al. Challenges for strain hardening cementitious compositesdeformability versus matrix density. in HPFRCC5. 2007.

46. Curosu, I., V. Mechtcherine, and O. Millon, Effect of fiber properties and matrix composition on the tensile behavior of strain-hardening cement-based composites (SHCCs) subject to impact loading. Cement and Concrete Research, 2016. 82: p. 23-35.

47. Wille, K., Ultra-High Performance Concrete with Compressive Strength Exceeding 150 MPa (22 ksi): A Simpler Way. ACI Materials Journal, 2011. 108(1).

48. Liew, K.M., M.F. Kai, and L.W. Zhang, Carbon nanotube reinforced cementitious composites: An overview. Composites Part A: Applied Science and Manufacturing, 2016. 91: p. 301-323.

49. Sobolkina, A., et al., Effect of Carbon-Based Materials on the Early Hydration of Tricalcium Silicate. Journal of the American Ceramic Society, 2016. 99(6): p. 2181-2196.

50. Breuer, O. and U. Sundararaj, Big returns from small fibers: a review of polymer/carbon nanotube composites. Polymer composites, 2004. 25(6): p. 630-645.

51. Tibbetts, G.G., et al., A review of the fabrication and properties of vaporgrown carbon nanofiber/polymer composites. Composites Science and Technology, 2007. 67(7): p. 1709-1718.

52. Finegan, I.C. and G.G. Tibbetts, Electrical conductivity of vapor-grown carbon fiber/thermoplastic composites. Journal of Materials Research, 2001. 16(06): p. 1668-1674.

53. Winey, K.I. and R.A. Vaia, Polymer nanocomposites. MRS bulletin, 2007. 32(04): p. 314-322.

54. Coleman, J.N., U. Khan, and Y.K. Gun'ko, Mechanical reinforcement of polymers using carbon nanotubes. Advanced materials, 2006. 18(6): p. 689706.

55. Shaffer, M.S. and A.H. Windle, Fabrication and characterization of carbon nanotube/poly (vinyl alcohol) composites. Advanced materials, 1999. 11(11): p. $937-941$. 
56. Xie, X.-L., Y.-W. Mai, and X.-P. Zhou, Dispersion and alignment of carbon nanotubes in polymer matrix: a review. Materials Science and Engineering: R: Reports, 2005. 49(4): p. 89-112.

57. Pisello, A.L., et al., Multipurpose experimental characterization of smart nanocomposite cement-based materials for thermal-energy efficiency and strain-sensing capability. Solar Energy Materials and Solar Cells, 2017. 161: p. $77-88$.

58. D'Alessandro, A., et al., Investigations on scalable fabrication procedures for self-sensing carbon nanotube cement-matrix composites for SHM applications. Cement and Concrete Composites, 2016. 65: p. 200-213.

59. Azhari, F. and N. Banthia, Cement-based sensors with carbon fibers and carbon nanotubes for piezoresistive sensing. Cement and Concrete Composites, 2012. 34(7): p. 866-873.

60. Han, B., X. Yu, and J. Ou, Effect of water content on the piezoresistivity of MWNT/cement composites. Journal of Materials Science, 2010. 45(14): p. 3714-3719.

61. Thomas, J.J., et al., Modeling and simulation of cement hydration kinetics and microstructure development. Cement and Concrete Research, 2011. 41(12): p. $1257-1278$.

62. !!! INVALID CITATION !!! \{\} .

63. Sobolkina, A., et al., Dispersion of carbon nanotubes and its influence on the mechanical properties of the cement matrix. Cement and Concrete Composites, 2012. 34(10): p. 1104-1113.

64. Torabian Isfahani, F., W. Li, and E. Redaelli, Dispersion of multi-walled carbon nanotubes and its effects on the properties of cement composites. Cement and Concrete Composites, 2016. 74: p. 154-163.

65. Stephens, C., L. Brown, and F. Sanchez, Quantification of the reagglomeration of carbon nanofiber aqueous dispersion in cement pastes and effect on the early age flexural response. Carbon, 2016. 107: p. 482-500.

66. Chen, Z., J.L.G. Lim, and E.-H. Yang, Ultra high performance cement-based composites incorporating low dosage of plasma synthesized carbon nanotubes. Materials \& Design, 2016. 108: p. 479-487. 
67. Redon, C., et al., Measuring and modifying interface properties of PVA fibers in ECC matrix. Journal of Materials in Civil Engineering, 2001. 13(6): p. 399406.

68. Li, V.C., From micromechanics to structural engineering - the design of cementitous composites for civil engineering applications. JSCE Journal of Structural Mechanics and Earthquake Engineering, 1993. 10(2).

69. Meyer, E.E., K.J. Rosenberg, and J. Israelachvili, Recent progress in understanding hydrophobic interactions. Proceedings of the National Academy of Sciences, 2006. 103(43): p. 15739-15746.

70. Horn, R.G. and J. Israelachvili, Direct measurement of forces due to solvent structure. Chemical Physics Letters, 1980. 71(2): p. 192-194.

71. Rahy, A., et al., Coating of carbon nanotubes on flexible substrate and its adhesion study. Applied Surface Science, 2009. 255(15): p. 7084-7089.

72. Kaempgen, M., G. Duesberg, and S. Roth, Transparent carbon nanotube coatings. Applied Surface Science, 2005. 252(2): p. 425-429.

73. Lin, Z. and V.C. Li, Crack bridging in fiber reinforced cementitious composites with slip-hardening interfaces. Journal of the Mechanics and Physics of Solids, 1997. 45(5): p. 763-787.

74. Marshall, D. and B. Cox, A J-integral method for calculating steady-state matrix cracking stresses in composites. Mechanics of materials, 1988. 7(2): p. 127-133.

75. Yang, E.-H. and V.C. Li, Strain-hardening fiber cement optimization and component tailoring by means of a micromechanical model. Construction and Building Materials, 2010. 24(2): p. 130-139.

76. Cao, Q., et al., Highly Bendable, Transparent Thin-Film Transistors That Use Carbon-Nanotube-Based Conductors and Semiconductors with Elastomeric Dielectrics. Advanced Materials, 2006. 18(3): p. 304-309.

77. Lum, K., D. Chandler, and J.D. Weeks, Hydrophobicity at small and large length scales. The Journal of Physical Chemistry B, 1999. 103(22): p. 45704577.

78. Singh, S., et al., Superhydrophobicity: drying transition of confined water. Nature, 2006. 442(7102): p. 526-526. 
79. Aveston, J., R. Mercer, and J. Sillwood. Fibre reinforced cements-scientific foundations for specifications. in Proc. National Physical Laboratory Conference. 1974.

80. Miller, M., et al., Surface roughness criteria for cement paste nanoindentation. Cement and Concrete Research, 2008. 38(4): p. 467-476.

81. Oliver, W.C. and G.M. Pharr, An improved technique for determining hardness and elastic modulus using load and displacement sensing indentation experiments. Journal of materials research, 1992. 7(06): p. 15641583. 